\title{
DETERMINAÇÃO DO POSICIONAMENTO ÓTIMO DOS APOIOS EM EDIFICAÇÕES ANALISADAS PELO MODELO DE GRELHA
}

\section{Moacir Kripka}

Tese apresentada à Escola de Engenharia de São Carlos, da Universidade de São Paulo, como parte dos requisitos para a obtenção do título de Doutor em Engenharia de Estruturas

ORIENTADORA: Profa. Dra. Helena M. C. Carmo Antunes

São Carlos

1998 


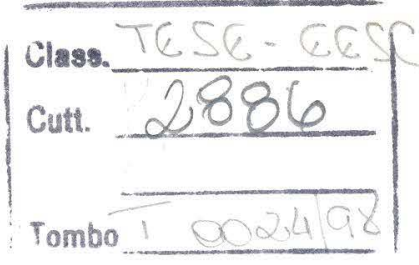

$5 / 5942247$

Ficha catalográfica preparada pela Seção de Tratamento da Inform ação do Serviço de Biblioteca - EESC-USP Moacir Kripka. -- São Carlos, 1998.

Tese (Doutorado). -- Escola de Engenharia de São Carlos-Universidade de São Paulo, 1998. Área: Engenharia de Estruturas.

Orientadora: Prof ${ }^{a}$. Dr ${ }^{a}$. Helena M. C. Carmo Antunes.

1. Otimização. 2. Grelhas. 3. Apoios. I. Título. 


\section{FOLHA DE APROVACÃO}

Candidato: Engenheiro MOACIR KRIPKA

Tese defendida e aprovada em 03-02-1998

pela Comissão Julgadora:

Helua Canum

Profa. Doutora HELENA MARIA CUNHA DO CARMO ANTUNES (Orientadora)

(Escola de Engenharia de São Carlos - Universidade de São Paulo)

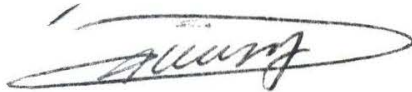

Prof. Assoc. ROBERTO LUIZ DE ARRUDA BARBATO

(Escola de Engenharia de São Carlos - Universidade de São Paulo)

$$
\text { hu h'de Cune }
$$

Profa. Doutora ANA LUCIA HOMCE DE CRESCE EL DEBS

(Escola de Engenharia de São Carlos - Universidade de São Paulo)

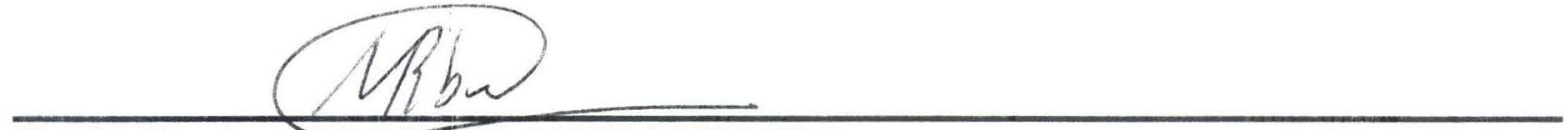

Profa. Doutora CASSILDA MARIA RIBEIRO

(Instituto de Ciências Matemáticas de São Carlos - Universidade de São Paulo)

\section{Alósio 6. Arsam}

Prof. Livre-Doc. ALOISIO ERNESTO ASSAN

(Universidade Estadual de Campinas - UNICAMP)

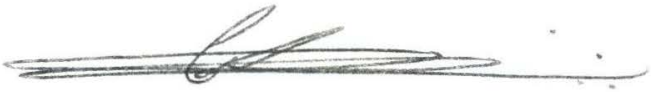

Prof. Titular CARLITO CALIL JUNIOR

Coordenador da Área de Engenharia de Estruturas

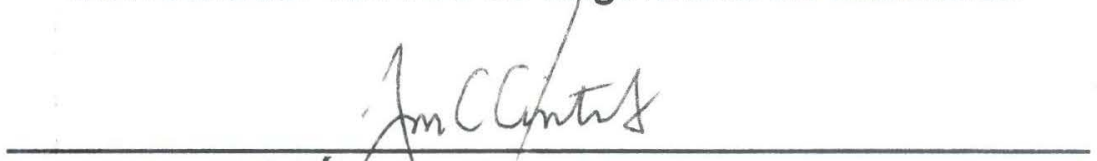

JOSÉ CARLOS A. CINTRA

Presidente da Comissão de Pós-Graduação 
"A preguiça é a mãe do progresso. Se não fosse a preguiça de caminhar, o homem não teria inventado a roda..." Mario Quintana, poeta de minha terra. 
A meus queridos pais e irmãs;

A minha esposa e companheira Rosana. Ao pequeno Vinícius, nossa primeira derivada. 


\section{AGRADECIMENTOS}

À professora Helena M. C. Carmo Antunes, pela orientação precisa;

Aos professores do Departamento de Estruturas da EESC de uma forma geral, e em particular aos amigos Libânio, Samuel, Hanai, Max, Barbato, Sérgio e Eloy;

Aos professores do Instituto de Ciências Matemáticas Cassilda Maria Ribeiro e Marcos Nereu Arenales;

Aos colegas Renata, Luís Fernando, João Ricardo, Manoel, Luttgardes, Saulo, Fudoli, João Augusto, Magid, Balbo, Ana Elisabete, Larissa, Suzana, Rodrigo e Rivelli;

Aos funcionários do SET, especialmente à Rosi, à Nadir e ao Sr. Rui;

Aos sempre amigos Roberto Girardi Fragomeni, Luis Paulo da Silva Barra, Gray Farias Moita e Marcílio de Sousa da Rocha Freitas;

À Fundação Universidade de Passo Fundo, pela oportunidade de aperfeiçoamento;

Aos escritórios EPLAN e TECSOF, pelo apoio nas etapas de testes e definição de exemplos;

À CAPES, pelo suporte financeiro via PICDT;

Aos amigos e colegas do Departamento de Engenharia Civil da UPF, pelo constante incentivo;

A todos aqueles que, de alguma forma, me auxiliaram em mais este passo. De coração, obrigado. 
SUMÁRIO

1 INTRODUÇÃO .01

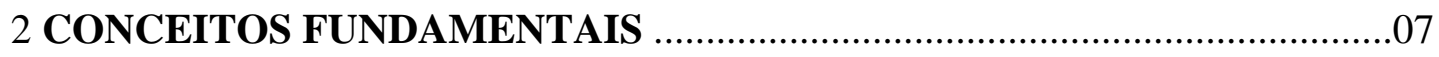

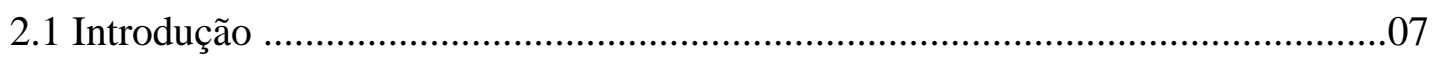

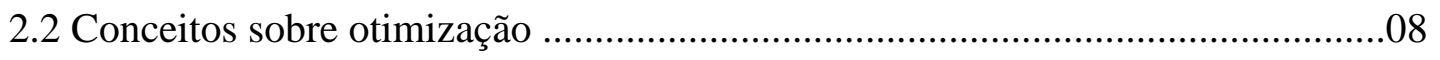

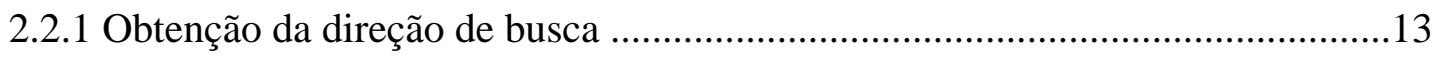

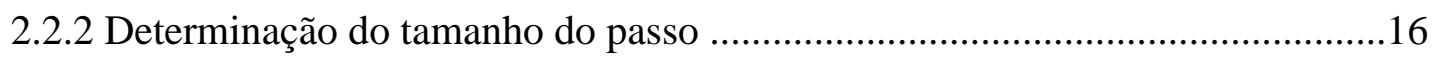

2.2.3 Otimização de problemas com restrições .........................................................19

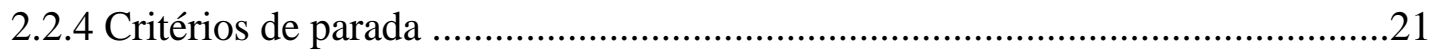

2.3 Formulação básica do Método dos Deslocamentos ...........................................22

3 OTIMIZAÇÃO GEOMÉTRICA DE VIGAS CONTÍNUAS .........................24

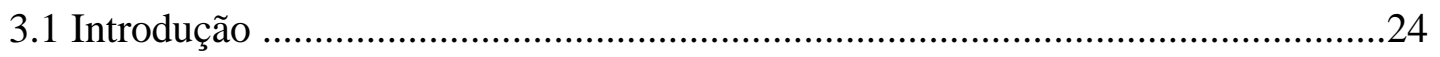

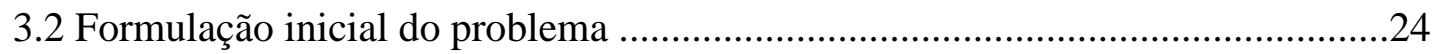

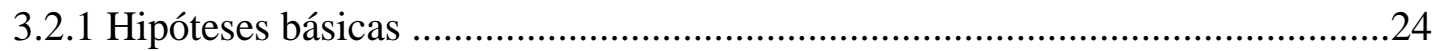

3.2.2 Teste da formulação inicial para uma estrutura isostática ..............................27

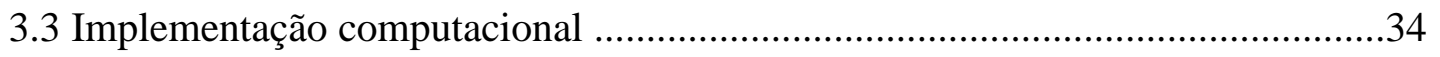

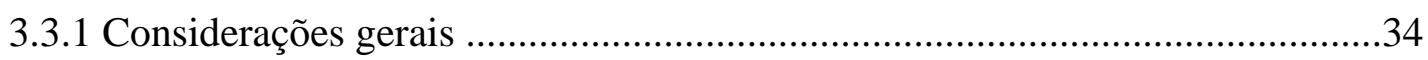

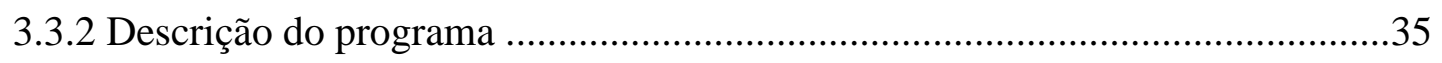

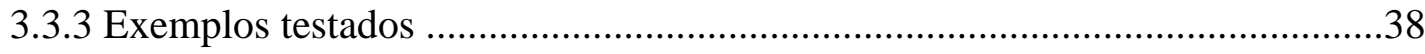

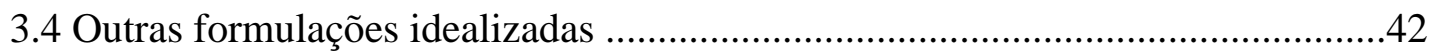

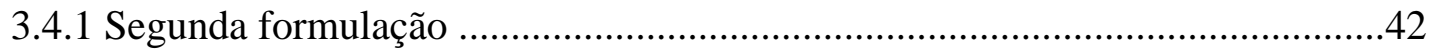

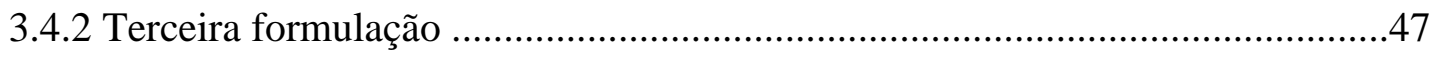

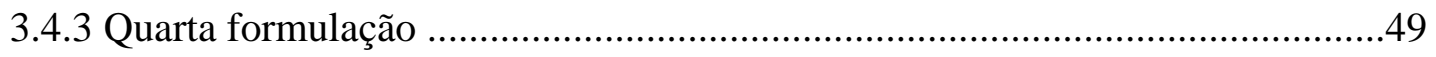

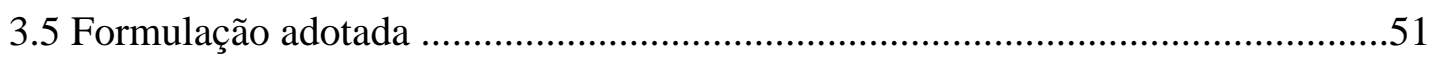

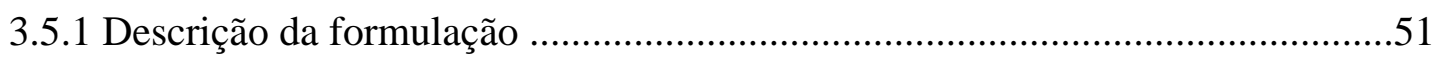

3.5.2 Modificações nos métodos e testes dos parâmetros empregados .....................53 


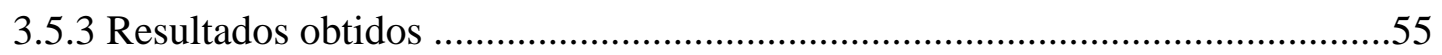

3.6 Considerações sobre a formulação adotada ...................................................60

4 OTIMIZAÇÃO GEOMÉTRICA DE GRELHAS .......................................62

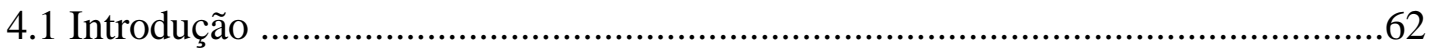

4.2 Adaptação da formulação ao modelo de grelha ..................................................63

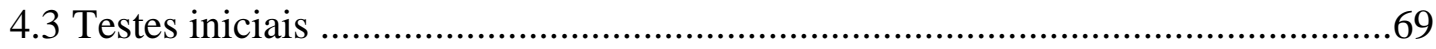

4.4 Estudo do comportamento das funções para o modelo de viga ...........................80

4.5 Alternativas para o aperfeiçoamento da formulação aplicada a grelhas ..............95

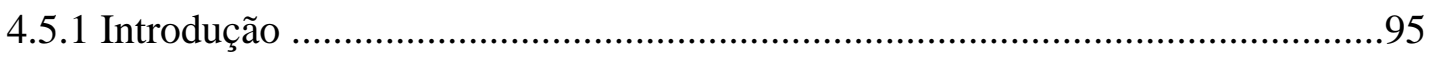

4.5.2 Alterações dos parâmetros de penalização .......................................................96

4.5.3 Valores obtidos no calculo da direção de descida ............................................98

4.6 Formulação adotada para o modelo de grelha .................................................99

4.6.1 Alteração na restrição de igualdade de momentos fletores .............................99

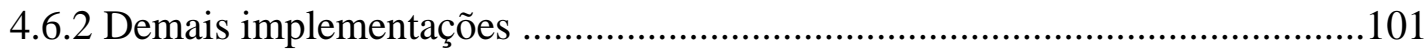

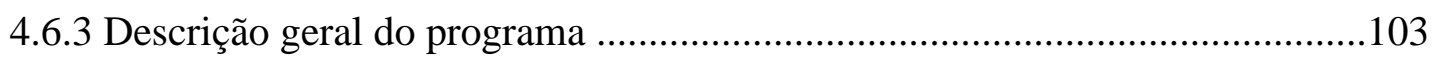

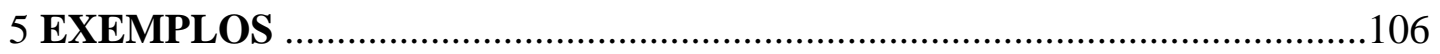

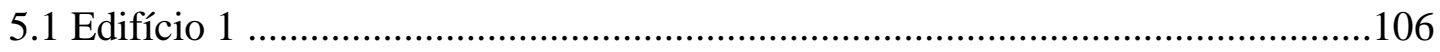

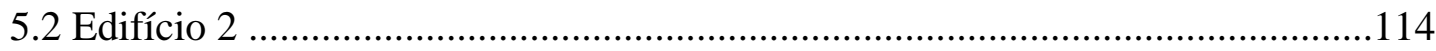

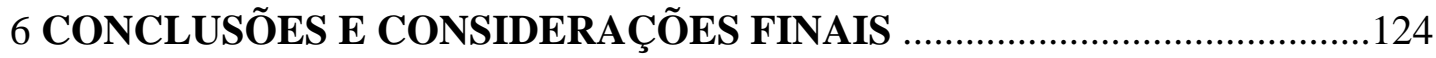

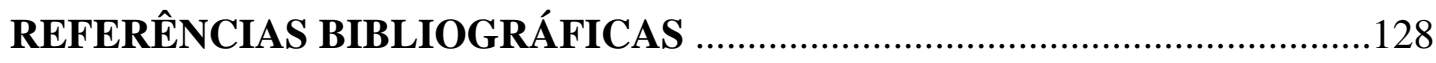

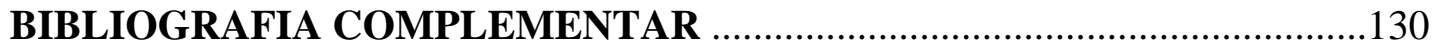




\section{RESUMO}

O trabalho proposto tem por objetivo a redução e uniformização de esforços em grelhas em função do posicionamento dos apoios, através de técnicas de otimização matemática. Busca-se, pela mudança nas posições inicialmente idealizadas para os apoios, a redistribuição dos esforços em edificações devido à alteração na rigidez relativa dos elementos, de modo a possibilitar maior economia no consumo dos materiais componentes. Objetiva-se ainda, com base na análise de estruturas correntes, verificar a eficiência do procedimento proposto, ainda que consideradas as limitações à livre mudança de posição dos apoios. Com as finalidades descritas, foi desenvolvido um programa de computador que pretende se constituir em uma ferramenta auxiliar ao projetista na fase de concepção da estrutura portante de edifícios. Apesar de direcionada a estruturas de concreto armado, a formulação proposta pode ser adotada para o emprego de outros materiais.

Palavras-chave: otimização, grelhas, apoios 


\begin{abstract}
The aim of this work is to reduce and to balance the internal forces on grillages based on the support positions, by the application of optimization techniques. By changing the initial position of the supports, a better redistribution of internal forces on the building due to the changes on the relative rigidity of the elements is achieved, consequently reducing the material consumption. Also, the objective is to verify, by means of several examples, the usefulness of the proposed procedure, even considering the limitations to the free displacements of the supports in the plane of the structure. To achieve these objectives, a software was developed, which intends to constitute an auxiliar tool to designers during the process of idealization of the structure. Initially developed to be applied to reinforced concrete structures, the presented formulation can be adopted to the use of other structural materials.
\end{abstract}

Keywords: optimization, grillages, supports 


\section{INTRODUÇÃO}

Tanto a análise como o dimensionamento de estruturas, de modo geral, se constituem em procedimentos de grande complexidade. Ao envolverem um número significativo de variáveis, necessitam ser efetuados de maneira iterativa, ou seja, por meio de aproximações sucessivas. Em função deste caráter iterativo, os valores inicialmente arbitrados para as variáveis dependem de forma determinante tanto da sensibilidade como da experiência prévia do calculista. Ainda assim, o número de repetições exigido seria demasiadamente elevado caso se desejasse obter os valores ideais (ou "ótimos"), dentro do intervalo de resultados aceitáveis. Descrevendo, porém, o comportamento físico da estrutura através de funções matemáticas, buscase valores extremos de tais funções com o emprego de técnicas de otimização.

Nas últimas décadas, devido às crescentes facilidades computacionais, diversos estudos vêm sendo desenvolvidos no sentido de se abandonar os processos simplificados de cálculo, buscando gradativamente a adoção de modelos que reproduzam de forma mais realista o comportamento das estruturas. Especificamente no que diz respeito à estruturas de edifícios, encontram-se atualmente disponíveis inúmeros programas de computador que efetuam tanto a análise como o dimensionamento e o detalhamento deste tipo de estrutura. Muito pouca ênfase, porém, tem sido dada à sistematização do processo de idealização da estrutura portante. O chamado "lançamento" da estrutura, em consequência, continua sendo efetuado basicamente de forma empírica, sendo que uma vez idealizada uma configuração inicial raramente são estudadas outras configurações possíveis, dentre um universo de alternativas também viáveis e eventualmente mais econômicas.

Quando se trabalha com estruturas correntes de edifícios, muitas vezes se tem como fator limitante do projeto a altura máxima das vigas, tanto por motivos estéticos como funcionais. Ocorre ainda que, por facilidades construtivas, é pratica 
comum a utilização de uma única área para a seção transversal de uma viga em todos os seus vãos, bem como a manutenção de um pequeno número de distintas áreas de seção transversal em um mesmo pavimento (acarretando, entre outros, em economia de fôrmas e escoramento). Normalmente, porém, estes procedimentos podem ocasionar o superdimensionamento de alguns tramos de vigas e, consequentemente, a sub-utilização da capacidade resistente dos materiais.

A otimização de estruturas pode ser classificada, entre outras formas, de acordo com os seguintes objetivos: otimização de seção transversal dos membros, otimização geométrica e otimização topológica. A primeira consiste na busca do menor peso ou custo para a estrutura pela redução nas dimensões da seção transversal dos elementos. A otimização geométrica, enfocada neste trabalho, possibilita a variação no comprimento de cada elemento pela alteração nas posições nodais. Já a otimização topológica, bem mais complexa, além dos objetivos comuns tanto à otimização de seção como à otimização geométrica, visa também a determinação de um número e disposição ótimos dos elementos.

Segundo VANDERPLAATS (1984b), o grande desenvolvimento dos estudos relacionados à otimização estrutural foi motivado principalmente por um trabalho apresentado por SCHMIT em 1960. Neste, técnicas de programação não-linear foram utilizadas objetivando a minimização do peso de uma treliça composta por três barras, sujeita a cinco distintas condições de carregamento e tendo como variáveis tanto as dimensões da seção transversal de cada barra como as coordenadas dos nós. O projeto final resultou em uma estrutura balanceada, a qual não é submetida a tensões extremas para nenhuma das condições de carregamento isoladamente. Foi ainda observado que, ao se incluir as coordenadas dos nós também como variáveis, uma estrutura ainda mais leve pode ser obtida. Este trabalho foi complementado por SCHMIT \& MALLETT (1963) de modo a permitir o tratamento tanto da configuração como da escolha dos materiais como variáveis contínuas.

Apesar dos primeiros resultados obtidos a partir da inclusão das coordenadas nodais como variáveis de projeto, os quais foram considerados bastante promissores, muito pouco esforço foi dedicado a este tipo de análise, e praticamente nenhum esforço ao problema de otimização topológica. De acordo com IMAM \& AL-SHIRI (1996), as estruturas usualmente analisadas consistem principalmente em treliças, 
com alguns trabalhos relativos à pórticos e membranas. Esta limitação se deve basicamente à complexidade dos problemas que envolve a otimização geométrica, a qual apresenta boas perspectivas do ponto de vista econômico, porém para os quais os processos usuais demonstram-se pouco eficientes. Esta opinião é compartilhada por diversos autores, entre os quais SPILLERS (1975) e KIRSCH (1989). IMAM \& AL-SHIRI (1996) destacam porém outras razões de natureza prática, entre elas o fato de que a otimização estrutural é vista quase que universalmente como uma ferramenta para obter o mínimo peso de uma estrutura. Ainda nestes casos, a economia obtida em relação ao custo total do projeto pode não ser suficientemente encorajadora para incentivar o aprofundamento dos estudos.

Como reforço à visão dos autores mencionados, destaca-se o trabalho de COHN, FELLOW \& DINOVITZER (1994) o qual, com base em mais de 500 exemplos retirados de artigos e livros publicados no período de maior evolução da otimização estrutural, enfatiza a grande preocupação com aspectos matemáticos, e em consequência a grande contribuição dada ao desenvolvimento das técnicas. Em contrapartida, o número de exemplos é muito pequeno em relação ao número de artigos e livros, sendo estes exemplos normalmente de interesse puramente acadêmico, em detrimento da aplicabilidade prática. A nível de ilustração, cinco são as grelhas catalogadas, ou seja, menos de um por cento dos exemplos. Como característica comum, todas são em estrutura de aço, contemplando a otimização de seção transversal. Adicionalmente, três delas consistem em estruturas idênticas e formadas por apenas dois elementos.

Como anteriormente citado, diversos trabalhos contemplando a otimização geométrica relacionados ao modelo de treliça foram apresentados, exemplificando-se com os de SPILLERS (1975), IMAI \& SCHMIT (1981) e KO \& WANG (1991), este último incluindo como variáveis também as posições dos apoios, e não apenas as dos nós internos. Muito pouco, porém, encontra-se a respeito da otimização geométrica aplicada à outros modelos estruturais, e em especial os abordados no presente trabalho, quais sejam, vigas contínuas e grelhas. KIRSCH (1991) efetua a análise tanto para o regime elástico como para o plástico de uma viga contínua com quatro apoios, com simetria de geometria e carregamento (três cargas concentradas). Ao permitir o deslocamento dos apoios internos sobre o eixo da viga busca minimizar as 
tensões em determinados pontos da seção transversal, concluindo que, apesar de valores finais significativamente diferentes para a função objetivo comparando-se as análises nos regimes elástico e plástico, o ótimo para as duas situações é obtido com geometrias similares. KO \& WANG (1991) apresentam a análise de uma viga engastada em uma extremidade e com um apoio simples, sendo permitido a este o deslocamento ao longo do comprimento da viga. Submetida a cargas concentradas, a estrutura foi subdividida em dez elementos, objetivando-se a obtenção das dimensões mínimas para a seção transversal de cada um destes elementos. Sem citar de forma explicita a economia obtida a partir do deslocamento do apoio, reiteram a importância deste procedimento para a obtenção de uma estrutura ainda mais leve. Por fim, destaca-se o trabalho desenvolvido por IMAM \& AL-SHIRI (1996), no qual são propostas tanto a minimização da máxima deflexão como do máximo momento fletor em pórticos planos (denominada pelos autores por "otimização de topologia de apoio"). Como principal contribuição, concluem que a geometria final da estrutura difere de forma significativa em função do objetivo (deflexão ou momento fletor).

Basicamente, o modelo de grelha tem sido abordado por KIRSCH (1981) e por KIRSCH \& TAYE (1985), em especial a otimização topológica. As principais dificuldades apontadas são o elevado grau de indeterminação do modelo estrutural e o fato de uma nova estrutura ser gerada a cada alteração no número de nós ou elementos. Assim, a forma básica adotada para o tratamento do problema consiste na pré-definição de uma estrutura de nós fixos, da qual vão sendo retirados elementos sem a consideração inicial da compatibilidade dos deslocamentos nodais ("Múltiplas Topologias Ótimas"). O limite inferior corresponderá à estruturas estaticamente determinadas, sendo que outras soluções serão igualmente aceitáveis se a posterior consideração da compatibilidade não afetar de forma significativa o resultado obtido.

O presente trabalho propõe a otimização de estruturas, a priori de concreto armado, analisadas segundo o modelo de grelha, em função do posicionamento dos apoios. Supondo que exista uma certa liberdade de posicionamento dos apoios no plano da estrutura busca-se, pela mudança nas posições inicialmente idealizadas, a redistribuição dos esforços em pavimentos de edifícios pela alteração na rigidez relativa dos elementos, de modo a possibilitar maior uniformização dos esforços e 
consequentemente maior economia no consumo dos materiais componentes (no caso o aço, devido à manutenção da seção transversal previamente adotada).

Com a finalidade descrita, foi desenvolvido um programa de computador associando técnicas de programação matemática ao Método dos Deslocamentos para a análise de estruturas reticuladas, buscando-se o posicionamento ótimo dos apoios em estruturas analisadas segundo o modelo de grelha. Apesar das simplificações adotadas e das consequentes limitações, pretende-se que este programa se constitua em um passo inicial para a construção de uma ferramenta auxiliar ao projetista na fase de concepção da estrutura portante de edifícios. Busca-se ainda ratificar a importância da inclusão, na otimização estrutural, do comprimento dos elementos (ou posições dos nós) como variáveis do problema. Apesar do direcionamento do presente trabalho à estruturas de concreto armado, a formulação proposta pode ser livremente empregada a outros materiais estruturais, como o aço, por exemplo.

O capítulo 2 deste trabalho enfoca conceitos básicos relativos à otimização de estruturas. Inicialmente, apresenta-se a formulação genérica de um problema de otimização, bem como a interpretação geométrica para problemas com e sem restrições. Descreve-se de forma sucinta as etapas envolvidas na resolução de um problema de otimização, apresentando os processos empregados ao longo do trabalho. Também a formulação genérica do Método dos Deslocamentos é apresentada, sendo particularizada para os modelos de viga e de grelha nos capítulos respectivos.

No capítulo 3 os conceitos anteriormente apresentados são aplicados à otimização da posição dos apoios em vigas contínuas, inicialmente estudadas devido à sua relativa simplicidade quando comparadas ao modelo de grelha. Descreve-se as hipóteses básicas empregadas, as formulações idealizadas e testadas, bem como a formulação adotada, sendo para esta última apresentada a forma de implementação acompanhada de exemplos de análises e observações decorrentes.

A adaptação da formulação utilizada ao modelo de grelha para otimização de vigas é apresentada no capítulo 4, bem como as devidas alterações no programa. As limitações da formulação adaptada geraram a necessidade da elaboração de uma formulação alternativa, também apresentada. 
O capítulo 5 é ilustrado com algumas das estruturas analisadas com o auxílio do programa desenvolvido para a otimização geométrica de grelhas, de modo a se verificar tanto os limites de aplicabilidade como o real grau de economia obtido.

Com base nos capítulos anteriores, no capítulo 6 são listadas as principais conclusões e as considerações finais, dando ênfase não apenas aos resultados obtidos a partir da aplicação do programa desenvolvido, mas também à utilização mais geral da forma de otimização nele empregado. 


\section{CONCEITOS FUNDAMENTAIS}

\subsection{Introdução}

O rápido desenvolvimento das técnicas de otimização, e em particular da otimização estrutural, está diretamente relacionado ao avanço dos recursos computacionais. A análise de estruturas, que antes necessitava de diversas simplificações para que se tornasse viável, gradualmente passa a utilizar modelos que melhor reproduzem o comportamento real das estruturas. $\mathrm{O}$ emprego de métodos de otimização pode desempenhar papel importante neste processo, não com o intuito de substituir a criatividade humana, como já destacavam SCHMIT \& MALLETT (1963), mas sim por proporcionarem o desenvolvimento, de forma rápida e eficiente, de tarefas com objetivos e critérios pré-definidos pelo programador. Desta forma, tanto a análise de estruturas como a otimização, por se constituirem em processos iterativos, se vêm bastante beneficiadas pelas facilidades computacionais. Exemplificando, segundo VANDERPLAATS (1984a), caso se desejasse efetuar a análise de um problema envolvendo 3 variáveis, e investigando-se 10 possíveis valores para cada variável (supondo que cada análise consumisse 0,1 segundos de CPU em um computador), o tempo total necessário seria de 100 segundos. Já um problema com as mesmas características, porém envolvendo 10 variáveis e sendo também investigados 10 possíveis valores para cada uma, consumiria cerca de 32 anos.

Destacadas a importância e crescente aplicação dos métodos de otimização no tratamento de problemas de engenharia, prentende-se neste capítulo apresentar de forma sucinta conceitos básicos relativos à otimização e à análise de estruturas por computador, bem como classificações gerais e os métodos empregados no presente trabalho. Para os conceitos e procedimentos apresentados, apesar da farta bibliografia 
disponível, indica-se uma fonte na qual estes são descritos de forma mais aprofundada, tentando-se o tanto quanto possível manter fidelidade às notações empregadas.

2.2 Conceitos sobre otimização

De forma genérica, um problema de otimização (no caso, minimização) pode ser expresso da seguinte forma:

$$
\begin{array}{lll}
\text { minimizar } & \mathbf{F}\left(\mathbf{x}_{\mathbf{i}}\right) & \mathrm{i}=1, \mathrm{n} \\
\text { sujeito a } & \mathbf{g}_{\mathbf{j}}\left(\mathbf{x}_{\mathbf{i}}\right) \leq \mathbf{0} & \mathrm{j}=1, \mathrm{~m} \\
& \mathbf{h}_{\mathbf{k}}\left(\mathbf{x}_{\mathbf{i}}\right)=\mathbf{0} & \mathrm{k}=1,1 \\
& & \\
& \mathbf{x}_{\mathbf{i}} \boldsymbol{l} \leq \mathbf{x}_{\mathbf{i}} \leq \mathbf{x}_{\mathbf{i}} \boldsymbol{u} &
\end{array}
$$

onde $\mathbf{F}$ designa a função objetivo e $\mathbf{X}=\left(\mathbf{x}_{1}, \mathbf{x}_{2}, \ldots \mathbf{x}_{\mathbf{n}}\right) \mathbf{T}$ consiste no vetor das variáveis de projeto as quais, no presente trabalho, são as coordenadas dos apoios no plano da estrutura. As demais funções são as chamadas restrições do problema (respectivamente, restrições de desigualdade, de igualdade e restrições laterais ou canalizadas). As funções envolvidas no problema podem conter as variáveis de projeto de forma explícita ou não, além de poderem ser desenvolvidas numérica ou analiticamente. Tanto a função objetivo como as funções de restrição podem ser lineares ou não lineares.

A forma utilizada anteriormente para a descrição de um problema de otimização não é única, sendo apresentadas diversas outras formas na literatura. Exemplificando, a inequação (4) é normalmente representada por duas restrições de desigualdade como as indicadas em (2). Porém, da maneira como foi aqui 
apresentada, ficam caracterizados com maior clareza os limites que podem ser assumidos pelas variáveis de projeto, nos quais $\boldsymbol{l}$ e $\boldsymbol{u}$ indicam respectivamente os limites inferior e superior.

As técnicas de otimização necessitam a priori da especificação de valores iniciais para as variáveis de projeto. Uma vez especificados estes valores, os mesmos são atualizados pela expressão

$$
\{X\}_{k+1}=\{X\}_{k}+\alpha\{d\}_{k}
$$

na qual o vetor $\mathbf{d}$, de mesma ordem do vetor $\mathbf{X}$, indica a direção de busca, também conhecida como direção de descida nos problemas de minimização, e o escalar positivo $\alpha$ indica o comprimento do passo a ser dado na direção determinada, de modo a minimizar a função nesta direção. Como se observa, um problema com $\boldsymbol{n}$ variáveis, uma vez determinada a direção de busca, passa a ser tratado como um problema unidimensional, função exclusivamente do escalar $\alpha$. O ponto obtido definirá um novo vetor $\mathbf{X}$, aqui representado pelo sub-índice $\mathbf{k}+\mathbf{1}$, sendo $\mathbf{k}$ o número da iteração anterior. Todo o procedimento descrito é então repetido a partir do novo ponto, até que um critério de parada pré-definido seja atendido.

As diversas técnicas de otimização variam de maneira predominante pela forma de obtenção, a cada iteração, dos valores do vetor $\mathbf{d}$ e de $\alpha$. A figura (1) ilustra o procedimento anteriormente descrito, considerando-se um problema sem restrições e com apenas duas variáveis.

De acordo com BAZARAA \& SHETTY (1979), para a obtenção de um ponto de mínimo na otimização de uma função não sujeita a qualquer tipo de restrição (não necessariamente o mínimo global), é necessário e suficiente que se tenha neste ponto, respectivamente, gradiente nulo (primeiras derivadas de $\mathbf{F}$ em relação a cada variável) e matriz Hessiana definida positiva (segundas derivadas) em relação ao vetor $\mathbf{X}$, sendo $\mathbf{F}$ uma função contínua e duas vezes diferenciável em $\mathbf{X}$ (denominada função de classe $\mathrm{C}^{2}$ ). Esta última condição, relativa à matriz Hessiana, é naturalmente atendida para problemas nos quais as funções apresentam 
características de convexidade. Define-se por convexa uma função para a qual, escolhidos dois pontos quaisquer sobre a curva que a define, e unindo-se estes pontos por um segmento de reta, qualquer valor obtido em algum ponto deste segmento é superior ao valor da função neste ponto. Ou seja, seguindo nomenclatura de BAZARAA \& SHETTY (1979),

seja $\boldsymbol{f}: \mathbf{S} \rightarrow \mathbf{R}$, onde $\mathbf{S}$ representa um conjunto convexo não-vazio em $\mathbf{R}_{\mathbf{n}}$. A função $\boldsymbol{f}$ é dita convexa se, para qualquer $\mathbf{x}_{\mathbf{1}}$ e $\mathbf{x}_{\mathbf{2}} \in \mathbf{S}$

$$
f\left[\lambda \mathbf{x}_{1}+(1-\lambda) \mathbf{x}_{2}\right] \leq \lambda f\left(\mathbf{x}_{1}\right)+(1-\lambda) f\left(\mathbf{x}_{2}\right) \forall \lambda \in(0,1)
$$

A figura (2) apresenta uma ilustração de uma função convexa, bem como de uma função não-convexa.

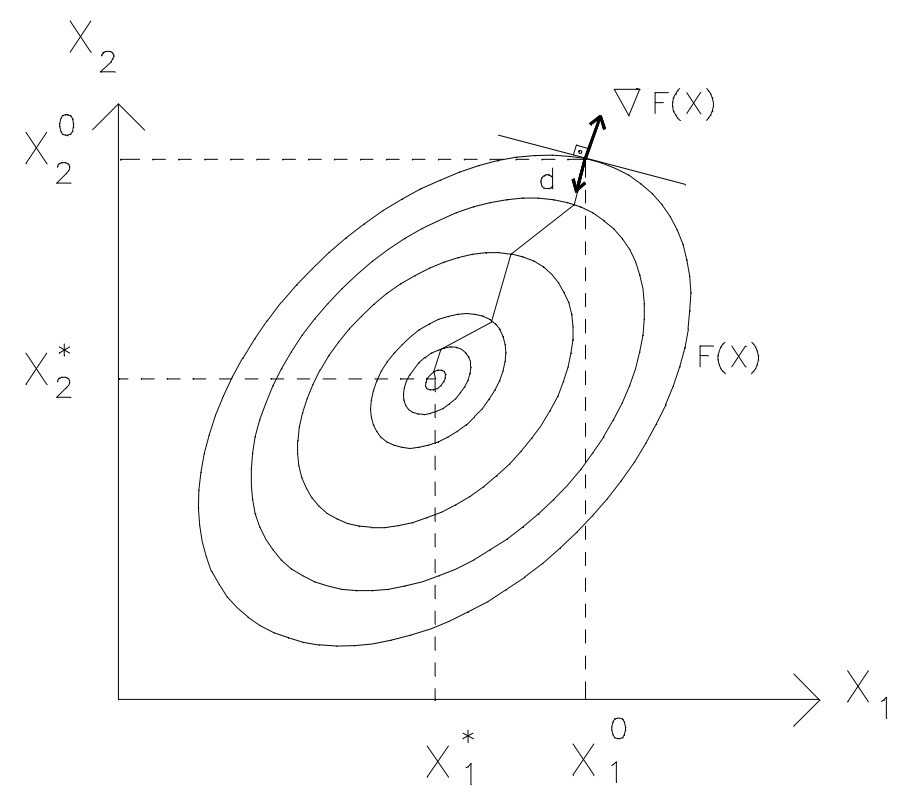

FIGURA (1) - Minimização irrestrita para duas variáveis 


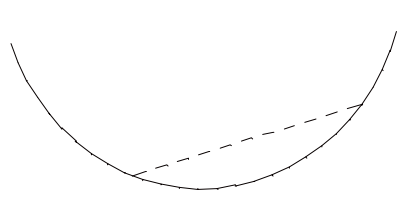

convexa

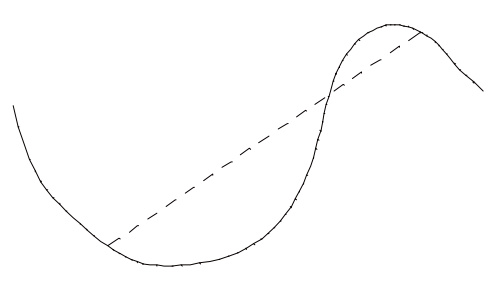

não-convexa

FIGURA (2) - convexidade: representação geométrica

As condições de mínimo descritas anteriormente aplicam-se a problemas de minimização sem restrições. No entanto, para a otimização de problemas sujeitos a restrições, os quais constituem a imensa maioria dos casos práticos em engenharia, deve ser dado um tratamento distinto, de maior complexidade. A região possível (ou região factível) para os valores de $\mathbf{X}$ que minimizem a função objetivo fica agora limitada pelas restrições do problema. No ponto de ótimo, as restrições do tipo $\mathbf{h}$ (restrições de igualdade) devem ser obrigatoriamente ativas, ou seja, iguais a zero. Já as restrições designadas por $\mathbf{g}$ (restriçõoes de desigualdade) devem ser satisfeitas, porém não necessariamente ativas.

Considerando que o gradiente de cada função indica o sentido no qual o valor da função cresce, tem-se como condição necessária para que $\mathbf{X}$ defina um ponto de valor mínimo $\left(\mathbf{X}^{*}\right)$ que o gradiente da função neste ponto seja igual e oposto em módulo à combinação linear das restrições ativas, conforme mostrado na figura (3), sendo atendidas as demais restrições. Estas condições, conhecidas como Condições de Kuhn-Tucker, podem ser escritas do seguinte modo:

$$
\begin{aligned}
& \nabla \mathbf{F}\left(\mathbf{X}^{*}\right)+\sum_{\mathbf{j}=1}^{\mathbf{m}} \lambda_{\mathbf{j}} \nabla \mathbf{g}_{\mathbf{j}}\left(\mathbf{X}^{*}\right)+\sum_{\mathbf{k}=1}^{\mathbf{l}} \lambda_{\mathbf{k}+\mathbf{m}} \nabla \mathbf{h}_{\mathbf{k}}\left(\mathbf{X}^{*}\right)=\mathbf{0} \\
& \lambda_{\mathbf{j}} \mathbf{g}_{\mathbf{j}}\left(\mathbf{X}^{*}\right)=\mathbf{0} \quad \mathrm{j}=1, \mathrm{~m}
\end{aligned}
$$




$$
\lambda_{\mathbf{j}} \geq \mathbf{0}
$$

nas quais os coeficientes $\lambda_{\mathbf{j}}$ e $\lambda_{\mathbf{k}+\mathbf{m}}$ são os escalares denominados como Multiplicadores de Lagrange. Conforme indicado nas equações (7) e (8), os escalares $\lambda_{\mathbf{j}}$ devem assumir valores positivos ou nulos. Já os multiplicadores $\lambda_{\mathbf{k}+\mathbf{m}}$, relacionados às restrições de igualdade, podem assumir valores quaisquer.

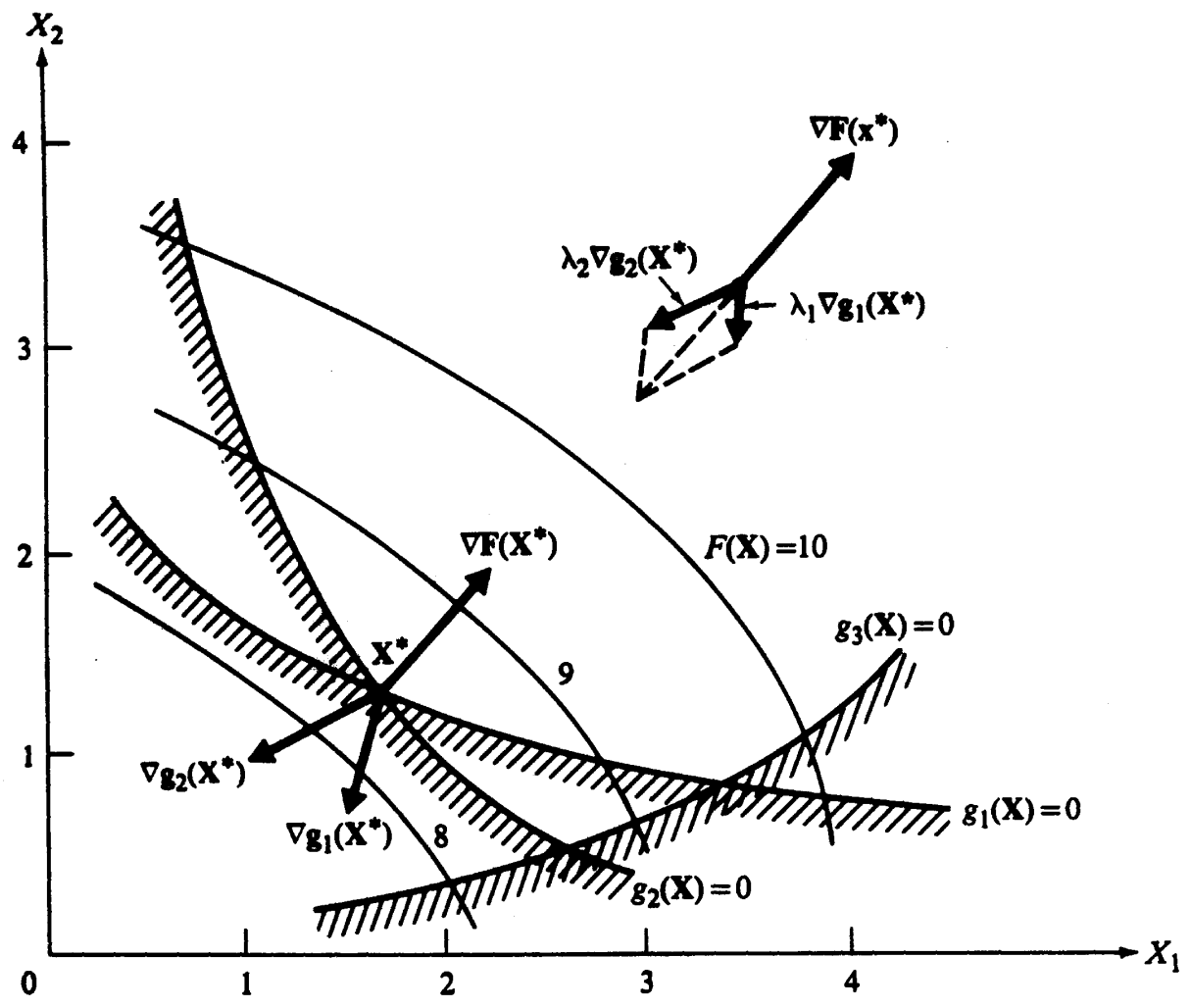

FIGURA (3): Condições de Kuhn-Tucker: Interpretação geométrica para problema com duas variáveis 


\subsubsection{Obtenção da direção de busca}

Os métodos de otimização podem ser classificados pelo processo utilizado para a definição de uma direção de busca. De acordo com esta classificação, os métodos são divididos em três grupos básicos, quais sejam: métodos de ordem zero, métodos de primeira ordem e métodos de segunda ordem. Os métodos de ordem zero utilizam apenas informações relativas à função, enquanto os demais consideram respectivamente as primeiras e segundas derivadas da função em relação a cada variável, para a obtenção dos gradientes e da matriz Hessiana. De forma geral, uma quantidade maior de informações resulta em maior precisão, porém ao custo de uma menor velocidade de convergência a cada iteração, em termos computacionais. Desta forma, ainda que as segundas derivadas sejam facilmente obtidas, não se pode afirmar que os métodos de segunda ordem sejam os mais eficientes. Especialmente em problemas nos quais as funções são derivadas analiticamente, o método torna-se mais complexo e suscetível a erros.

Neste trabalho, inicialmente optou-se pela utilização de um método de segunda ordem, ou mais precisamente o Método de Newton Modificado. O Método de Newton em sua forma básica consiste na atualização das variáveis de projeto tratando a função como localmente quadrática, sendo obtido a partir da expansão em série de Taylor até os termos de segunda ordem e resultando na expressão apresentada em LUENBERGER (1984):

$$
\{\mathbf{X}\}_{k+1}=\{\mathbf{X}\}_{k}-\alpha\left[\nabla^{2} \mathbf{F}\left(\mathbf{X}_{k}\right)\right]^{-1} \nabla \mathbf{F}\left(\mathbf{X}_{k}\right)^{T}
$$

na qual $\nabla \mathbf{F}\left(\mathbf{X}_{\mathbf{k}}\right)$ é a matriz Jacobiana (matriz das primeiras derivadas) e $\left[\nabla^{\mathbf{2}} \mathbf{F}\left(\mathbf{X}_{\mathbf{k}}\right)\right]$ a matriz Hessiana. O tamanho do passo $\alpha$ é considerado igual a unidade, dispensando portanto a busca unidimensional. Assim, o vetor das direções de descida d é obtido pela resolução do sistema de equações (10), sendo que este sistema só terá solução se a matriz Hessiana for inversível (determinante não nulo). 


$$
\left[\nabla^{2} \mathbf{F}\left(\mathbf{X}_{\mathbf{k}}\right)\right]\left\{\mathbf{d}_{\mathbf{k}}\right\}=\left\{\nabla \mathbf{F}\left(\mathbf{X}_{\mathbf{k}}\right)\right\}
$$

O Método de Newton Modificado acarreta em alterações na expressão (9) tanto pela introdução do cálculo do tamanho do passo como eventualmente pela forma de determinação da direção de descida. O cálculo do tamanho do passo tem como objetivo básico melhorar os resultados caso os valores inicialmente arbitrados para as variáveis de projeto não estejam situados nas proximidades dos valores ótimos. Adicionalmente, tem como função evitar que sejam gerados pontos infactíveis ao problema, o que poderia ocorrer ao considerar um passo unitário. Quanto à direção de descida, como longe da solução a inversa da matriz Hessiana pode ainda não ser definida positiva, outras alterações na formulação básica devem ser efetuadas. Dentre as várias modificações possíveis optou-se pela eventual alteração da inversa da matriz Hessiana pelo Método de Cholesky para resolução de sistemas de equações lineares. Ao se tentar efetuar a decomposição da matriz, caso esta não fosse possível devido à existência de um coeficiente não-positivo na diagonal principal da matriz, este coeficiente assumiria valor unitário, prosseguindose com o procedimento de decomposição. Desta forma, tanto a inversa da matriz Hessiana como uma aproximação desta podem ser obtidas, garantindo-se portanto uma matriz definida positiva e consequentemente uma direção de descida.

Outro método utilizado no trabalho foi o desenvolvido por DAVIDON e aperfeiçoado por FLETCHER \& POWELL, denominado usualmente por DFP. Dentre os métodos de primeira ordem, é sugerido por diversos pesquisadores, como por exemplo FOX (1971) e KIRSCH (1981), em função inclusive da dimensão do problema a ser analisado. O procedimento básico consiste na substituição da inversa da matriz Hessiana por uma outra matriz construída e atualizada a partir das informações fornecidas pelos gradientes podendo, também segundo LUENBERGER (1984), representar-se a atualização das variáveis por:

$$
\{\mathbf{X}\}_{k+1}=\{\mathbf{X}\}_{k}-\alpha \mathbf{H}_{k} \nabla \mathbf{F}\left(\mathbf{X}_{k}\right)^{T}
$$


Partindo-se de uma matriz $\mathbf{H}_{\mathbf{k}}$ definida positiva, uma nova matriz é construída de acordo com a expressão

$$
\mathbf{H}_{\mathbf{k}+1}=\mathbf{H}_{\mathbf{k}}+\frac{\mathbf{p}_{\mathbf{k}} \mathbf{p}_{\mathbf{k}}^{\mathbf{T}}}{\mathbf{p}_{\mathbf{k}}^{\mathbf{T}} \mathbf{q}_{\mathbf{k}}}-\frac{\mathbf{H}_{\mathbf{k}} \mathbf{q}_{\mathbf{k}} \mathbf{q}_{\mathbf{k}}^{\mathbf{T}} \mathbf{H}_{\mathbf{k}}}{\mathbf{q}_{\mathbf{k}}^{\mathbf{T}} \mathbf{H}_{\mathbf{k}} \mathbf{q}_{\mathbf{k}}}
$$

sendo então definida uma nova direção de descida por

$$
\mathbf{d}_{\mathrm{k}+1}=-\mathbf{H}_{\mathrm{k}+1} \mathbf{g}_{\mathrm{k}+1}
$$

Nas expressões anteriores,

$$
\begin{aligned}
& \mathbf{p}_{\mathbf{k}}=\mathbf{X}_{\mathbf{k}+1}-\mathbf{X}_{\mathbf{k}} \\
& \mathbf{g}_{\mathbf{k}+1}=\nabla \mathbf{F}\left(\mathbf{X}_{\mathbf{k}+1}\right)^{\mathbf{T}} \\
& \mathbf{q}_{\mathbf{k}}=\mathbf{g}_{\mathbf{k}+1}-\mathbf{g}_{\mathbf{k}}
\end{aligned}
$$

Para a aplicação do método, considera-se normalmente a matriz identidade como primeira aproximação da inversa da Hessiana ( $\left.\mathbf{H}_{\mathbf{0}}\right)$, tornando a primeira iteração igual a direção do gradiente porém com sentido oposto a este (procedimento adotado pelo denominado Método do Gradiente). Visto que a matriz identidade é positiva definida, tem-se que a matriz $\mathbf{H}_{\mathbf{0}}$ também será positiva definida.

Pelo fato de aproximar a inversa da matriz Hessiana, estes métodos possuem características de convergência semelhantes às do Método de Newton, sendo por este motivo também denominados métodos quasi-Newton. 


\subsubsection{Determinação do tamanho do passo}

Como ilustrado de forma genérica pela expressão (5), uma vez determinado o vetor direção de busca d, novos valores para as variáveis de projeto são obtidos ao se calcular o tamanho do passo $\alpha$ a ser dado na direção de busca. Os processos para a determinação do passo, ou processos de busca unidimensional, podem ser classificados em função do grau de precisão desejado ou ainda, a exemplo dos métodos para determinação do vetor direção de busca d, pela disponibilidade de informações de ordem zero ou de primeira ordem.

Um dos processos utilizados neste trabalho, a Regra de Armijo, é classificado como um método de busca imprecisa. Apesar de necessitar tanto de valores da função em diversos pontos como valores de suas respectivas derivadas, objetiva a determinação aproximada do valor do parâmetro $\alpha$, situando-o em um intervalo aceitável de forma que este valor não seja considerado nem muito grande nem muito pequeno. Por não muito grande entende-se um $\alpha$ para o qual, definindo-se segundo LUENBERGER (1984), a igualdade

$$
\phi(\alpha)=f\left(x_{k}+\alpha d_{k}\right)
$$

tem-se que

$$
\phi(\alpha) \leq \phi(0)+\varepsilon \phi^{\prime}(0) \alpha, \text { para } 0<\varepsilon<1
$$

Por outro lado, $\alpha$ não é muito pequeno se

$$
\phi(\eta \alpha)>\phi(0)+\varepsilon \phi^{\prime}(0) \eta \alpha, \text { sendo } \eta>1
$$

A utilização da Regra de Armijo, ao sacrificar a precisão do cálculo, acarreta em aumento no número de iterações necessárias à convergência. Como compensação, oferece uma redução bastante significativa no tempo gasto em cada 
iteração, relativamente a processos de busca exata. Esta constatação resultou da implementação e comparação direta com alguns métodos exatos, como o Ajuste Cúbico e o Método da Seção Áurea.

Como a própria denominação sugere, o método do Ajuste Cúbico consiste na aproximação sucessiva do valor de $\alpha$ pela construção de uma função do terceiro grau, partindo-se de dois outros pontos $\mathbf{x}_{\mathbf{k}}$ e $\mathbf{x}_{\mathbf{k}-\mathbf{1}}$ e dos respectivos valores da função e da derivada nestes pontos. O valor de $\mathbf{x}_{\mathbf{k}+\mathbf{1}}$, contido no intervalo delimitado pelos dois valores imediatamente anteriores é obtido, segundo LUENBERGER (1984), pela expressão

$$
x_{k+1}=x_{k}-\left(x_{k}-x_{k-1}\right)\left[\frac{f^{\prime}\left(x_{k}\right)+u_{2}-u_{1}}{f^{\prime}\left(x_{k}\right)-f^{\prime}\left(x_{k-1}\right)+2 u_{2}}\right]
$$

sendo

$$
u_{1}=f^{\prime}\left(x_{k-1}\right)+f^{\prime}\left(x_{k}\right)-3 \frac{f\left(x_{k-1}\right)-f\left(x_{k}\right)}{x_{k-1}-x_{k}}
$$

e

$$
u_{2}=\left[u_{1}^{2}-f^{\prime}\left(x_{k-1}\right) f^{\prime}\left(x_{k}\right)\right]^{1 / 2}
$$

O Método da Seção Áurea, descrito de forma bastante detalhada por VANDERPLAATS (1984a), possui como característica relevante o fato de, verificada a unimodalidade da função (existência de um único ponto de mínimo no intervalo), necessitar exclusivamente do cálculo de valores da função em determinados pontos, não importando sequer se as primeiras derivadas são ou não contínuas. Como resultado, apresenta grande velocidade de convergência, comparativamente ao Ajuste Cúbico.

Simplificadamente, o método da Seção Áurea consiste na determinação, supostos conhecidos os limites superior $\mathbf{X} \boldsymbol{u}$ e inferior $\mathbf{X} \boldsymbol{l}$, de dois pontos intermediários e dos respectivos valores da função nestes pontos, de forma que a determinação do próximo valor de $\mathbf{X}$ seja efetuada redefinindo-se os limites do 
intervalo a uma fração do intervalo considerado na iteração anterior. Esta fração é obtida inicialmente pela determinação de dois valores intermediários $\mathbf{X}_{\mathbf{1}}$ e $\mathbf{X}_{\mathbf{2}}$ (sendo $\mathbf{X}_{1}$ menor que $\mathbf{X}_{2}$ ), dispostos simetricamente em relação aos centro do intervalo, sendo então

$$
\mathrm{X}^{u}-\mathrm{X}_{2}=\mathrm{X}_{1}-\mathbf{X}^{l}
$$

Ao impor que, por exemplo, $\mathbf{X}_{\mathbf{1}}$ venha a se tornar o novo limite inferior $\mathbf{X} \boldsymbol{l}$, então $\mathbf{X}_{2}$ assumirá o valor de $\mathbf{X}_{1}$, para que a razão entre $\mathbf{X}_{2}-\mathbf{X}_{1}$ em relação a $\mathbf{X} \boldsymbol{u}$ - $\mathbf{X} \boldsymbol{l}$ mantenha-se a mesma, conforme a relação (24).

$$
\left(\mathbf{X}_{1}-\mathbf{X}^{l}\right)\left(\mathbf{X}^{u}-\mathbf{X}_{1}\right)=\left(\mathbf{X}_{2}-\mathbf{X}_{1}\right)\left(\mathbf{X}^{u}-\mathbf{X}^{l}\right)
$$

Assim, tomando-se respectivamente os valores um e zero para $\mathbf{X} \boldsymbol{u}$ e $\mathbf{X} \boldsymbol{l}$, tem-se das duas equações imediatamente anteriores que

$$
\mathbf{X}_{2}=1-\mathbf{X}_{1}
$$

$\mathrm{e}$

$$
\mathbf{X}_{1}\left(\mathbf{1}-\mathbf{X}_{1}\right)=\left(\mathbf{X}_{2}-\mathbf{X}_{1}\right)
$$

ou, simplificando-se esta última expressão,

$$
X_{1}^{2}-3 X_{1}+1=0
$$

Chega-se desta forma às relações

$$
X_{1}=\left(3-5^{1 / 2}\right) / 2=0,38197 \quad \text { e } \quad X_{2}=0,61803
$$


Tem-se então que a razão entre $\mathbf{X}_{2}$ e $\mathbf{X}_{1}$ será o chamado número da Seção Áurea, aproximadamente igual a 1,61803. Os novos valores de $\mathbf{X}_{\mathbf{1}}$ e de $\mathbf{X}_{\mathbf{2}}$ para as iterações subsequentes serão determinados como

$$
\mathbf{X}_{1}=(1-\eta) \mathbf{X}^{l}+\eta \mathbf{X}^{u}
$$

$\mathrm{e}$

$$
\mathbf{X}_{2}=\eta \mathbf{X}^{\boldsymbol{l}}+(1-\eta) \mathbf{X} \boldsymbol{u}
$$

sendo $\eta=0,38197$

Desta forma, pela substituição progressiva de $\mathbf{X}^{\boldsymbol{l}}$ por $\mathbf{X}_{\mathbf{1}}$ ou, no outro extremo, de $\mathbf{X} \boldsymbol{u}$ por $\mathbf{X}_{2}$, reduz-se o intervalo inicial de forma a $\mathbf{X}_{\mathbf{1}}$ e $\mathbf{X}_{2}$ convergirem para um único valor, conforme a tolerância desejada.

\subsubsection{Otimização de problemas com restrições}

Os procedimentos até aqui descritos aplicam-se integralmente a problemas sem restrições, como o ilustrado na figura (1), de difícil ocorrência em problemas práticos de Engenharia. No trabalho desenvolvido, as restrições foram consideradas pela Técnica de Minimização Sequencial de Problemas sem Restrições (conhecida abreviadamente por SUMT). Por esta técnica as restrições não atendidas são penalizadas pela substituição destas funções de restrição por outras que potencializem o efeito de seu não atendimento às condições impostas, bem como através da multiplicação por um coeficiente pré-determinado. Estas funções penalizadas são então somadas à função objetivo original, minimizando-se a função resultante. Uma vez obtida a convergência, o coeficiente de penalização inicialmente adotado é multiplicado por um fator e o processo repetido até que a alteração deste coeficiente não gere mudanças significativas nos resultados obtidos.

Dentre os processos para penalização, foi adotada a penalização exterior, segundo a qual parte-se de uma solução não necessariamente factível, ou seja, de um ponto que não atenda as condições impostas no problema, caminhando-se sucessivamente também por soluções não factíveis até a obtenção de um resultado 
final que atenda as restrições. A clara desvantagem deste procedimento consiste no fato de que, caso o processo iterativo seja interrompido precocemente, o resultado obtido não será uma solução factível para o problema formulado. Em contrapartida, dispensa-se a obrigatoriedade do conhecimento a priori de uma solução factível, solução esta que tanto pode ser de difícil determinação como, dependendo das características do problema, pode ser a própria solução do problema, tornando o processo de otimização inócuo.

Pela convenção adotada por VANDERPLAATS (1984a), a função penalizada é escrita como

$$
\Phi(\mathbf{X}, \mathbf{r})=\mathbf{F}(\mathbf{X})+\mathbf{r} \mathbf{P}(\mathbf{X})
$$

onde $\mathbf{P}(\mathbf{X})$ é a função que representa o conjunto das restrições penalizadas e $\mathbf{r}$ é o coeficiente de penalização. No caso, a função $\mathbf{P}(\mathbf{X})$ foi definida como

$$
P(X)=\sum_{j=1}^{m}\left\{\max \left[0, g_{j}(X)\right]\right\}^{2}+\sum_{k=1}^{l}\left[h_{k}(X)\right]^{2}
$$

De forma sucinta, o procedimento a adotar consiste na adição da função penalizadora $\mathbf{P}(\mathbf{X})$, multiplicada pelo coeficiente positivo $\mathbf{r}$, à função objetivo $\mathbf{F}(\mathbf{X})$, conforme a expressão (29). Minimiza-se a função resultante, majorando a seguir o coeficiente de penalização por um fator de penalização positivo $\gamma$ e novamente procedendo-se à minimização da função resultante. Na medida em que o coeficiente $\mathbf{r}$ tende ao infinito e a função objetivo $\mathbf{F}(\mathbf{X})$ tende a um mesmo valor, dentro da tolerância pré-estabelecida, significa que a função penalizadora $\mathbf{P}(\mathbf{X})$ assumiu um valor próximo a zero, ou seja, que todas as restrições foram atendidas.

Encontra-se na literatura técnica diversas sugestões para valores tanto do coeficiente de penalização como do fator de multiplicação, porém nenhuma indicação mais precisa é fornecida, sendo necessária a aferição destes parâmetros em função das características do problema formulado. 


\subsubsection{Critérios de parada}

Como a maioria dos métodos de otimização converge de forma mais rápida apenas nas proximidades da solução, grande cuidado deve ser tomado na seleção do critério de parada a adotar. No caso de utilização de métodos de penalização exterior para consideração das restrições, conforme citado no sub-ítem anterior, a interrupção precoce do processo iterativo conduz a um resultado que não atende às condições de factibilidade. Por outro lado, a boa escolha de um critério pode evitar um esforço computacional excessivo sem que isto resulte em alteração significativa dos resultados.

Uma grande diversidade de critérios é apresentada por GILL, MURRAY \& WRIGHT (1981), sendo classificados em relação tanto das características do problema como da função a extremizar. No presente trabalho optou-se pela comparação dos valores assumidos por cada uma das variáveis em duas iterações consecutivas, de modo a interromper o processo quando a diferença entre estes valores estiver limitada a uma tolerância $\varepsilon$ sendo então que, para cada variável:

$$
\left|\mathbf{x}_{\mathbf{k}}-\mathbf{x}_{\mathbf{k}-1}\right| \leq \varepsilon
$$

onde $\mathrm{k}$ representa o número da última iteração.

Uma outra situação possível constitui-se na qual o processo iterativo diverge ou apresenta convergência bastante lenta. Para esta situação, definiu-se um número máximo de iterações a cada ciclo, bem como um número máximo total. Apesar de diversas sugestões, normalmente relacionando o número de iterações ao número de variáveis, optou-se inicialmente por definir um valor de forma aleatória. Posteriormente, ao longo dos testes, o mesmo poderia ser aferido. 


\subsection{Formulação básica do Método dos Deslocamentos}

Para efeito de análise computacional, os métodos matriciais demonstram-se como ferramentas de grande eficiência. Dentre estes, o Método dos Deslocamentos é o de emprego mais difundido, basicamente pela fácil sistematização do processo para a determinação dos deslocamentos e esforços.

O Método dos deslocamentos, segundo notação utilizada por SOUZA \& ANTUNES (1995), envolve a resolução do sistema

$$
[\mathbf{R}]\{\mathbf{U}\}=\{\mathbf{F}\}
$$

no qual $\mathbf{R}, \mathbf{F}$ e $\mathbf{U}$ representam, respectivamente: a matriz de rigidez global da estrutura (função das características do material, da seção transversal e do comprimento de cada elemento, bem como de sua orientação no plano ou espaço relativamente aos demais elementos); o vetor de forças nodais (ou forças nodais equivalentes), determinadas pelo carregamento aplicado e pelo comprimento do elemento carregado; e o vetor de deslocamentos nodais, este último contendo as incógnitas do sistema. Uma vez determinados os deslocamentos, calcula-se os esforços nos extremos de cada elemento a partir da rigidez do próprio elemento ( $\mathbf{r}_{\mathbf{i}}$ ) e das ações eventualmente aplicadas ao longo do mesmo ( $\mathbf{P} \mathbf{0}$ ), ou ações de engastamento perfeito:

$$
\{\mathbf{P}\}_{\mathbf{i}}=[\mathbf{r}]_{\mathbf{i}}\{\delta\}_{\mathbf{i}}+\left\{\mathbf{P}_{\mathbf{0}}\right\}_{\mathbf{i}}
$$

Por se tratar de um método largamente empregado e portanto bastante familiar à engenharia de estruturas, serão aqui omitidos maiores detalhes sobre sua utilização, deixando-se para os capítulos seguintes as expressões derivadas do 
Método dos Deslocamentos aplicadas diretamente ao problema de otimização estrutural. 


\section{OTIMIZAÇÃO GEOMÉTRICA DE VIGAS CONTÍNUAS}

\subsection{Introdução}

Como citado no primeiro capítulo deste trabalho, optou-se inicialmente pela definição de uma formulação especificamente adequada ao modelo de viga, devido fundamentalmente à simplicidade apresentada por este em relação ao modelo de grelha. Com este objetivo diversas formulações foram estudadas, cada uma tendo como base tanto hipóteses gerais pré-definidas como observações oriundas das formulações já idealizadas e testadas. O estudo desenvolvido, mais do que se constituir em uma etapa intermediária do trabalho, acabou por demonstrar a grande eficiência da determinação do posicionamento ótimo dos apoios em vigas propriamente ditas, apontando uma economia significativa para os vários exemplos analisados. Por este motivo, o presente trabalho da ênfase também ao modelo de viga o qual, além de reproduzir com relativa fidelidade o comportamento a que alguns tipos de estruturas são submetidas, é ainda hoje utilizado na análise simplificada de estruturas de edifícios.

\subsection{Formulação inicial do problema}

\subsubsection{Hipóteses básicas}

Para a elaboração de uma formulação para a otimização de vigas tendo como variáveis de projeto as posições dos apoios, diversas considerações foram efetuadas a partir de fatores tidos como relevantes do ponto de vista econômico, em relação tanto ao consumo de materiais componentes da estrutura como também em relação ao 
consumo de materiais provisórios utilizados na confecção da estrutura portante. Sendo o trabalho voltado principalmente à aplicação em estruturas de concreto armado, as quais constituem a imensa maioria das edificações construídas no País, foram de grande importância nesta etapa estudos como os apresentados por PORCELLO (1993), contendo diretrizes para a redução nos custos da construção em função do projeto estrutural. Devido à tendência da adoção de no máximo duas ou três seções transversais distintas, e normalmente pré-definidas, em um pavimento de edifício, optou-se por não incluir na análise a otimização de seção transversal dos elementos. O objetivo, portanto, foi o de propiciar de forma direta apenas uma redução no peso total de aço, tendo-se porém a possibilidade de, a partir dos resultados da análise, efetuar o redimensionamento da seção transversal. Cabe enfatizar que, desta forma, uma eventual economia obtida deve-se unicamente à redistribuição dos esforços na estrutura, e portanto sem detrimento da segurança.

Pelo fato de, como anteriormente citado, os estudos relativos à vigas se constituírem a priori em uma etapa intermediária do trabalho, as estruturas analisadas possuíam diversas restrições, quais sejam: possibilidade de aplicação de um único carregamento, uniformemente distribuído, ao longo de toda a estrutura; manutenção de uma mesma dimensão da seção transversal para todos os elementos componentes; existência de apoios simples em todos os nós, excetuando-se os nós extremos, os quais não possuem qualquer tipo de vinculação.

Todas as formulações idealizadas e implementadas partiram dos mesmos princípios básicos descritos a seguir. Inicialmente, considerando que a altura da seção transversal de uma viga é definida em função do maior momento fletor, e considerando ainda que em uma análise elástica normalmente os maiores momentos são os negativos (tracionam a face superior do elemento), busca-se a redução e uniformização nos valores destes esforços. Estes objetivos são perseguidos pela alteração nas posições dos apoios, sendo portanto estas posições o conjunto das variáveis de projeto. Uma outra consideração foi a de que a existência de trechos em balanço nas extremidades da viga seria benéfica pelo fato de, ao introduzir momentos negativos, ocasionar em uma redistribuição dos esforços ao longo da estrutura, com consequente redução dos momentos nos demais tramos. De forma a definir limites inferiores para os momentos nos balanços foram impostas restrições em ambas as 
extremidades, relacionando os momentos negativos e os positivos imediatamente adjacentes.

De modo a simplificar a notação utilizada, considera-se que o sub-índice para os momentos fletores positivos $\mathbf{M}^{(+)}$corresponde ao número do elemento, enquanto o sub-índice relativo aos momentos fletores negativos $\mathbf{M}^{(-)}$corresponde ao número do nó.

As variáveis do problema foram tomadas como as coordenadas dos apoios em relação ao primeiro nó da estrutura, situado à esquerda dos demais. Pelo fato do comprimento total da viga permanecer inalterado, bem como pela imposição dos balanços nos extremos (momentos fletores nulos), o vetor das variáveis de projeto exclui estes nós extremos, sendo portanto de dimensão total NNO-2, onde NNO corresponde ao número total de nós do modelo, sendo o número de elementos igual a NNO-1. O comprimento L de um determinado elemento i da viga é determinado por:

$$
\mathbf{L}_{\mathbf{i}}=\mathbf{x}_{\mathbf{i}+\mathbf{1}}-\mathbf{x}_{\mathbf{i}}
$$

conforme ilustrado na figura (4).

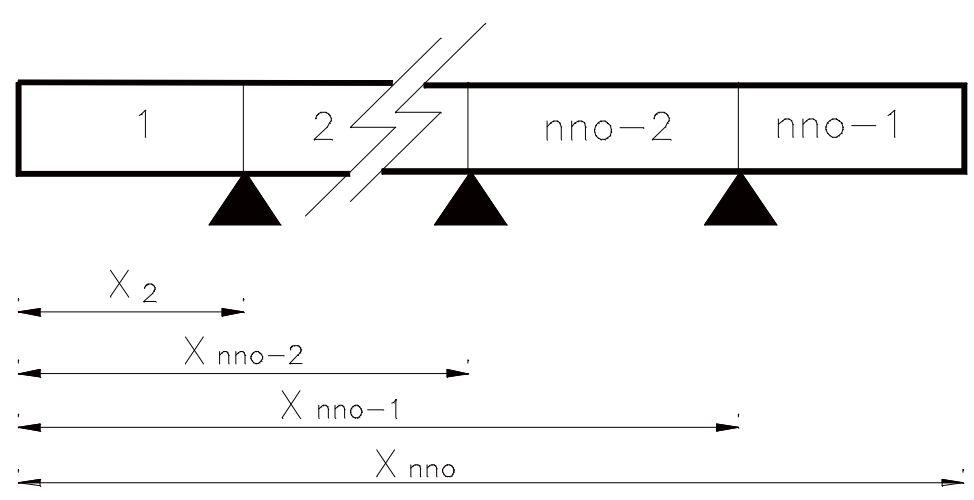

FIGURA (4) - Otimização em função da posição dos apoios: viga genérica 
Uma vez caracterizado o problema de otimização, descreve-se uma formulação inicial na forma dada pelas expressões (1) a (4), sendo o objetivo portanto:

$$
\begin{array}{ll}
\text { minimizar } \quad & \sum_{\mathbf{i}=\mathbf{2}}^{\mathbf{N N O}-\mathbf{1}} \mathbf{M}_{\mathbf{i}}^{(-)} \\
\text {sujeito a } & \mathbf{h}_{\mathbf{1}}: \mathbf{M}_{\mathbf{2}}^{(+)}+\mathbf{M}_{\mathbf{2}}^{(-)}=\mathbf{0} \\
& \mathbf{h}_{\mathbf{2}}: \mathbf{M}_{\mathbf{N N O}-\mathbf{2}}^{(+)}+\mathbf{M}_{\mathbf{N N O}-\mathbf{1}}^{(-)}=\mathbf{0} \\
& \\
& \mathbf{g}_{\mathbf{1}}: \mathbf{M}_{\mathbf{k}}^{(-)} \leq \mathbf{0} \quad \mathrm{k}=2, \mathrm{NNO}-1
\end{array}
$$

ou seja, minimizar o somatório dos momentos fletores sobre os apoios internos impondo-se como restrições a igualdade nos extremos entre momentos fletores negativos e positivos, sendo todos os momentos sobre os apoios efetivamente nãopositivos.

3.2.2 Teste da formulação inicial para uma estrutura isostática

Com o objetivo de verificar a relevância do procedimento proposto, optou-se inicialmente pela análise de uma estrutura simples, no caso uma viga biapoiada. Caso não se verificasse economia significativa para esta estrutura, haveria fortes indícios da pouca aplicabilidade prática da otimização pela movimentação dos apoios.

Como a estrutura, ilustrada em na figura (5), constitui-se em estrutura isostática, a resolução pôde ser efetuada de forma analítica, pelo equilíbrio de esforços, e portanto sem o emprego da formulação matricial, a qual considera a compatibilidade dos deslocamentos nodais. 


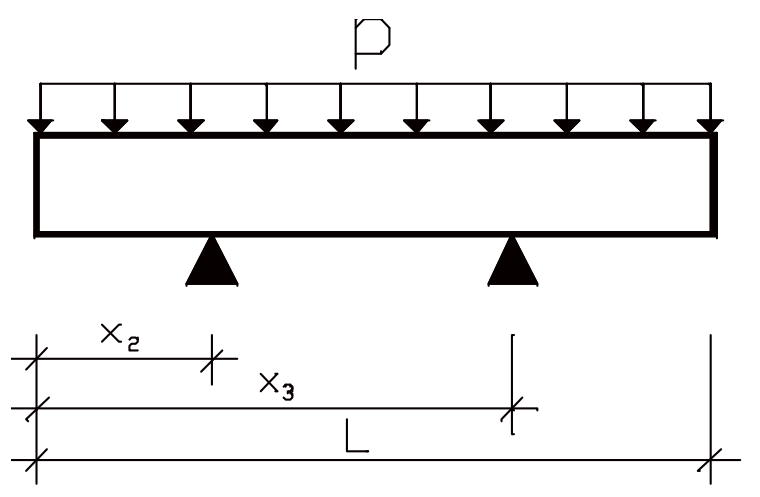

FIGURA (5) - Viga isostática: croquís e convenções adotadas

Pelo fato da viga em análise apresentar características de simetria em relação ao carregamento, e dada a possibilidade de livre posicionamento dos nós internos, espera-se uma estrutura final ou ótima também simétrica. Aplicando a formulação inicialmente proposta, especificamente à estrutura em análise, propõe-se então:

$$
\begin{gathered}
\min \quad \mathbf{M}_{2}^{(-)}+\mathbf{M}_{\mathbf{3}}^{(-)} \\
\text {s.a. } \quad \mathbf{h}_{\mathbf{1}}: \mathbf{M}_{2}^{(+)}+\mathbf{M}_{2}^{(-)}=\mathbf{0} \\
\mathbf{h}_{\mathbf{2}}: \mathbf{M}_{2}^{(+)}+\mathbf{M}_{\mathbf{3}}^{(-)}=\mathbf{0} \\
\mathbf{g}_{\mathbf{1}}: \mathbf{M}_{2}^{(-)} \leq \mathbf{0} \\
\mathbf{M}_{\mathbf{3}}^{(-)} \leq \mathbf{0}
\end{gathered}
$$


Observa-se que a aplicação desta formulação à viga biapoiada tem como intuito tornar cada um dos momentos fletores negativos igual ao momento fletor positivo, e portanto garante também a igualdade entre os momentos negativos. Pela igualdade em módulo, e considerando-se que para a estrutura em questão os momentos fletores nos apoios só podem ser não-positivos, a restrição de desigualdade (38), representada no problema pelas restrições (42) e (43), é automaticamente atendida em cada apoio.

Ao se explicitar os esforços como função das variáveis $\mathbf{x}_{\mathbf{2}}$ e $\mathbf{x}_{\mathbf{3}}$, os valores destas foram obtidos pela aplicação das equações de equilíbrio de esforços seguida do equacionamento segundo as condições de Kuhn-Tucker conforme a equação (6), tendo-se então que, tomando como dados adicionais $\mathrm{p}=1,0 \mathrm{kN} / \mathrm{m}$ e $\mathrm{L}$ total $=10,0 \mathrm{~m}$ :

$$
\begin{aligned}
& \nabla \mathbf{f}=\left(\frac{\partial \mathbf{f}}{\partial \mathbf{x}_{2}}, \frac{\partial \mathbf{f}}{\partial \mathbf{x}_{3}}\right)=(2,071,2,929) \\
& \lambda_{1} \nabla \mathbf{h}_{1}=1,146\left(\frac{\partial \mathbf{h}_{1}}{\partial \mathbf{x}_{2}}, \frac{\partial \mathbf{h}_{1}}{\partial \mathbf{x}_{3}}\right)=(-5,239,2,866) \\
& \lambda_{2} \nabla \mathbf{h}_{2}=-1,268\left(\frac{\partial \mathbf{h}_{2}}{\partial \mathbf{x}_{2}}, \frac{\partial \mathbf{h}_{2}}{\partial \mathbf{x}_{3}}\right)=(3,168,-5,795)
\end{aligned}
$$

como ilustrado na figura (6) para o ponto de ótimo $\mathbf{X}^{*}=\left(\mathbf{x}_{2}, \mathbf{x}_{3}\right)=(2,071,7,929)$.

Tem-se portanto, as restrições de igualdade plenamente atendidas (ativas no ponto de ótimo), bem como a simetria final, visto que

$$
\mathrm{L}_{\text {tot }}-\mathrm{x}_{3}=10,0-7,929=2,071 \mathrm{~m}=\mathbf{x}_{\mathbf{2}}
$$




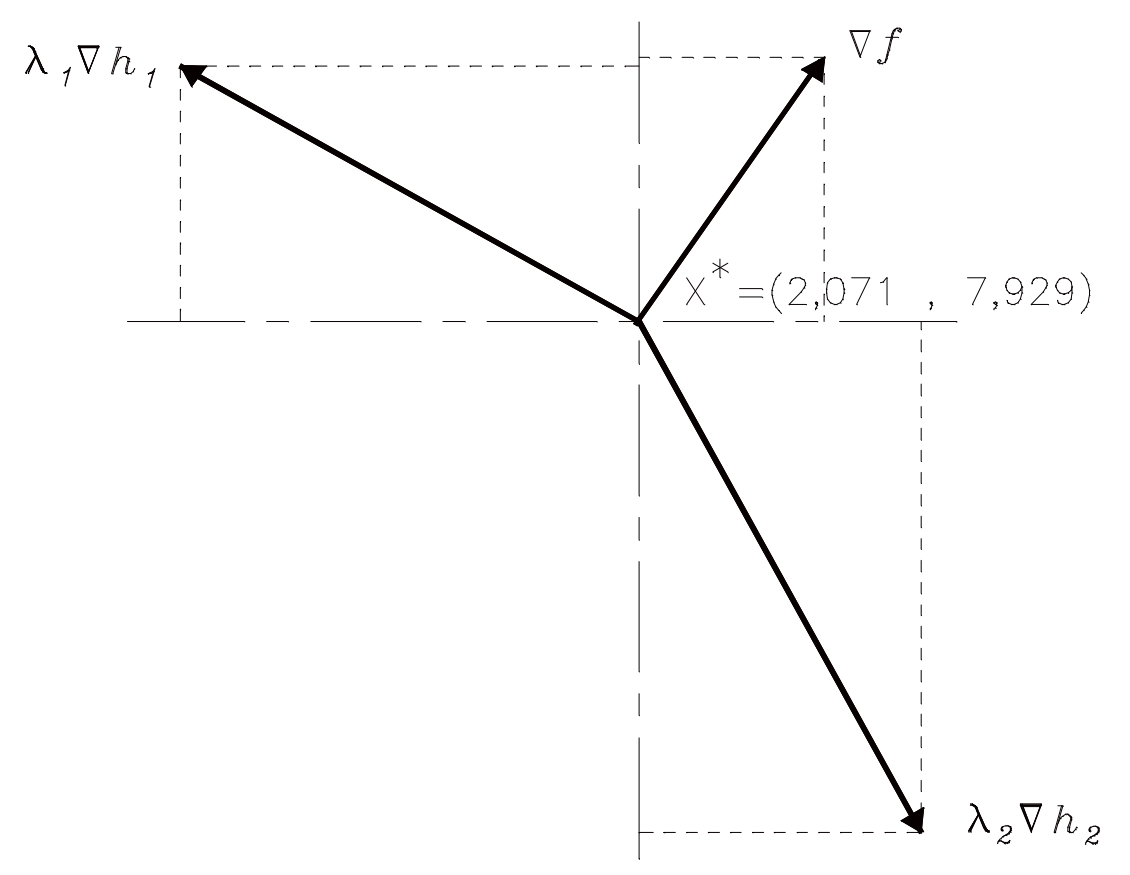

FIGURA (6) - Viga biapoiada: gradientes no ponto de ótimo

Como indicado na sequência, comparando-se os esforços obtidos na situação ótima com os apoios dispostos nas extremidades da viga, é verificada uma redução, em módulo, superior a 80 por cento no máximo momento fletor. No entanto, pela observação de uma série de estudos nos mais diversos campos da Engenharia Estrutural, verifica-se que nem sempre a uma diferença nos esforços corresponde uma economia nos custos da estrutura. Isto se deve, entre outros fatores, a determinados limites impostos no projeto, tais como dimensões mínimas ou deformações máximas. Desta forma, a estrutura anterior, bem como as mais significativas apresentadas neste trabalho, não ficaram restritas à determinação dos esforços para cada situação, sendo efetuado ainda o detalhamento para posterior comparação do gasto com material. Para esta análise quantitativa foi adotado o material concreto armado, ainda que o mesmo não integre a formulação do problema. O dimensionamento e detalhamento completos das estruturas analisadas foram efetuados com o auxílio de um mesmo software, tomando-se por base a Norma Brasileira NBR-6118 (1978). 
Em sequência à análise anterior, apresenta-se a mesma estrutura adotando-se agora dados mais realistas, quais sejam, vão total L igual a 6 metros e carregamento uniformemente distribuído p de $11,2 \mathrm{kN} / \mathrm{m}$, já incluído o peso próprio. Utilizou-se concreto C 20 e aços CA-50A e CA-60. De modo a facilitar o tratamento dos resultados, uma nova convenção é adotada para este exemplo em particular, conforme a figura (7).

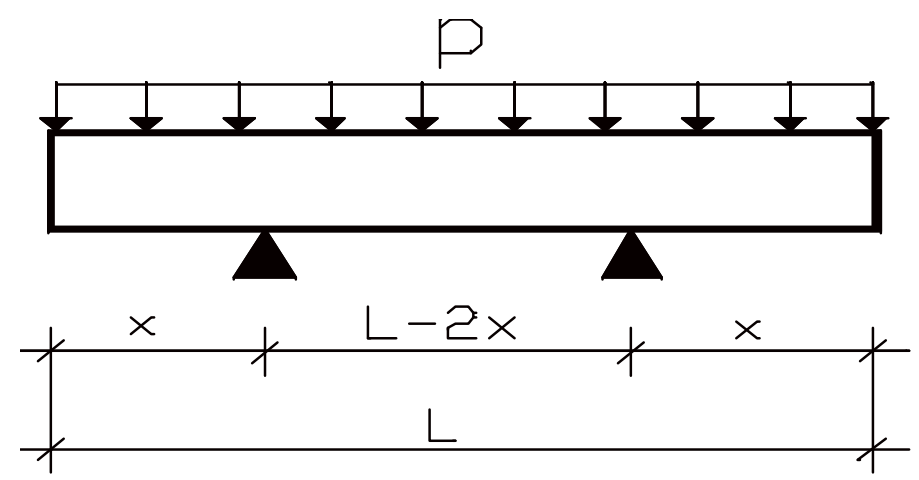

FIGURA (7) - Exemplo: croquis e convenções adotadas

Os resultados obtidos para as diferentes análises, considerando-se a área da seção transversal fixa $(12 \times 40 \mathrm{~cm})$ estão ilustrados na tabela (1). Nesta tabela designa-se por: $\mathrm{M}_{\max } \mathrm{o}$ maior momento na estrutura, independente da face tracionada; $\mathrm{A}_{\mathrm{Sl}}$ a armadura longitudinal calculada em função deste momento; Vc o volume total de concreto e $\mathrm{Ps}_{\text {tot }} \mathrm{o}$ peso total de aço, sendo estes dois últimos relativos à estrutura como um todo. $\mathrm{O}$ caso A consiste na análise com os apoios situados nas extremidades, conforme a segunda coluna da tabela. Já o caso B indica a situação ideal determinada a partir da formulação proposta. O caso $\mathrm{C}$ representa um deslocamento de 10 centímetros na posição de cada apoio, a partir do ótimo, no sentido dos extremos da estrutura. Efetuando uma comparação entre os pontos de ótimo deste teste com os do teste anterior, verifica-se que o posicionamento relativo dos apoios (x/L) independe da magnitude do carregamento, para a formulação em questão. Especificamente para este exemplo, observa-se a grande economia obtida no consumo de aço, sendo que para as dimensões indicadas os casos A e B representam 
praticamente situações limites quanto ao dimensionamento, as quais seriam, respectivamente, necessidade do uso de armadura dupla e uso de armadura mínima.

TABELA (1) - Exemplo: consideração de uma única seção transversal

\begin{tabular}{|c|c|c|c|c|c|c|c|c|}
\hline caso & $\mathrm{x} / \mathrm{L}$ & $\begin{array}{c}\mathrm{M}_{\max } \\
(\mathrm{kN} . \mathrm{m})\end{array}$ & $\mathrm{h}(\mathrm{cm})$ & $\begin{array}{c}\mathrm{As}_{\min } \\
\left(\mathrm{cm}^{2}\right)\end{array}$ & $\begin{array}{c}\mathrm{Asl} \\
\left(\mathrm{cm}^{2}\right)\end{array}$ & $\begin{array}{c}\mathrm{Asl} / \\
\mathrm{Asl}_{(\mathrm{A})}\end{array}$ & $\begin{array}{c}\mathrm{Vc} / \\
\mathrm{Vc}_{(\mathrm{A})}\end{array}$ & $\begin{array}{c}\mathrm{Ps}_{\text {tot }} \\
\mathrm{Ps}_{\text {tot }}(\mathrm{A})\end{array}$ \\
\hline $\mathrm{A}$ & 0 & 50,40 & 40 & 0,72 & 5,69 & 1,000 & 1,00 & 1,00 \\
\hline $\mathrm{B}$ & 0,2071 & 8,65 & 40 & 0,72 & 0,78 & 0,137 & 1,00 & 0,38 \\
\hline $\mathrm{C}$ & 0,1904 & 12,01 & 40 & 0,72 & 1,09 & 0,192 & 1,00 & 0,49 \\
\hline
\end{tabular}

Tanto pelo caso $\mathrm{C}$ da tabela como pelo gráfico (1) verifica-se que, mesmo para pequenos deslocamentos na posição dos apoios, são obtidas variações significativas nos valores dos esforços. Observa-se que o deslocamento de apenas 10 centímetros na posição de cada apoio, no sentido dos extremos da estrutura, representado pelo caso $\mathrm{C}$, gera um acréscimo de aproximadamente 40 por cento no momento máximo (e em consequência, de 29 por cento no consumo de aço). Esta grande variação para pequenos deslocamentos dos apoios (mantida a simetria da estrutura) é representada adimensionalmente no gráfico (1). O ponto de ótimo, no caso, é obtido pela interseção das curvas. 


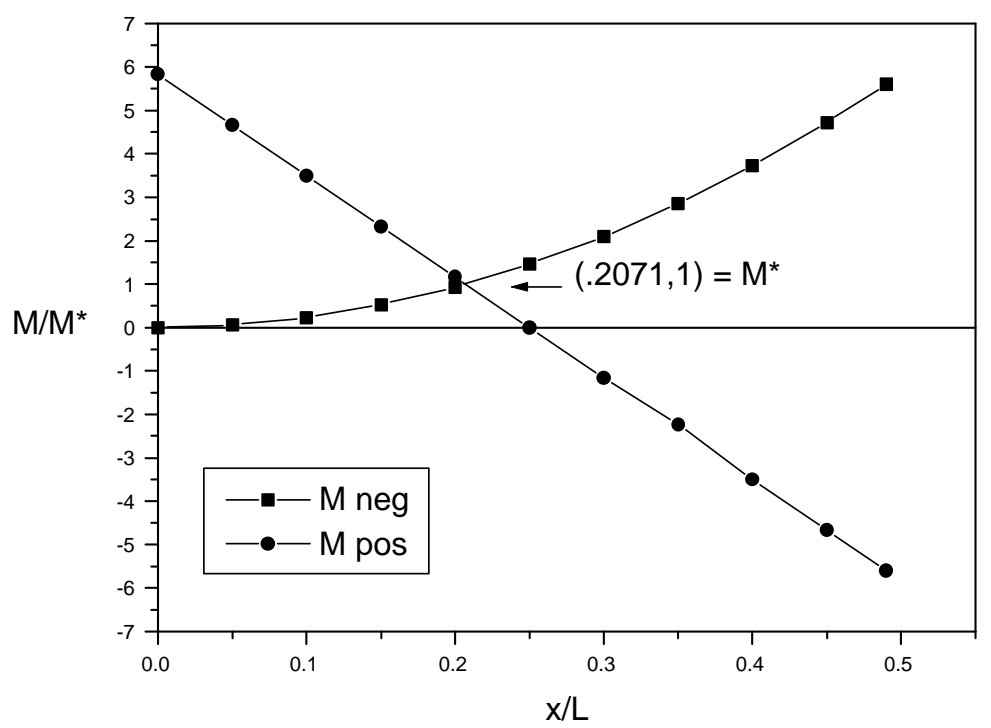

GRÁFICO (1) - Relação posição dos apoios - momento extremo (adimensional)

Ainda que não se enquadre no objetivo do presente trabalho a alteração nas dimensões da seção transversal dos elementos, a título ilustrativo a tabela (2) repete nos casos D e E, respectivamente, as situações indicadas na tabela anterior, porém com a alteração na altura da viga (sempre considerando-se a altura mínima relativa a peças normalmente armadas). Novamente pode ser verificada a economia obtida, observando-se que além da redução ainda significativa no volume de concreto é mantida uma boa economia no consumo de aço. Por simplicidade, os valores listados foram obtidos sem a respectiva alteração no peso próprio da estrutura.

TABELA (2) - Exemplo: variação na seção transversal

\begin{tabular}{|c|c|c|c|c|c|c|c|c|}
\hline caso & $\mathrm{x} / \mathrm{L}$ & $\begin{array}{c}\mathrm{M}_{\max } \\
(\mathrm{kN} . \mathrm{m})\end{array}$ & $\mathrm{h}(\mathrm{cm})$ & $\begin{array}{c}\mathrm{As}_{\min } \\
\left(\mathrm{cm}^{2}\right)\end{array}$ & $\begin{array}{c}\mathrm{Asl} \\
\left(\mathrm{cm}^{2}\right)\end{array}$ & $\begin{array}{c}\mathrm{Asl} / \\
\mathrm{Asl}(\mathrm{A})\end{array}$ & $\begin{array}{c}\mathrm{Vc} / \\
\mathrm{Vc}_{(}(\mathrm{A})\end{array}$ & $\begin{array}{c}\mathrm{Ps}_{\text {tot }} / \\
\mathrm{Ps}_{\text {tot }}(\mathrm{A})\end{array}$ \\
\hline $\mathrm{A}$ & 0 & 50,40 & 40 & 0,72 & 5,69 & 1,000 & 1,00 & 1,00 \\
\hline $\mathrm{D}$ & 0,2071 & 8,65 & 18 & 0,32 & 2,46 & 0,432 & 0,45 & 0,73 \\
\hline $\mathrm{E}$ & 0,1904 & 12,01 & 21 & 0,38 & 2,80 & 0,492 & 0.53 & 0,62 \\
\hline
\end{tabular}


Como verificado na tabela (1), pela comparação entre o consumo de aço para os apoios situados nos pontos ótimos relativamente à situação dos apoios nos extremos da viga, uma economia considerável pode ser obtida. Verificou-se ainda que, mesmo diante da impossibilidade da locação dos apoios nas posições indicadas, um pequeno deslocamento no sentido da posição ótima também apresenta relativa eficiência. A tabela (2), apesar de igualmente apresentar redução no consumo de materiais, incluindo o volume de concreto, passa a desempenhar papel meramente ilustrativo visto que, como já mencionado, o objetivo do presente trabalho constituise na busca de indicativos para a redução de custos, porém pela manutenção das seções transversais previamente adotadas pelo calculista.

\subsection{Implementação computacional}

\subsubsection{Considerações gerais}

A partir dos resultados promissores obtidos analiticamente para uma viga isostática, estruturas de complexidade crescente necessitam ser igualmente analisadas para que se possa validar a formulação inicialmente proposta, bem como as observações até o momento efetuadas. Foi a partir daí iniciada a implementação computacional, seguida de alterações tanto nos métodos como na própria formulação do problema, explicitadas na sequência do trabalho. O código computacional foi desenvolvido na linguagem FORTRAN, tendo como base um programa para análise estrutural pelo Método dos Deslocamentos implementado segundo trabalho de SORIANO (1983) e complementado posteriormente pelo de SOUZA \& ANTUNES (1995). Cabe mencionar que, especificamente em relação a otimização, a escolha dos métodos teve como intuito viabilizar a otimização geométrica de vigas, não havendo portanto, nesta etapa do trabalho, preocupação maior com a eficiência dos procedimentos adotados em comparação com outros procedimentos eventualmente também eficazes. Ao tempo de processamento, igualmente, foi dada importância secundária, devido às limitações mesmo dos casos práticos a um número relativamente pequeno de variáveis. Visto que todos os métodos adotados ao longo 
do trabalho foram descritos no Capítulo 2, apresenta-se na sequência basicamente algumas características particulares e critérios adicionais relacionados à implementação computacional do problema de otimização formulado.

\subsubsection{Descrição do programa}

No que diz respeito especificamente a otimização, o programa foi inicialmente desenvolvido pela associação do Método de Newton Modificado para o cálculo da direção de descida com o Método do Ajuste Cúbico para a determinação do tamanho do passo. Buscou-se portanto métodos bastante rigorosos do ponto de vista matemático, ou seja, um método de segunda ordem e um método exato, respectivamente. Os diversos exemplos analisados acabaram por demonstrar que a modificação implementada no Método de Newton não foi necessária, uma vez que a função a minimizar apresentou-se como definida positiva a cada iteração, podendo-se trabalhar com a verdadeira matriz Hessiana.

A técnica de minimização sequencial de problemas sem restrição foi adotada com a forma de penalização descrita na equação (30). Dentre as poucas sugestões encontradas na literatura para o coeficiente de penalização $\mathbf{r}$ e para $\mathbf{o}$ fator de penalização $\gamma$ optou-se, após uma série de testes, respectivamente pelos valores 1,0 e 3,0, sendo estes os indicados por VANDERPLAATS (1984a).

Devido à adoção do Método dos Deslocamentos para a análise de estruturas, os valores dos esforços são obtidos, uma vez determinados os deslocamentos nodais da estrutura a partir da resolução do sistema de equações (32), segundo a expressão (33). Substituindo-se a matriz de rigidez $\mathbf{r}$ do elemento de viga e o vetor de ações de engastamento perfeito $\mathbf{P}_{\mathbf{0}}$ para carregamento uniformemente distribuído: 


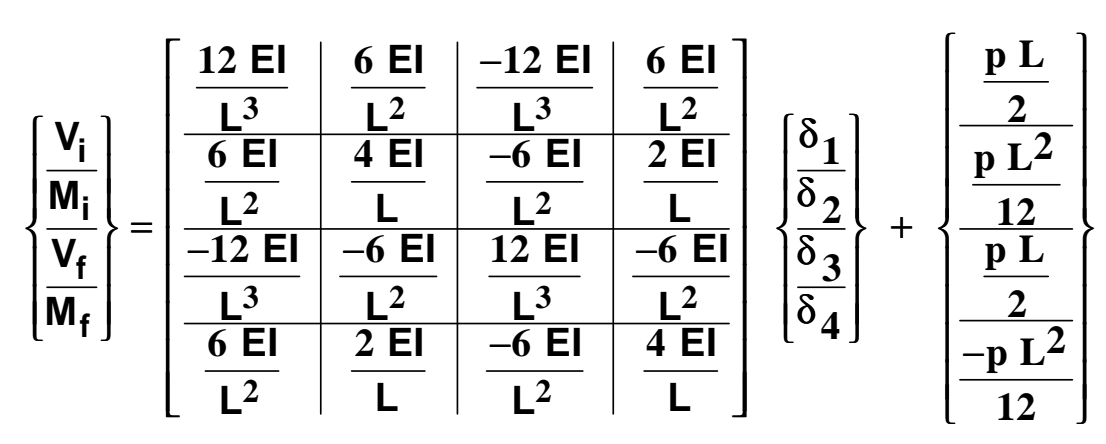

A obtenção dos valores de $\mathbf{M}_{\mathbf{i}}^{(-)}$pode ser efetuada da seguinte forma (convencionado como positivo o sentido anti-horário), para i variando de 2 a NNO-1:

$$
M_{i}^{(-)}=M_{i}=\frac{4 E I}{L_{i}} \delta_{2}-\frac{6 E I}{L_{i}^{2}} \delta_{3}+\frac{2 E I}{L_{i}} \delta_{4}+\frac{p L_{i}^{2}}{12}
$$

ou, simplificando-se:

$$
M_{i}^{(-)}=M_{i}=\frac{2 E I}{L_{i}}\left(2 \delta_{2}+\delta_{4}\right)-\frac{6 E I}{L_{i}^{2}} \delta_{3}+\frac{p L_{i}^{2}}{12}
$$

Nas expressões anteriores, $\mathbf{E}$ corresponde ao módulo de elasticidade longitudinal, $\mathbf{I}$ ao momento de inércia à flexão e $\delta$ aos deslocamentos, sendo $\delta_{2}$ e $\boldsymbol{\delta}_{4}$ as rotações respectivamente nós extremos inicial e final de cada elemento e $\boldsymbol{\delta}_{3}$ a translação vertical do nó final. $\mathbf{L}_{\mathbf{i}}$ como já definido pela equação (34), representa o comprimento do elemento i, calculado em função das variáveis de projeto.

Para a determinação dos esforços em todos os nós internos ou seja, exceto quando i = NNO-1, o segundo termo a direita na expressão (46) pode ser desprezado, visto que os apoios são supostos fixos. Conhecido o carregamento aplicado, os esforços ao longo de cada elemento são prontamente determinados a partir da obtenção dos momentos fletores $\mathbf{M}$ e dos esforços de cisalhamento $\mathbf{V}$. 
As derivadas parciais para a composição das matrizes Jacobiana e Hessiana foram obtidas de forma analítica. Ao se formular o problema de otimização em função da posição de alguns nós na estrutura, os esforços solicitantes nos elementos passam a ser influenciados de forma determinante por qualquer variação na posição destes nós, pela alteração no comprimento dos elementos. Desta forma, tanto as matrizes de rigidez como os vetores que contêm as ações de engastamento perfeito, ao envolverem explicitamente as distâncias relativas entre seus nós extremos, permitem a obtenção direta das derivadas dos coeficientes em relação a cada um dos nós. Já para a obtenção das derivadas dos deslocamentos necessita-se de um processo um pouco mais trabalhoso do ponto de vista computacional, por serem estes deslocamentos funções implícitas das posições dos nós. De modo a contornar esta dificuldade, determina-se inicialmente as derivadas do produto do sistema (32). Temse então

$$
\frac{\partial \mathbf{R}}{\partial \mathbf{x}_{\mathbf{i}}} \mathbf{U}+\mathbf{R} \frac{\partial \mathbf{U}}{\partial \mathbf{x}_{\mathbf{i}}}=\frac{\partial \mathbf{F}}{\partial \mathbf{x}_{\mathbf{i}}}
$$

de onde

$$
\mathbf{R} \frac{\partial \mathbf{U}}{\partial \mathbf{x}_{\mathbf{i}}}=\frac{\partial \mathbf{F}}{\partial \mathbf{x}_{\mathbf{i}}}-\frac{\partial \mathbf{R}}{\partial \mathbf{x}_{\mathbf{i}}} \mathbf{U}
$$

ou ainda

$$
\frac{\partial \mathbf{U}}{\partial \mathbf{x}_{\mathbf{i}}}=\mathbf{R}^{-1}\left(\frac{\partial \mathbf{F}}{\partial \mathbf{x}_{\mathbf{i}}}-\frac{\partial \mathbf{R}}{\partial \mathbf{x}_{\mathbf{i}}} \mathbf{U}\right)
$$


Analogamente, derivando-se a expressão (47), tem-se:

$$
\frac{\partial^{2} \mathbf{U}}{\partial \mathbf{x}_{\mathbf{i}} \partial \mathbf{x}_{\mathbf{j}}}=\mathbf{R}^{-1}\left(\frac{\partial \mathbf{F}}{\partial \mathbf{x}_{\mathbf{i}}} \frac{\partial \mathbf{F}}{\partial \mathbf{x}_{\mathbf{j}}}-\frac{\partial \mathbf{R}}{\partial \mathbf{x}_{\mathbf{i}}} \frac{\partial \mathbf{R}}{\partial \mathbf{x}_{\mathbf{j}}} \mathbf{U}-\frac{\partial \mathbf{R}}{\partial \mathbf{x}_{\mathbf{i}}} \frac{\partial \mathbf{U}}{\partial \mathbf{x}_{\mathbf{j}}}-\frac{\partial \mathbf{R}}{\partial \mathbf{x}_{\mathbf{j}}} \frac{\partial \mathbf{U}}{\partial \mathbf{x}_{\mathbf{i}}}\right)
$$

ou simplificadamente para $\mathrm{i}=\mathrm{j}$,

$$
\frac{\partial^{2} \mathbf{U}}{\partial \mathbf{x}_{\mathbf{i}}^{2}}=\mathbf{R}^{-1}\left(\frac{\partial^{2} \mathbf{F}}{\partial \mathbf{x}_{\mathbf{i}}^{2}}-\frac{\partial^{2} \mathbf{R}}{\partial \mathbf{x}_{\mathbf{i}}^{2}} \mathbf{U}-2 \frac{\partial \mathbf{R}}{\partial \mathbf{x}_{\mathbf{i}}} \frac{\partial \mathbf{U}}{\partial \mathbf{x}_{\mathbf{i}}}\right)
$$

Como critério de parada foi definida uma tolerância $\varepsilon$ igual a $1 \times 10^{-5}$ para as diferenças entre os valores das variáveis de projeto entre duas iterações consecutivas. Ao ser obtida a convergência, o fator de penalização é aumentado (multiplicado pelo coeficiente de penalização) e inicia-se nova busca pela convergência encerrando-se o processamento quando, além do atendimento ao critério descrito, as diferenças entre dois ciclos consecutivos também atinja a tolerância (significando que o valor da função de penalização passa a ser desprezível em relação ao valor da função objetivo). Como critério adicional, foi fixado aleatoriamente em 40 o número máximo de iterações a cada ciclo. Já o valor de $\varepsilon$ representa uma variação máxima de 0,01 milímetros na posição de cada apoio, considerando-se como usual a introdução na entrada de dados do programa da medida de comprimento em metros.

\subsubsection{Exemplos testados}

Além dos exemplos anteriores terem sido testados no programa, outras estruturas foram analisadas. Os resultados obtidos a partir dos testes para diversas estruturas e situações foram utilizados não apenas para a verificação da eficiência da formulação, como também para a própria aferição de parâmetros e testes do próprio programa. Em decorrência, o processo de busca unidimensional exata (Ajuste Cúbico) foi substituído por um processo de busca imprecisa (Regra de Armijo), por ter este último demonstrado maior rapidez de convergência sem alteração nos 
resultados. Para os diversos exemplos as estruturas foram analisadas a partir de uma série de valores iniciais para as variáveis de projeto, obtendo-se sempre os mesmos valores finais e portanto garantindo na prática a existência de um ponto de mínimo global, o que permitiu supor que a função seja estritamente convexa.

Com o objetivo de verificar a variação na economia de armadura a medida em que o número de apoios aumenta analisou-se inicialmente, por meio do programa desenvolvido, uma viga com três apoios, sendo a partir dos resultados efetuado o dimensionamento e detalhamento da estrutura. As características da estrutura, bem como os materiais empregados foram, respectivamente:

- comprimento total da viga igual a 10 metros;

- carregamento uniformemente distribuído de $22 \mathrm{kN} / \mathrm{m}$;

- dimensões dos vãos (seção transversal): 20 cm x $40 \mathrm{~cm}$;

- concreto C 20;

- aços CA-50A e CA-60.

Para a viga descrita foram analisadas quatro situações distintas, mantida a simetria. Na tabela (3) designa-se respectivamente como caso A o posicionamento dos apoios nas extremidades, constituindo dois vãos de 5 metros cada um, e como caso B o deslocamento destes apoios para os pontos de ótimo, segundo a formulação, verificando-se uma economia de 25 por cento no consumo de aço. Em razão da simetria, apenas a posição relativa de um dos apoios, no caso o segundo, é apresentada, indicando-se ainda na segunda coluna, em módulo, o valor da função.

TABELA (3) - Viga com três apoios: resultados obtidos

\begin{tabular}{|c|c|c|c|}
\hline caso & $\mathrm{x}_{2} / \mathrm{L}$ & $\mathrm{f}(\mathrm{kN} . \mathrm{m})$ & $\mathrm{Ps}_{\text {tot }} / \mathrm{Ps}_{\text {tot }}(\mathrm{A})$ \\
\hline $\mathrm{A}$ & 0,000 & 62,50 & 1,00 \\
\hline $\mathrm{B}$ & 0,121 & 57,87 & 0,75 \\
\hline $\mathrm{C}$ & 0,131 & 59,78 & 0,81 \\
\hline $\mathrm{D}$ & 0,111 & 56,31 & 0,66 \\
\hline
\end{tabular}


Efetuando-se um deslocamento de apenas um por cento (equivalente a 10 centímetros) dos apoios em relação ao ponto de ótimo, observa-se o deslocamento destes no sentido do centro da viga (caso C), apesar de um pequeno aumento no valor da função objetivo f (somatório dos momentos negativos), corresponder a um aumento no consumo de aço na ordem de 8 por cento, porém ainda significativo relativamente ao caso A. No entanto ao se efetuar deslocamento de igual valor porém no sentido das extremidades da estrutura (caso D) verifica-se a redução no valor da função objetivo com redução também no consumo de aço, desta vez da ordem de 12 por cento relativamente ao ótimo. Este fato indica claramente que, ainda que a formulação inicial atinja o objetivo proposto, uma economia maior poderia ser obtida, provavelmente ao custo do relaxamento das restrições de igualdade de momentos negativos, já que como sugere o gráfico (2), o atendimento a estas restrições de igualdade, representadas por h1, constitui-se em fator determinante no processo.

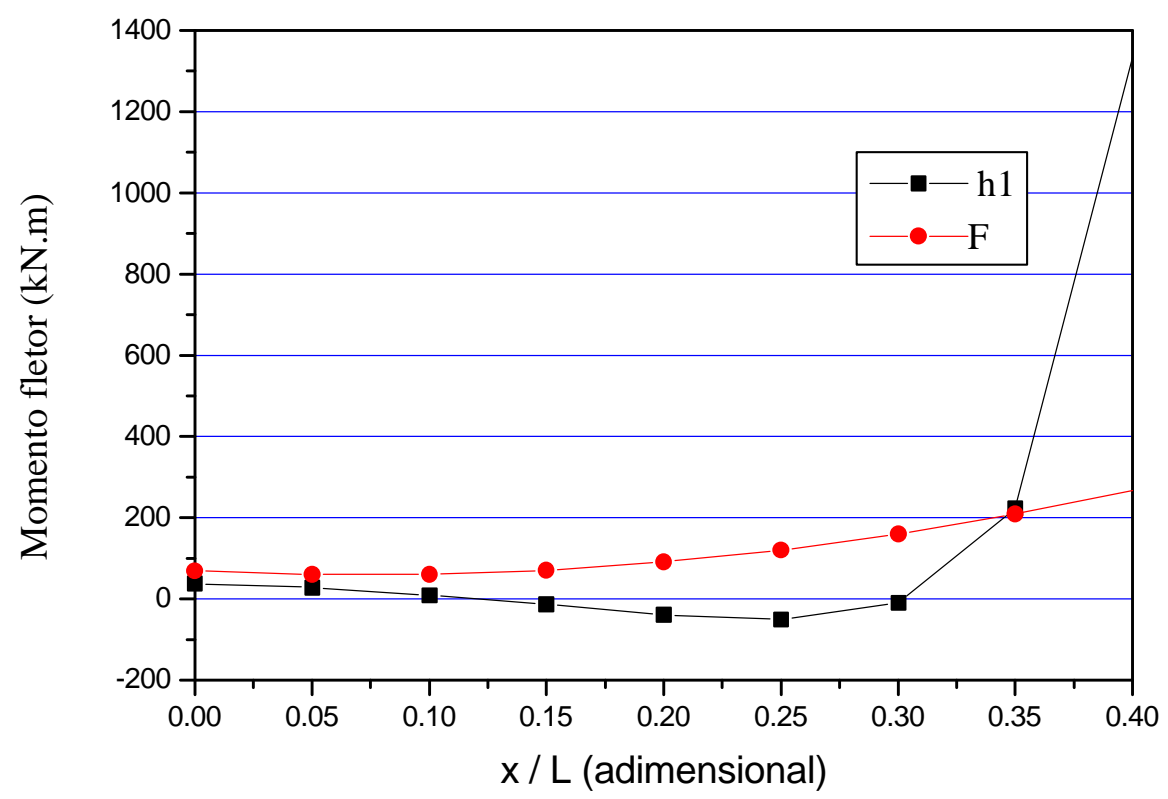

GRÁFICO (2) - Diagrama momento fletor - posição dos apoios extremos 
A análise seguinte refere-se a uma viga com quatro apoios. Como dados do problema, tem-se:

- comprimento total da viga igual a 12 metros;

- dimensões das vigas (seção transversal): $12 \mathrm{~cm} \mathrm{x} 40 \mathrm{~cm}$;

- carregamento uniformemente distribuído de $15 \mathrm{kN} / \mathrm{m}$;

- concreto C 20;

- aços CA-50A e CA-60.

TABELA (4) - Viga com quatro apoios: resultados obtidos

\begin{tabular}{|c|c|c|c|c|}
\hline caso & $\mathrm{x}_{2} / \mathrm{L}$ & $\mathrm{x}_{3} / \mathrm{L}$ & $\mathrm{M}_{\max }(\mathrm{kN} . \mathrm{m})$ & $\mathrm{Ps}_{\text {tot }} / \mathrm{Ps}_{\text {tot }}(\mathrm{A})$ \\
\hline $\mathrm{A}$ & 0,000 & 0,3333 & 24,00 & 1,00 \\
\hline $\mathrm{B}$ & 0,0623 & 0,3084 & 22,78 & 0,93 \\
\hline
\end{tabular}

Em função da simetria, apenas dois dos quatro apoios são indicados na tabela (4). Os resultados apresentados referem-se, respectivamente, a disposição dos apoios de forma igualmente espaçada, constituindo uma estrutura formada portanto por três vãos (caso A), e a disposição ótima dos apoios, aqui novamente denominada por caso B. Verifica-se que, pela formulação proposta, o resultado obtido apresenta economia pouco significativa, novamente pela necessidade de atendimento às restrições de igualdade, determinantes na obtenção do ponto de ótimo. Com o atendimento a estas restrições, os momentos nos balanços ficam fortemente limitados. Desta forma, na medida em que é aumentado o número de apoios da viga, diminui a influência destes momentos na distribuição dos demais esforços, fazendo com que o mínimo da função seja composto pelo somatório de valores muito grandes com valores muito pequenos. Consequentemente, a economia verificada é inversamente proporcional ao número de tramos da viga, decrescendo rapidamente em função deste número.

Com base nas estruturas analisadas observa-se a pouca eficiência da formulação utilizada, com uma tendência assintótica à unidade para a relação entre o peso de aço para apoios nos pontos de ótimo e para apoios equidistantes. Esta última 
configuração é a utilizada para termos de comparação, uma vez que constitui-se na tendência natural para disposição dos apoios, caso não se disponha de indicativos que sugiram de alguma forma uma alteração nesta disposição.

Apesar dos resultados pouco significativos apresentados pela formulação até aqui empregada, ficam patentes as potencialidades da utilização de técnicas de otimização também na etapa de concepção, ou definição da topologia.

\subsection{Outras formulações idealizadas}

\subsubsection{Segunda formulação}

Com base nas limitações verificadas na formulação inicialmente proposta, objetiva-se a determinação de uma nova formulação para o problema visando sobretudo estender os bons resultados obtidos para vigas biapoiadas também para estruturas maiores, independente do número de apoios que possuam.

A segunda formulação idealizada buscou a uniformização nos valores dos momentos fletores negativos, colocando-se como objetivo a redução das diferenças entre o momento fletor em um nó interno e o momento fletor no nó interno seguinte.

Relativamente às restrições de igualdade impostas na formulação anterior, as mesmas foram transformadas em restrições de desigualdade, ou seja, momentos fletores negativos sobre os apoios extremos maiores ou iguais aos momentos positivos adjacentes. Desta forma é mantido um limite inferior para os momentos fletores negativos, flexibilizando-se porém esse valor. Observa-se que, caso nenhuma relação deste tipo fosse incluída na descrição do problema, a configuração ótima para a formulação inicial corresponderia, por exemplo, a de uma viga sem balanços para a estrutura biapoiada.

A presente formulação, ao contrário da anterior, não apenas permite, e sim condiciona a resolução do problema à utilização em estruturas em concreto armado. Pela introdução da respectiva restrição, procura-se evitar a sub-utilização da armadura positiva em todos os vãos internos da viga, uma vez conhecidas as dimensões da seção transversal de cada elemento. Define-se então o momento 
absorvido pela armadura mínima de flexão $\mathbf{M}_{\mathbf{i}, \mathbf{m i n}}^{(+)}$, impondo por consequência que a armadura positiva em cada vão deve ser maior ou igual a armadura mínima prescrita pela NBR-6118 (1978).

Descritas as hipóteses e condições impostas, tem-se então o problema formulado como:

$$
\begin{array}{ll}
\min & \sum_{\mathbf{i}=2}^{\mathrm{NNO}-2}\left[\mathbf{M}_{\mathbf{i}+1}^{(-)}-\mathbf{M}_{\mathbf{i}}^{(-)}\right]^{2} \\
\text { s.a. } & \mathbf{g}_{1}: \mathbf{M}_{2}^{(+)}+\mathbf{M}_{2}^{(-)} \leq 0 \\
& \mathbf{g}_{2}: \mathbf{M}_{\mathrm{NNO}-2}^{(+)}+\mathbf{M}_{\mathrm{NNO}-1}^{(-)} \leq 0 \\
& \mathbf{g}_{3}:-\mathbf{M}_{\mathbf{i}}^{(+)}+\mathbf{M}_{\mathrm{i}, \mathrm{min}}^{(+)} \leq \mathbf{0} \\
\mathbf{g}_{4}: \mathbf{M}_{\mathbf{k}}^{(-)} \leq 0 & \mathrm{k}=2, \mathrm{NNO}-1
\end{array}
$$

A expressão que define o momento $\mathbf{M}_{\mathbf{i}, \mathbf{m i n}}^{(+)}$foi derivada diretamente das tabelas de PINHEIRO (1986), as quais fornecem o valor do coeficiente $\mathbf{k}_{\mathbf{s}}$ do aço como

$$
\mathbf{k}_{\mathrm{s}}=\frac{\mathbf{A}_{\mathbf{s}} \mathbf{d}}{\mathbf{M}_{\mathbf{d}}}
$$


Fazendo

$$
\begin{aligned}
& \mathbf{k}_{\mathrm{s}}=\frac{A_{\mathrm{s} \min } \mathbf{d}}{M_{d}}\left(\mathrm{~m}^{2} / \mathrm{kN}\right), \\
& A_{\mathrm{s} \min }=\frac{0,15}{100} b_{w} h \quad\left(\mathrm{~cm}^{2}\right)=15 b_{w} h \quad\left(\mathrm{~m}^{2}\right),
\end{aligned}
$$

e considerando

$$
\mathbf{d}=\mathbf{h}-\mathbf{0 , 0 3}(\mathbf{m})
$$

chega-se a

$$
M_{i, \min }=\frac{15 b_{w} h(h-0,03)}{1,4 k_{s}} \cong 446 b_{w} h(h-0,03) \quad(k N . m)
$$

para $\mathbf{k}_{\mathbf{s}}=0,024$, considerados aço CA-50A e concreto $\mathrm{C}$ 20. Para estas características dos materiais o erro de aproximação cometido é favorável à segurança, sendo que para concretos de resistência maior observa-se pouca variação nos resultados.

Como resultado da implementação computacional da segunda formulação apresenta-se a tabela (5) contendo valores fornecidos pela análise da viga com três apoios também estudada no item (3.3.3). Esta viga possui vão total de 10 metros, e seção transversal 20 × 40 centímetros, estando submetida a um carregamento uniforme de $22 \mathrm{kN} / \mathrm{m}$. Novamente, designa-se por caso A a situação na qual os apoios são posicionados igualmente espaçados em 5 metros, e por caso B a disposição ótima dos apoios. Devido a simetria, apenas a posição do primeiro apoio é indicada na tabela.

De acordo com a expressão (57), o momento absorvido pela armadura mínima de flexão para esta seção é aproximadamente igual a 13,20 kN.m. 
TABELA (5) - Viga com três apoios: configurações inicial e ótima

\begin{tabular}{|c|c|c|c|c|c|c|c|}
\hline caso & $\mathrm{x}(\mathrm{m})$ & $\begin{array}{c}\mathrm{M}_{\max }^{(-)} \\
(\mathrm{kN} . \mathrm{m})\end{array}$ & $\begin{array}{c}\mathrm{M}_{\max }^{(+)} \\
(\mathrm{kN} . \mathrm{m})\end{array}$ & $\begin{array}{c}\mathrm{V}_{\max } \\
(\mathrm{kN})\end{array}$ & $\begin{array}{c}\mathrm{M}_{\max }^{(-)} / \\
\mathrm{M}_{\max }^{(-)}(\mathrm{A})\end{array}$ & $\begin{array}{c}\mathrm{M}_{\max }^{(+)} / \\
\mathrm{M}_{\max }^{(+)}(\mathrm{A})\end{array}$ & $\mathrm{V}_{\max } /$ \\
$\mathrm{V}_{\max }(\mathrm{A})$ \\
\hline $\mathrm{A}$ & 0 & 68,75 & 38,68 & 68,75 & 1,00 & 1,00 & 1,00 \\
\hline $\mathrm{B}$ & 1,36 & 20,33 & 26,28 & 41,68 & 0,30 & 0,68 & 0,61 \\
\hline
\end{tabular}

A necessidade da definição a priori das dimensões da seção transversal, e em consequência do momento resistente da seção, implica no fato de que a posição dos apoios para carregamentos abaixo de um determinado valor passe a ser função deste valor. Como abaixo deste ponto a cada magnitude do carregamento corresponde uma nova configuração, a inclusão da restrição $\mathbf{g}_{3}$ correspondente, de acordo com a equação (55), apresenta a característica altamente indesejável de não mais permitir a superposição dos efeitos.

A variação na posição dos apoios extremos é ilustrada no gráfico (3) para a mesma viga apresentada, porém variando-se o carregamento aplicado.

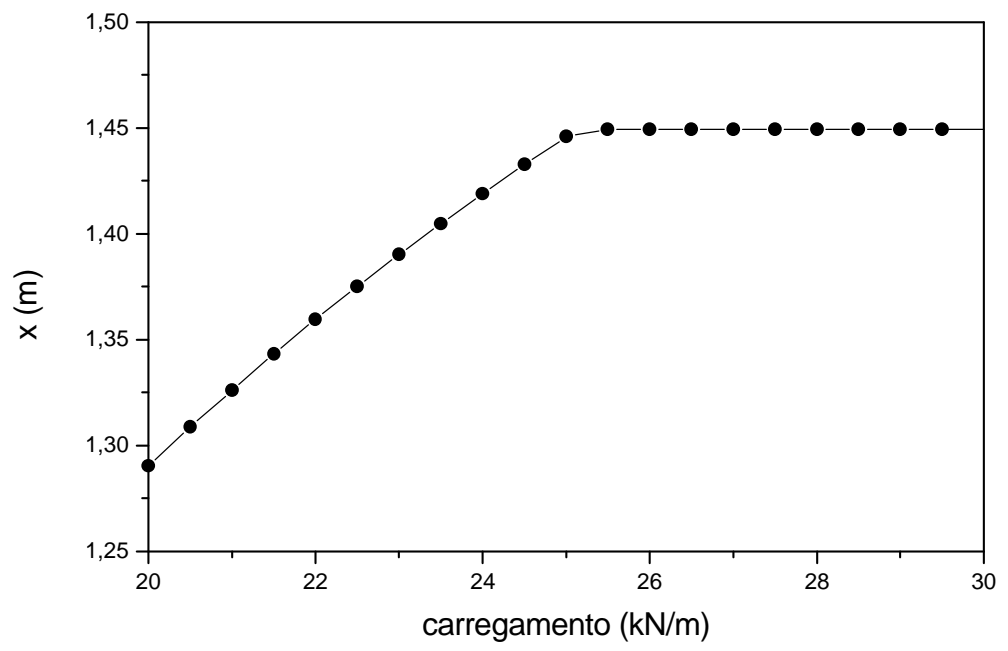

GRÁFICO (3) - Relação carregamento x posição dos apoios extremos 
Adicionalmente, observou-se que para carregamentos inferiores ao valor limitante, deixa de haver uniformidade nos momentos negativos. Como consequência, a função objetivo não poderia mais assumir valor nulo, como demonstra o gráfico (4) para a mesma estrutura.

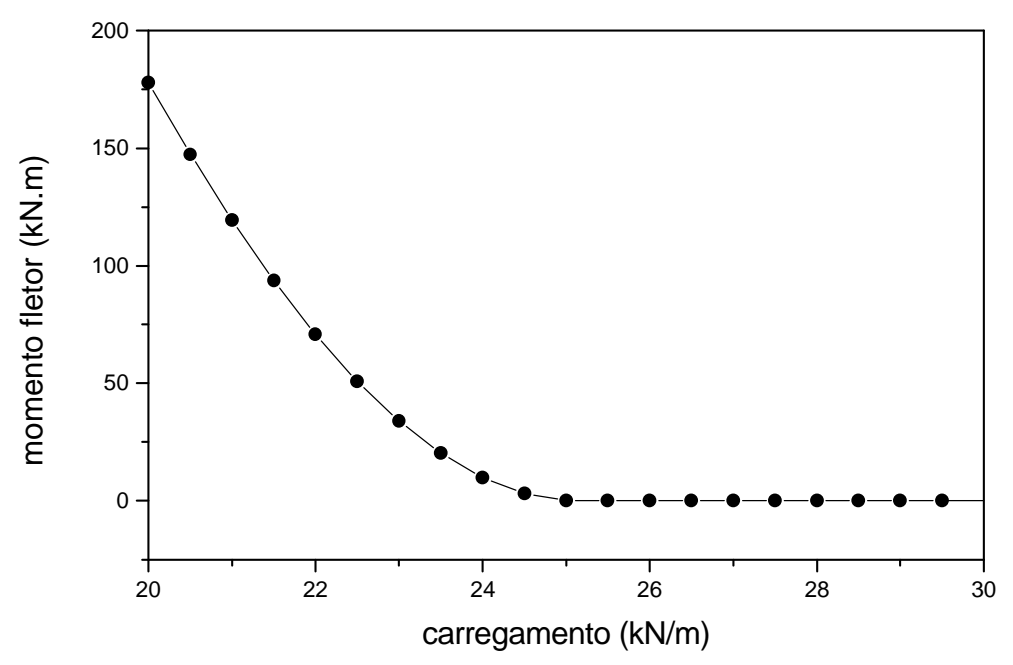

GRÁFICO (4) - Relação carregamento x valor da função

A construção dos dois gráficos anteriores foi efetuada tomando-se sempre uma disposição inicial simétrica para os apoios. De modo a verificar as características de convexidade da função foram feitas diversas análises para a mesma estrutura, adotando-se um carregamento para o qual a uniformização dos momentos negativos fosse possível. Partindo-se de diversos valores iniciais para os apoios, uma série de distintas configurações finais foi obtida. Todas elas porém poderiam ser consideradas ótimas, já que atendiam as restrições impostas ao problema. Desta forma constatou-se a existência de mínimos locais para a função. Assim, a forma de determinação da configuração ótima consistiria na análise da estrutura a partir de uma diversidade de conjuntos iniciais para as variáveis de projeto e adotando-se o que fornecesse os melhores resultados tanto em termos de distribuição dos esforços como em relação à disposição final dos apoios. Esta solução, porém, apresenta pouca praticidade, uma vez que o objetivo do trabalho consiste na otimização dos esforços 
a partir de uma única configuração inicial pré-definida pelo projetista, eliminando desta forma o procedimento iterativo necessário para facultar o estudo de diversas disposições para os apoios.

\subsubsection{Terceira formulação}

Destacado o grande inconveniente inerente à formulação anterior, qual seja a necessidade de uma série de análises para a definição da melhor configuração, uma nova formulação foi adotada, consistindo essencialmente na mesma apresentada no sub-ítem anterior, porém transformando-se a restrição de desigualdade $\mathbf{g}_{\mathbf{3}}$ (relativa ao momento mínimo) em restrição de igualdade. $\mathrm{O}$ intuito de eliminar os pontos de mínimo local obtendo-se apenas uma solução ótima foi efetivamente atingido, acarretando porém em uma dificuldade adicional. Desta vez o valor do carregamento a partir do qual haveria uma mesma posição para os apoios deixa de existir, pela imposição de que a armadura positiva de flexão seja sempre igual a mínima prescrita por Norma. Assim, a dependência em relação ao carregamento, que já era grande, torna-se fundamental. Ainda com a imposição de um valor determinado para os momentos positivos, as diferenças entre os valores dos momentos negativos, as quais já existiam, tornam-se agora bastante grandes. Os gráficos (5) e (6) ilustram para a mesma estrutura dos gráficos anteriores a relação entre a variação do carregamento e, respectivamente, dos valores da função e das posições dos apoios extremos. Para efeito de comparação, os gráficos relativos à segunda e terceira formulações aparecem superpostos. 


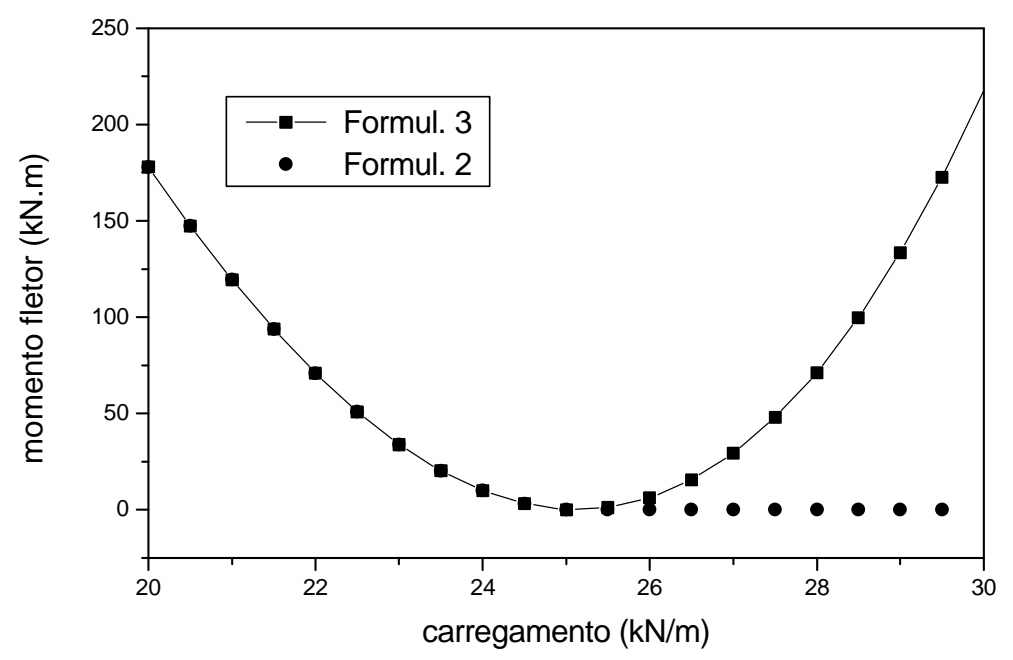

GRÁFICO (5) - Relação carregamento x valor da função

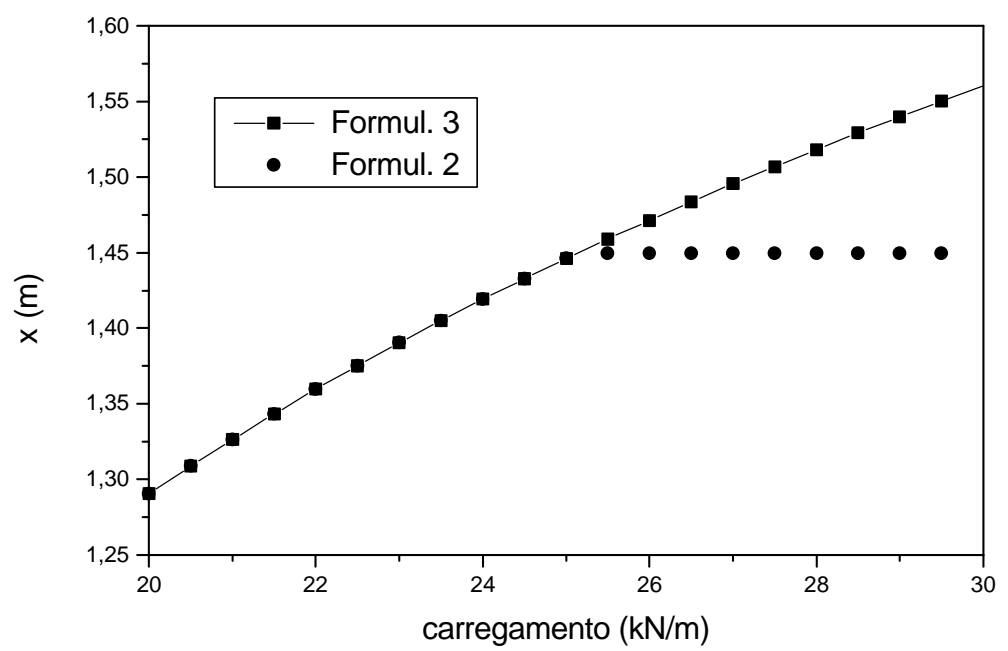

GRÁFICO (6) - Relação carregamento x posição dos apoios extremos

Tomando por base os inconvenientes de ordem prática apresentados pela segunda e terceira formulações, optou-se pela eliminação da restrição relativa à armadura mínima de flexão. Com esta medida torna-se o problema de busca do ótimo não apenas novamente independente do carregamento como, não menos 
importante, restitui a independência da resolução do problema em relação ao tipo de material estrutural.

Não são apresentados neste trabalho estudos mais aprofundados em relação à economia de material decorrente do detalhamento da estruturas, uma vez que o número de variações possível a cada viga em função do carregamento e da seção transversal seria demasiado.

\subsubsection{Quarta formulação}

Com base na observação do comportamento do modelo estrutural decorrente da implementação das formulações anteriores foi elaborada uma nova formulação para o problema. Nesta, visou-se o aproveitamento de características positivas apresentadas por cada função individualmente.

Para a definição de uma nova função objetivo buscou-se não apenas a redução do somatório dos momentos negativos, visto que o valor final da função pode ser resultante da associação de momentos muito grandes em determinados pontos da estrutura com momentos muito pequenos em outros, mas também a uniformização dos momentos fletores. As formulações anteriores consideravam apenas um desses objetivos.

Quanto às restrições, verificou-se que as que relacionam os momentos fletores negativos resultantes dos balanços com os momentos positivos imediatamente internos a estes devem ser mantidas, visto que realmente contribuem de maneira significativa para a redistribuição e consequente redução dos esforços ao longo da estrutura. As mesmas, porém, devem ser consideradas como restrições de desigualdade, de modo a não transformarem esta contribuição num fator demasiadamente limitante. 
Definidas as características desejadas, uma nova formulação do problema resulta em

$$
\begin{array}{ll}
\min & \sum_{\mathbf{i}=1}^{\mathrm{NNO}-1}\left[\mathbf{M}_{\mathbf{i}}^{(-)}\right]^{2}+\sum_{\mathbf{j}=2}^{\mathrm{NNO}-2}\left[\mathbf{M}_{\mathbf{j}+1}^{(-)}-\mathbf{M}_{\mathbf{j}}^{(-)}\right]^{2} \\
\text { s.a. } & \mathbf{g}_{\mathbf{1}}: \mathbf{M}_{2}^{(+)}+\mathbf{M}_{2}^{(-)} \leq \mathbf{0}
\end{array}
$$

$$
g_{2}: M_{\text {NNO-2 }}^{(+)}+M_{\text {NNO-1 }}^{(-)} \leq 0
$$

$$
\mathbf{g}_{\mathbf{3}}: \mathbf{M}_{\mathbf{k}}^{(-)} \leq \mathbf{0} \quad \mathrm{k}=2, \mathrm{NNO}-1
$$

No caso, pelo fato da função objetivo ser composta por duas funções distintas, não se deveria esperar que os pontos de mínimo destas duas funções fossem coincidentes. Desta forma, apesar de uma melhora nos resultados em relação às formulações anteriores (a exceção de viga biapoiada, para a qual obteve-se os mesmos esforços da primeira formulação), nenhum dos objetivos é plenamente atingido. Constatou-se que dependendo dos valores inicialmente adotados para as variáveis de projeto os valores finais, apesar de diferentes, estariam situados dentro do intervalo limitado pelo ótimo relativo a cada função obtido isoladamente.

Apresenta-se na tabela (6) resultados obtidos da análise de uma viga com três apoios, comprimento total igual a 10 metros e carregamento de $30 \mathrm{kN} / \mathrm{m}$. Das cinco disposições iniciais consideradas apenas esta gerou uma configuração final simétrica, sendo portanto a adotada (caso B da tabela). 
TABELA (6) - Viga com três apoios: configurações inicial e ótima

\begin{tabular}{|c|c|c|c|c|c|c|c|}
\hline caso & $\mathrm{x}(\mathrm{m})$ & $\begin{array}{c}\mathrm{M}_{\max }^{(-)} \\
(\mathrm{kN} . \mathrm{m})\end{array}$ & $\begin{array}{c}\mathrm{M}_{\max }^{(+)} \\
(\mathrm{kN} . \mathrm{m})\end{array}$ & $\begin{array}{c}\mathrm{V}_{\max } \\
(\mathrm{kN})\end{array}$ & $\begin{array}{c}\mathrm{M}_{\max }^{(-)} / \\
\mathrm{M}_{\max }^{(-)}(\mathrm{A})\end{array}$ & $\begin{array}{c}\mathrm{M}_{\max }^{(+)} / \\
\mathrm{M}_{\max }^{(+)}(\mathrm{A})\end{array}$ & $\mathrm{V}_{\max } /$ \\
$\mathrm{V}_{\max }(\mathrm{A})$ \\
\hline $\mathrm{A}$ & 0 & 93,75 & 52,73 & 93,75 & 1,00 & 1,00 & 1,00 \\
\hline $\mathrm{B}$ & 1,40 & 55,25 & 16,98 & 55,25 & 0,36 & 0,32 & 0,59 \\
\hline
\end{tabular}

Diversas análises foram efetuadas também para maior número de apoios. Como regra geral, o valor ótimo para a função apresentou pouca variação, não refletindo porém a variação no posicionamento final de cada apoio, esta bem mais significativa.

Com o intuito de verificar a origem das diferenças obtidas as mesmas estruturas foram analisadas com a consideração de apenas uma das parcelas da função objetivo. Observou-se que para a parcela relativa a diferença entre os valores dos esforços foram obtidos diversos mínimos locais, enquanto a parcela da função relativa ao somatório do quadrado dos momentos aparentou ser estritamente convexa. Concluiu-se que os resultados fornecidos por essa quarta formulação idealizada, apesar de não coincidentes em vista das observações mencionadas, apontaram uma situação bastante promissora, sugerindo que pequenas alterações poderiam conduzir a uma formulação definitiva.

\subsection{Formulação adotada}

\subsubsection{Descrição da formulação}

A idéia básica desta formulação consistiu em amenizar inconvenientes encontrados em formulações que visavam apenas a redução dos momentos negativos ou a uniformização destes momentos. Os estudos relacionados à formulação anterior indicaram que o atendimento a estes dois requisitos se verificaria pela uniformização 
dos momentos fletores negativos imposta como restrição de igualdade, sendo então redefinido o problema como:

$$
\begin{aligned}
& \min \sum_{\mathbf{i}=2}^{\mathbf{N N O}-1}\left[\mathbf{M}_{\mathbf{i}}^{(-)}\right]^{2} \\
& \text { s.a. } \quad \mathbf{h}_{\mathbf{1}}: \mathbf{M}_{\mathbf{j}+\mathbf{1}}^{(-)}-\mathbf{M}_{\mathbf{j}}^{(-)}=\mathbf{0} \quad \mathbf{j}=2, \text { NNO - } 2 \\
& g_{1}: M_{2}^{(+)}+M_{2}^{(-)} \leq 0 \\
& \mathrm{~g}_{2}: \mathrm{M}_{\mathrm{NNO}-2}^{(+)}+\mathrm{M}_{\mathrm{NNO}-1}^{(-)} \leq 0 \\
& \mathbf{g}_{\mathbf{3}}: \mathbf{M}_{\mathbf{k}}^{(-)} \leq \mathbf{0} \quad \mathrm{k}=2, \mathrm{NNO}-1
\end{aligned}
$$

Em relação à formulação imediatamente anterior destaca-se que a parcela relativa à igualdade de momentos fletores, ao ser transformada em restrição do problema deixa de ser elevada à segunda potência na descrição da formulação, já que pela forma de penalização o será.

Esta última formulação, por reunir as características desejáveis verificadas nas anteriores, foi então também implementada no modelo de viga. Os resultados, como esperado, apresentaram economia bastante significativa, além de conduzirem a uma única configuração final, motivo pelo qual esta foi a formulação adotada.

Até esta etapa do trabalho a preocupação básica no que diz respeito ao processo de otimização foi a de buscar técnicas eficazes para a obtenção dos resultados comparativos. A eficiência do processo adotado, bem como eventuais alternativas, passaram a ser objeto de estudo, ainda que considerada como de importância secundária, a partir deste ponto do trabalho. 
3.5.2 Modificações nos métodos e testes dos parâmetros empregados

A formulação adotada, mantidas as limitações comuns as demais, apresentou como característica a existência de um único conjunto ótimo para as variáveis de projeto para cada estrutura. Dados os objetivos propostos no trabalho, esta característica assume particular importância na medida em que se pretende, uma vez definida uma configuração inicial para a estrutura, alterar as posições dos apoios de modo a tentar uma redistribuição mais favorável. Caso não existisse um mínimo estrito, a necessidade de partir-se de vários pontos distintos tornaria inócua a definição da disposição inicial dos apoios.

Os resultados obtidos tomando-se pontos iniciais os mais variados possíveis apresentaram variações na terceira casa decimal. Em termos práticos estes resultados poderiam ser considerados idênticos, visto que representam diferenças de milímetros no posicionamento dos apoios (sem qualquer significado quando se raciocina em termos de construção). Porém, levando em conta a precisão de computador, as variações pareceram significativas. Assim sendo, diversas modificações no programa foram efetuadas, buscando entre outros a redução na quantidade de operações aritméticas e em consequência nos erros de truncamento.

Inicialmente procedeu-se a uma revisão em relação ao método de busca da direção de descida. O Método de Newton, até então implementado, foi substituído por um método quasi-Newton. Uma das motivações para esta alteração foi a suposição, a qual acabou por não se confirmar, de que as descontinuidades nas segundas derivadas das restrições de desigualdade poderiam ocasionar problemas na aplicação de um método que utilizasse diretamente as segundas derivadas (matriz Hessiana). Estas descontinuidades devem-se à forma empregada para a penalização das restrições de desigualdade, consistindo na substituição de valores negativos por valores nulos, acarretando na não-diferenciabilidade da função no ponto em que a restrição é ativa. Seguindo sugestão de diversos pesquisadores foi implementado o Método de Davidon, Fletcher e Powell (DFP). Com a alteração no processo de busca unidimensional, descrita no parágrafo seguinte, não foi observada mudança nos resultados. Em contrapartida, obteve-se grande simplificação no código computacional, visto que o cálculo das segundas derivadas foi dispensado. Numa 
etapa posterior, a aproximação da inversa da matriz Hessiana passou a ser reinicializada (tornada igual a matriz identidade) a cada $\mathbf{n}$ iterações, sendo $\mathbf{n}$ o número de variáveis de projeto. Este procedimento, sugerido entre outros por MINOUX (1983), reduz a possibilidade de mau condicionamento da matriz.

Ainda nos primeiros testes desenvolvidos, verificou-se que a substituição de um processo de busca unidimensional denominada exata (no caso, a Técnica do Ajuste Cúbico) por um processo de busca imprecisa (a Regra de Armijo) não trazia qualquer prejuízo em relação aos resultados, reduzindo ainda o tempo de processamento. Contudo, como passou-se a utilizar um método aproximado para a determinação da direção de busca (a quantidade de informações fornecidas foi reduzida), a utilização de um método também aproximado para o cálculo do tamanho do passo seria pouco aconselhável. Como a Técnica do Ajuste Cúbico necessita de valores tanto da função em alguns pontos como também da derivada nesses pontos, e sendo o cálculo das derivadas bastante oneroso, implementou-se o Método da Seção Áurea, o qual elimina esse último cálculo (método de ordem zero). Neste caso contrariou-se o senso comum, visto que a Técnica do Ajuste Cúbico é a mais recomendada. Adicionalmente, o vetor direção de descida foi normalizado a cada iteração. Manteve-se assim a mesma ordem de grandeza para as direções, facilitando a definição de um intervalo inicial de busca e acelerando o processo de convergência.

Para a consideração das restrições a técnica de minimização sequencial de funções sem restrição (SUMT) foi mantida. Foi mantido também o processo de penalização exterior, pela dificuldade na determinação de um conjunto inicial factível.

Os fatores e coeficientes de penalização, normalmente determinantes no processo, foram testados para diversas combinações de valores. $O$ fator de multiplicação, arbitrado inicialmente como $\gamma=3$, foi alterado para os valores 5 e 10, sendo para estes efetuada a análise de uma mesma estrutura a partir de diversos pontos iniciais, não se verificando uma mesma tendência para os resultados em função da variação de $\gamma$. Para $\gamma=10$ observou-se pequena redução na dispersão dos valores finais, além de também pequena redução no número de iterações. Como um menor número de iterações não conduz necessariamente à maior eficiência do programa, e como em média os valores finais da função são menores para $\gamma=3$, 
optou-se pela manutenção deste valor. Também para o coeficiente de penalização $\mathbf{r}$ foi mantido o valor inicial $\mathbf{r}=1$, visto que para valores iguais a 0,1 e 0,01 observouse em muitos exemplos o não atendimento às restrições, bastante enfraquecidas.

A tolerância definida para utilização no critério de parada $\left(1 \times 10^{-5}\right)$ não foi alterada. Para testes envolvendo uma maior precisão $\left(1 \times 10^{-8}\right)$ os resultados mantiveram-se idênticos, havendo apenas em alguns casos isolados um pequeno acréscimo no número de iterações necessárias.

Pela pouca redução nas diferenças obtidas, e considerando-se que tanto os processos anteriores quanto os implementados posteriormente são compatíveis entre sí, e destacando ainda que os valores finais obtidos pelo uso de técnicas de programação não-linear são altamente dependentes dos valores iniciais, concluiu-se que tanto em termos relativos como absolutos as diferenças observadas podem ser consideradas como perfeitamente admissíveis.

\subsubsection{Resultados obtidos}

Neste sub-ítem apresenta-se de forma sucinta alguns resultados relevantes obtidos a partir da implementação da formulação considerada como satisfatória, de acordo com os objetivos definidos.

As vigas biapoiadas analisadas segundo a formulação imediatamente anterior a esta bem como segundo a formulação inicial apresentam os mesmos resultados pela presente formulação, visto que também busca-se a minimização do somatório dos momentos fletores negativos, com valores maiores ou iguais aos do momento fletor positivo.

Para efeito das comparações seguintes considerou-se uma viga subdividida em módulos de 4,5 metros cada, tendo como dimensões da seção transversal bw igual a $12 \mathrm{~cm} \mathrm{e} \mathrm{h} \mathrm{igual} \mathrm{a} 40 \mathrm{~cm}$. A viga é submetida a um carregamento uniformemente distribuído de $16 \mathrm{kN} / \mathrm{m}$, e os materiais componentes foram definidos como concreto C 20 e aços CA-50A e CA-60. 
Inicialmente foi analisada uma viga com 2 módulos (comprimento total de 9 metros) e 3 apoios, um apoio disposto em cada extremo e outro no eixo de simetria (caso A).

Conforme pode ser verificado tanto nas figuras (8) e (9) como de forma mais precisa na tabela (7), uma série de efeitos favoráveis foram produzidos na medida em que os apoios foram deslocados para os pontos de ótimo (caso B). Destaca-se, dentre estes efeitos: redução significativa dos momentos fletores ao longo da estrutura, tanto dos negativos como dos positivos; uniformização e redução também nos valores dos esforços cisalhantes devido à uniformização dos momentos fletores sobre os apoios (conduzindo a menor quantidade e diversidade de estribos); redução nas diferenças das reações verticais (pilares de dimensões iguais ou semelhantes). Apenas a posição do apoio esquerdo é indicada, devido à simetria da estrutura.

Nas figuras representa-se o diagrama de esforços de cisalhamento à esquerda do eixo de simetria, e o diagrama de esforços de flexão à direita do eixo.
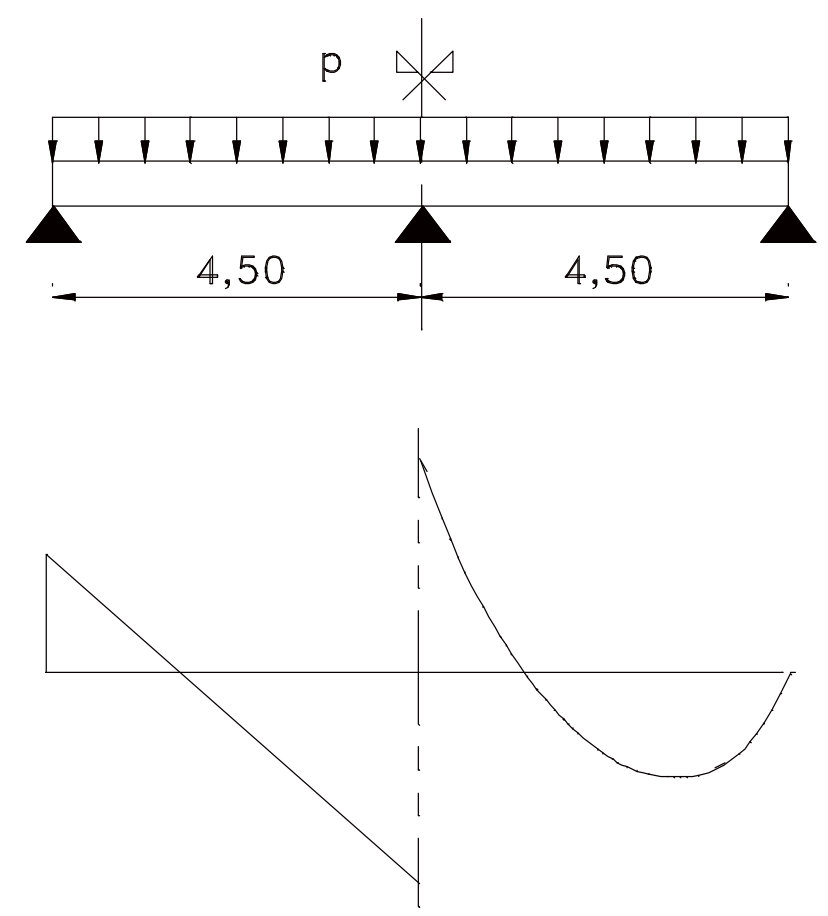

FIGURA (8) - Viga com 3 apoios: diagramas de esforços (configuração inicial) 

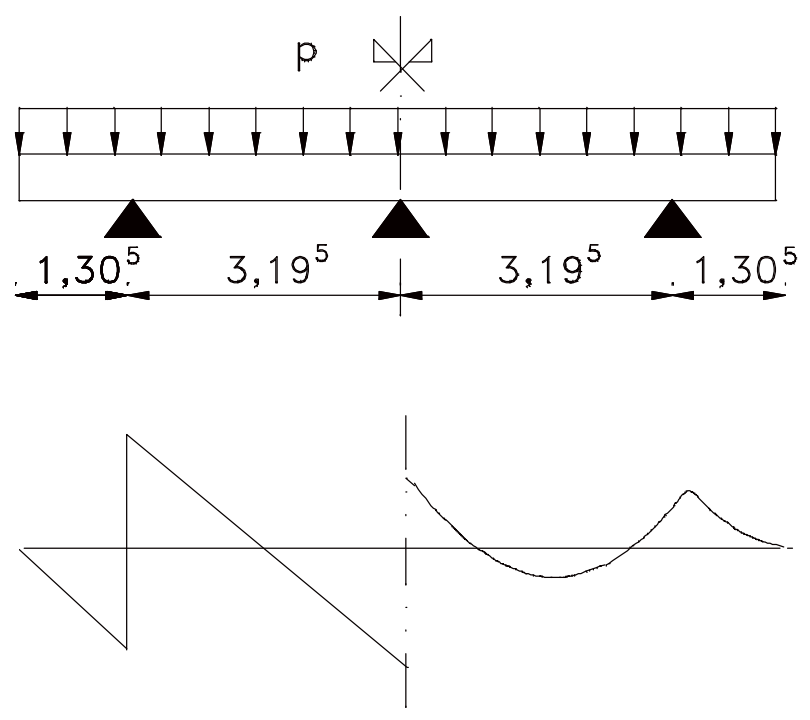

FIGURA (9) - Viga com 3 apoios: diagramas de esforços (configuração ótima)

TABELA (7) - Viga com 3 apoios (simétrica): valores comparativos

\begin{tabular}{|c|c|c|c|c|c|c|c|c|}
\hline caso & $\mathrm{x}(\mathrm{m})$ & $\begin{array}{c}\mathrm{M}_{\max }^{(+)} \\
(\mathrm{kN} . \mathrm{m})\end{array}$ & $\begin{array}{c}\mathrm{M}_{\max }^{(-)} \\
(\mathrm{kN} . \mathrm{m})\end{array}$ & $\begin{array}{c}\mathrm{V}_{\max } \\
(\mathrm{kN})\end{array}$ & $\mathrm{R}_{\mathrm{a}}$ & $\begin{array}{c}\mathrm{A}_{\mathrm{sl}} \\
\left(\mathrm{cm}^{2}\right)\end{array}$ & $\begin{array}{c}\mathrm{A}_{\mathrm{sw}} \\
\left(\mathrm{cm}^{2} / \mathrm{m}\right)\end{array}$ & $\begin{array}{c}\mathrm{P}_{\mathrm{S}} / \\
\mathrm{P}_{\mathrm{S}(\mathrm{A})}\end{array}$ \\
\hline $\mathrm{A}$ & 0 & 22,78 & 40,50 & 45,00 & 3,33 & 4,25 & 3,54 & 1,00 \\
\hline $\mathrm{B}$ & 1,305 & 6,81 & 13,62 & 25,56 & 1,10 & 1,25 & 1,68 & 0,66 \\
\hline
\end{tabular}

$\mathrm{Na}$ tabela, $\mathrm{V}_{\max }$ indica o máximo esforço cortante, $\mathrm{R}_{\mathrm{a}}$ a razão entre os esforços normais extremos nos apoios e $\mathrm{A}_{\mathrm{SW}}$ a armadura ao cisalhamento.

Movimentando-se os apoios extremos em $10 \mathrm{~cm}$ e em ambos os sentidos, analogamente ao efetuado para a primeira estrutura (e mantida a simetria), os maiores momentos fletores crescem em média em 16 por cento.

Seguindo a mesma estrutura modular do exemplo anterior, foram analisadas ainda vigas variando de 2 apoios (1 elemento, comprimento total de 4,5 metros) a 6 apoios (5 elementos, comprimento total de 22,5 metros). Foram comparados os resultados obtidos para apoios nos extremos de cada vão $\left(\mathrm{X}^{0}\right)$ com os obtidos para as posições ótimas $(\mathrm{X} *)$. O gráfico (7) apresenta para cada uma destas situações a economia relativa de aço, mantidas as demais características de cada estrutura. Cabe 
ressaltar que, devido às dimensões adotadas para a seção transversal, a armadura para combate ao cisalhamento na situação ótima foi para 2 e 3 apoios inferior à especificada por Norma, sendo evidentemente esta última a adotada.

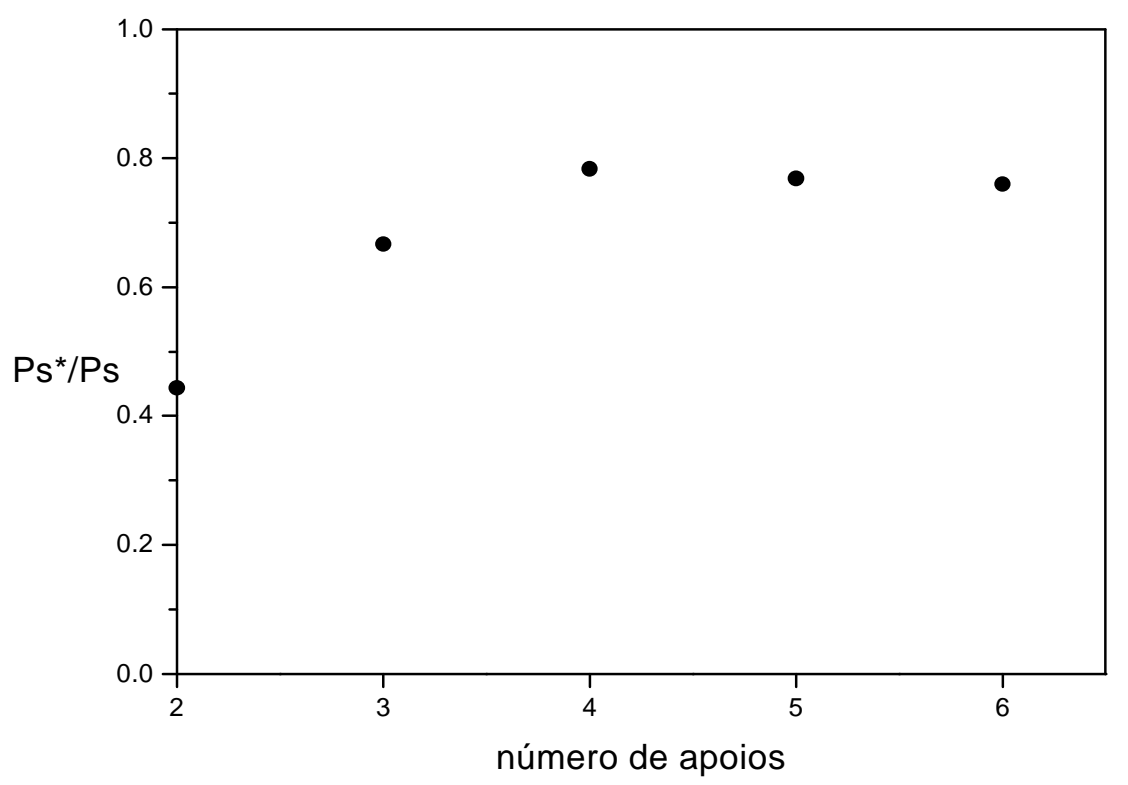

GRÁFICO (7) - Economia relativa de aço x número de apoios (adimensional)

No gráfico pode-se observar uma tendência aproximadamente assintótica porém não à unidade (o que representaria economia zero), mas sim uma estabilização permitindo supor que, independente do número de apoios e dos comprimentos relativos que venham a ser assumidos pelos vãos, a diferença relativa no consumo de aço permanece significativa.

Na tabela anterior observou-se que, ainda que não se constitua no objetivo do estudo, o posicionamento dos apoios nos pontos ótimos conduziu a uma maior uniformização das reações verticais nos apoios. Ainda assim, a título de ilustração, apresenta-se nas tabelas (8) e (9), respectivamente, os esforços e excentricidades ao longo dos apoios caso a viga fosse considerada como constituindo um pavimentotipo ou uma estrutura em pilotis. A viga do exemplo, submetida a um carregamento 
uniforme igual a 7,5 kN/m e com dimensão da seção transversal de 20 x 40 centímetros, possui vão total igual a 35 metros e 6 apoios dispostos inicialmente (caso A) de forma equidistante. Os pilares, de comprimento igual a 3 metros, possuem seção transversal de 20 x 20 centímetros, sendo a todos atribuída uma grande rigidez axial de modo a sustentar a hipótese de indeslocabilidade dos apoios na direção vertical.

A tabela (8) aponta os esforços normais $\mathbf{N}$, os esforços de flexão $\mathbf{M}$ e as excentricidades iniciais resultantes $\mathbf{e} \mathbf{i}$, com seus respectivos sub-índices relacionando os apoios no sentido da extremidade ao centro da estrutura. Devido à simetria, constam da tabela apenas os valores relativos aos três apoios à esquerda do eixo de simetria. Os sinais dos momentos fletores obedecem a convenção de Grinter. Nesta tabela, relativa a suposição de pavimento-tipo, foram supostos pontos de inflexão a meia altura de cada pavimento. Como nas demais análises, o caso B representa a situação ótima.

TABELA (8) - Influência nos pilares: pavimento-tipo

\begin{tabular}{|c|c|c|c|c|c|c|c|c|c|}
\hline caso & $\begin{array}{c}\mathrm{N}_{1} \\
(\mathrm{kN})\end{array}$ & $\begin{array}{c}\mathrm{M}_{1} \\
(\mathrm{kN} . \mathrm{m})\end{array}$ & $\begin{array}{c}\mathrm{e}_{\mathrm{i}, 1} \\
(\mathrm{~m})\end{array}$ & $\begin{array}{c}\mathrm{N}_{2} \\
(\mathrm{kN})\end{array}$ & $\begin{array}{c}\mathrm{M}_{2} \\
(\mathrm{kN} . \mathrm{m})\end{array}$ & $\begin{array}{c}\mathrm{e}_{\mathrm{i}, 2} \\
(\mathrm{~m})\end{array}$ & $\begin{array}{c}\mathrm{N}_{3} \\
(\mathrm{kN})\end{array}$ & $\begin{array}{c}\mathrm{M}_{3} \\
(\mathrm{kN} . \mathrm{m})\end{array}$ & $\begin{array}{c}\mathrm{e}_{\mathrm{i}, 3} \\
(\mathrm{~m})\end{array}$ \\
\hline A & 23,24 & $-15,01$ & 0,646 & 56,04 & 2,71 & 0,048 & 51,98 & $-0,57$ & 0,011 \\
\hline B & 41,42 & $-0,66$ & 0,016 & 44,91 & 0,82 & 0,018 & 44,93 & $-0,83$ & 0,018 \\
\hline
\end{tabular}

Observa-se pelos dados contidos na tabela que, indiretamente, a uniformização dos momentos na viga gera também a uniformização das reações verticais no topo dos pilares e redução dos momentos fletores na ligação dos pilares com a viga. Como consequência direta as excentricidades iniciais passam a assumir de uma forma geral valores pouco relevantes, possibilitando a adoção de uma mesma seção transversal para os pilares.

Considerando-se a viga como constituindo uma estrutura em pilotis pode ser verificado comportamento bastante semelhante, conforme tabela (9). Como os pilares 
foram supostos engastados nas extremidades inferiores, passa-se a apresentar na tabela também os momentos no topo de cada pilar ( $\left.\mathbf{M}_{\text {sup }}\right)$ e na base $\left(\mathbf{M}_{\mathbf{i n f}}\right)$. As demais considerações são as mesmas efetuadas em relação à tabela anterior.

TABELA (9) - Influência nos pilares: pilotis (unidades em kN e m)

\begin{tabular}{|c|c|c|c|c|c|c|c|c|c|}
\hline caso & $\mathrm{N}_{1}$ & $\mathrm{M}_{1, \text { sup }}$ & $\mathrm{e}_{\mathrm{i}, 1}$ & $\mathrm{~N}_{2}$ & $\mathrm{M}_{2, \text { sup }}$ & $\mathrm{e}_{\mathrm{i}, 2}$ & $\mathrm{~N}_{3}$ & $\mathrm{M}_{3, \text { sup }}$ & $\mathrm{e}_{\mathrm{i}, 3}$ \\
& & $\mathrm{M}_{1, \text { inf }}$ & & & $\mathrm{M}_{2, \text { inf }}$ & & & $\mathrm{M}_{3, \text { inf }}$ & \\
\hline A & 43,91 & $-15,10$ & 0,344 & 115,46 & 3,60 & 0,031 & 103,13 & $-0,96$ & 0,009 \\
& & $-7,49$ & & & 1,83 & & & $-0,47$ & \\
\hline B & 82,79 & $-0,71$ & 0,009 & 89,86 & 0,78 & 0,009 & 89,85 & $-0,78$ & 0,009 \\
& & $-0,35$ & & & 0,39 & & & $-0,39$ & \\
\hline
\end{tabular}

3.6 Considerações sobre a formulação adotada

Os estudos e testes efetuados para o desenvolvimento de uma formulação para a análise de vigas contínuas apresentaram resultados bastante promissores com relação ao objetivo final, o qual se constitui na otimização geométrica de pavimentos de edifícios segundo o modelo de grelha. Em função destes resultados, deu-se por encerrada esta etapa do estudo, optando-se pela implementação da última formulação elaborada bem como dos métodos de otimização empregados até o momento, uma vez demonstrada a eficácia dos mesmos. O próximo capítulo deste trabalho tratará portanto das necessárias adaptações. 
Cabe destacar que o estudo do modelo de vigas para aplicação direta deste tipo de estrutura não se constituiu em objetivo do trabalho. Desta forma, algumas limitações inerentes à formulação foram retiradas ou amenizadas especificamente durante o estudo do modelo de grelha. Ainda assim, em vista do grande potencial apresentado, objetiva-se um posterior retorno ao estudo de vigas contínuas não apenas com o intuito de fornecer maiores subsídios para a análise de grelhas, como também para a aplicação direta do programa. 


\section{OTIMIZAÇÃO GEOMÉTRICA DE GRELHAS}

\subsection{Introdução}

Como já destacado, devido à maior complexidade apresentada na análise de uma estrutura ou parte dela pelo modelo de grelha, em relação ao modelo de viga, optou-se por este último para o estudo de uma formulação inicial. Uma vez determinada esta formulação, foram efetuadas análises de diversas vigas, sendo também verificado o consumo de materiais. Os resultados obtidos permitiram que se concluísse pela relativa eficiência em função dos objetivos inicialmente propostos. A formulação adotada para a otimização de vigas contínuas foi então implementada para o modelo de grelha com as devidas adaptações inerentes ao modelo estrutural, buscando-se a reprodução da mesma com a maior fidelidade possível. No entanto, em razão do caráter tridimensional assumido pelo conjunto formado pela estrutura e pelo carregamento aplicado, as mínimas alterações necessárias, de aparente simplicidade, acabaram por demandar em modificações descritas na sequência deste capítulo.

Apresentam-se nos sub-itens seguintes tanto as adaptações necessárias, incluindo testes e exemplos, como os problemas de ordem matemática encontrados e as formas estudadas com o intuito de contornar estas dificuldades. Descrevem-se ainda implementações efetuadas no programa de grelhas objetivando a redução das limitações inicialmente impostas à formulação idealizada para a otimização de vigas contínuas. 
4.2 Adaptação da formulação ao modelo de grelha

As alterações efetuadas no programa de vigas contínuas de modo a adaptá-lo ao modelo de grelha a princípio não acarretaram em modificação das hipóteses nas quais se baseou o problema do ponto de vista da otimização estrutural.

Em analogia à formulação adotada para vigas, descrita nas equações (62) a (66), tem-se as seguintes observações:

- A função objetivo (somatório do quadrado dos momentos negativos) pode ser mantida segundo a formulação original. Porém todos os nós, com exceção dos nós extremos, eram supostos apoiados (indeslocáveis na direção perpendicular ao plano da estrutura), hipótese esta pouco realista para o modelo de grelha. Desta forma o vetor das variáveis de projeto assume ordem $\mathbf{n}_{\mathbf{c c}}$, onde $\mathbf{n}_{\mathbf{c c}}$ representa o número total de nós deslocáveis no plano da estrutura, também designados por nós móveis;

- A restrição $\mathbf{h}_{1}$ (igualdade entre momentos negativos adjacentes) efetuava a comparação entre o valor do momento fletor em um apoio com o valor no apoio seguinte, sendo que pela forma de numeração adotada estes momentos eram sempre adjacentes. Adicionalmente, a inexistência de nós internos não vinculados na direção vertical resultava simplificadamente no cálculo da diferença nos valores dos esforços de flexão entre os nós final e inicial nas extremidades de um mesmo elemento, chegando-se a um número de equações igual ao número total de nós menos três (NNO-3). Já o modelo de grelha, por não possuir um eixo principal comum a todos os elementos, impossibilita a manutenção desta sequência. Desta forma, passam a ser comparados o esforço entre um determinado nó com o do nó imediatamente subsequente segundo a ordem escolhida. O número de nós móveis é igual a $\mathbf{n}_{\mathbf{c c}}$, sendo o i-ésimo nó móvel denominado por NNR ( i ). Adicionalmente, o valor do esforço no último nó é comparado ao do primeiro, gerando assim $\mathbf{n}_{\mathbf{c c}}$ equações relativas à restrição de igualdade; 
- As restrições $\mathbf{g}_{1}$ e $\mathbf{g}_{2}$ impunham para cada viga a igualdade entre os momentos negativo no primeiro e último nós internos, respectivamente, em relação ao momento máximo positivo, no elemento imediatamente interior. Com a adição de nós internos não vinculados, o momento máximo positivo não mais ocorre necessariamente neste elemento, sendo necessária a pesquisa ao longo de todos os elementos até o próximo nó apoiado. Para a manutenção deste tipo de restrição na formulação específica para grelhas, a estrutura passou a ser descrita por sequências de elementos na entrada de dados do programa. Assim, o número de restrições de desigualdade $\mathbf{g}_{1}$ e $\mathbf{g}_{2}$ será o mesmo, cada um igual ao número total de sequências de elementos componentes da grelha e que possuam dois ou mais apoios. Destaca-se que a denominação "sequência de elementos", doravante representada por Seqxx (sendo xx o número da sequência), passa a ser utilizada de modo a evitar a eventual confusão com o termo "viga", uma vez que este último pressupõe a inexistência de compatibilidade de deslocamentos com os elementos com os quais é interceptado.

- Por fim, a restrição de desigualdade $\mathbf{g}_{3}$, a qual impõe que os momentos fletores sobre os apoios sejam não-positivos também é mantida, agora em número igual a $\mathbf{n}_{\mathbf{c c}}$.

A exemplo do modelo tratado anteriormente, as variáveis de projeto foram tomadas como as coordenadas dos apoios em relação ao referencial global da estrutura, porém agora não mais necessariamente coincidente para todos os elementos. Sendo as posições relativas de nós e elementos descritas em função das coordenadas $\mathbf{x}$ e $\mathbf{y}$, mas considerando que para a posterior determinação da direção de descida de acordo com a equação (5) tem-se que

$$
\begin{aligned}
& \{X\}_{k+1}=\{X\}_{k}+\alpha\{d\}_{k} \\
& \{Y\}_{k+1}=\{Y\}_{k}+\alpha\{d\}_{k},
\end{aligned}
$$


optou-se por armazenar no programa as coordenadas nodais em um único vetor $\mathbf{X}$ de dimensão igual a 2NNO (número total de nós). Assim,

$\mathbf{x}_{\mathbf{i}}$ corresponde à coordenada $\mathrm{x}$, para $\mathrm{i}$ variando de 1 a NNO;

$\mathbf{y}_{\mathbf{i}}$ corresponde à coordenada $\mathrm{y}$, para i variando de NNO+1 a $2 \mathrm{NNO}$.

Limita-se o problema a estruturas compostas por sequências de elementos paralelos ou perpendiculares entre si, de forma a facultar a cada apoio a movimentação, no plano da estrutura, apenas em uma direção, relativamente às coordenadas globais. Adicionalmente, é impossibilitada a existência de apoios nas interseções de sequências de elementos, uma vez que um novo nó e um novo elemento seriam gerados por ocasião da movimentação deste apoio. Respectivamente, as figuras (10) e (11) ilustram a movimentação de apoios de canto e de extremidade, para $\mathbf{n}$ nós e m elementos. A situação é análoga quando se considera apoios intermediários.
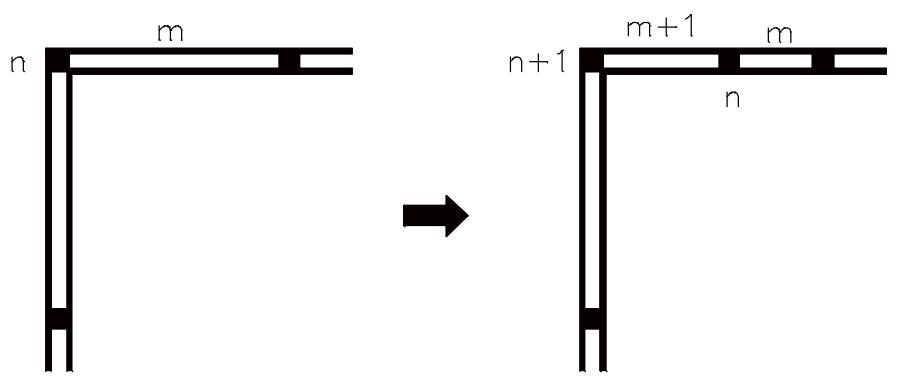

FIGURA (10) - Movimentação de apoio de canto 


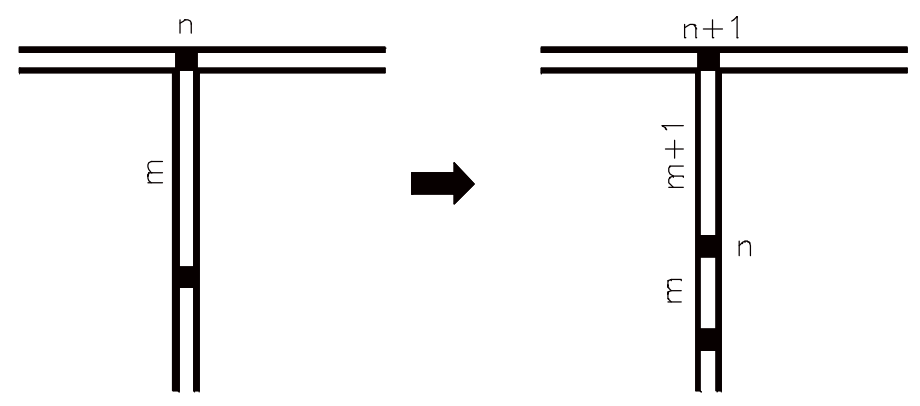

FIGURA (11) - Movimentação de apoio de extremidade

Como se observa, a adição ou mesmo retirada de um nó ou elemento, denominada por otimização topológica, acarreta na geração de uma nova estrutura, sendo normalmente necessária a reinicialização do processo de otimização.

Adicionalmente, para a obtenção desta nova estrutura, seria necessária a definição de um critério adicional para a determinação da direção a adotar, uma vez que a tendência do apoio não seria obrigatoriamente a de deslocar-se apenas sobre o eixo de uma das sequências.

Em função das limitações impostas ao programa o vetor das coordenadas $\mathrm{X}$ passa a conter, das $\mathbf{2 N N O}$ posições, apenas $\mathbf{n}_{\mathbf{c c}}$ coeficientes não constantes, reduzindo portanto de forma considerável as dimensões do problema já que apenas estes últimos constituem-se nas variáveis de projeto.

A entrada de dados para o programa é efetuada descrevendo-se a grelha em função das NV sequências de elementos que a compõe, para as quais NELVIG ( i ) representa o número de elementos da sequência i. Atendendo a uma das premissas iniciais, todos os elementos de uma determinada sequência terão a mesma seção transversal.

Respeitadas as hipóteses básicas e condições impostas ao modelo de viga, foi formulado o problema de otimização geométrica de grelhas. Novamente a notação utilizada indica o sub-índice para os momentos fletores positivos $\left(\mathbf{M}^{(+)}\right)$ correspondendo ao número do elemento, enquanto o sub-índice relativo aos momentos fletores negativos $\left(\mathbf{M}^{(-)}\right)$corresponde ao número do nó (apoio). 
Sendo assim, tem-se como problema

$$
\begin{aligned}
& \min \sum_{\mathbf{i}=1}^{\mathbf{N C C}}\left[\mathbf{M}_{\mathbf{N N R}(\mathbf{i})}^{(-)}\right]^{2} \\
& \text { s.a. } \quad \mathbf{h}_{1}: \mathbf{M}_{\mathrm{NNR}(\mathrm{i})}^{(-)}-\mathbf{M}_{\mathrm{NNR}(\mathrm{i}+\mathbf{1})}^{(-)}=\mathbf{0} \\
& \mathbf{g}_{\mathbf{1}}: \mathbf{M}_{\mathbf{2}, \mathbf{k}}^{(+)}+\mathbf{M}_{\mathbf{2 , k}}^{(-)} \leq \mathbf{0} \quad \mathrm{k}=1, \mathrm{NV} \\
& \mathrm{g}_{2}: \mathrm{M}_{\mathrm{NELVIG}(\mathrm{k})-2, \mathrm{k}}^{(+)}+\mathrm{M}_{\mathrm{NELVIG}(\mathrm{k})-1, \mathrm{k}}^{(-)} \leq 0 \\
& \mathrm{~g}_{3}: \mathrm{M}_{\mathrm{NNR}(\mathrm{i})}^{(-)} \leq \mathrm{0}
\end{aligned}
$$

Os deslocamentos nodais, bem como os esforços nos elementos, são obtidos também com a utilização do Método dos Deslocamentos. Como particularidade em relação ao modelo de viga, apresenta-se apenas a necessidade da consideração das características de rigidez e do carregamento relativamente a um único referencial, condição automaticamente atendida no modelo de viga. No caso de elementos de grelha, as expressões para os momentos fletores foram descritas de forma análoga à efetuada para a otimização de vigas, sendo o sistema de equações representado como em (44), resultando em 


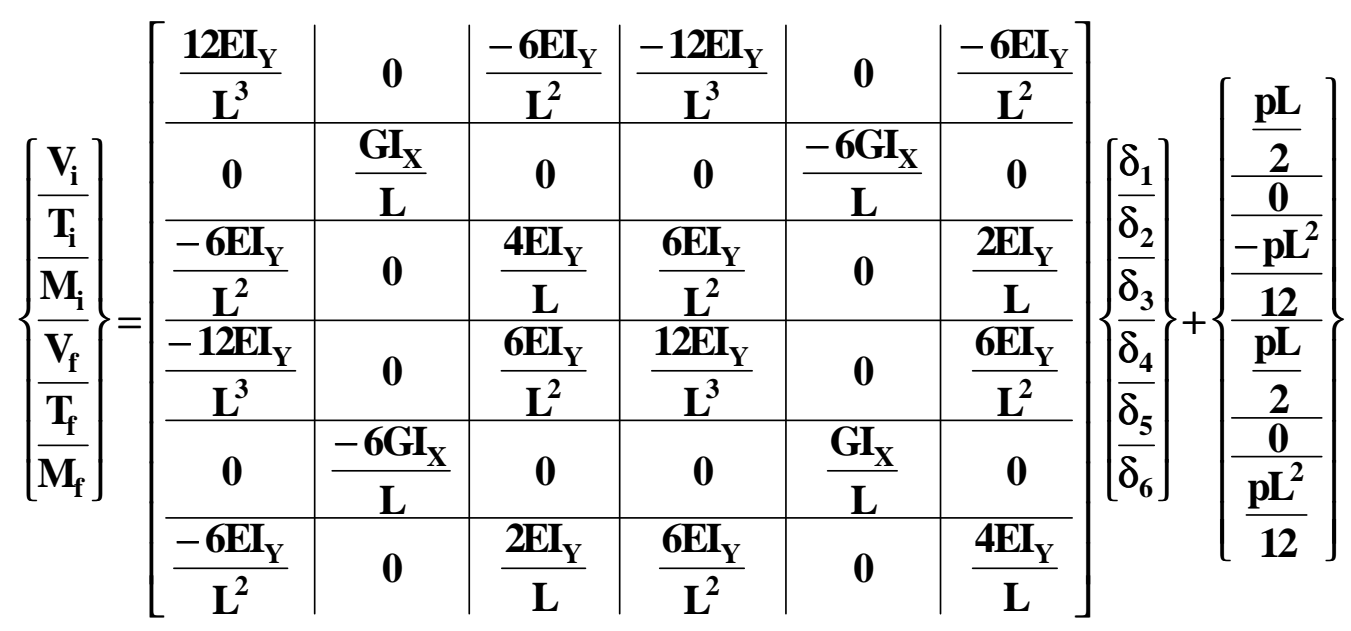

ou, isolando-se o momento fletor no nó inicial, como

$$
M_{i}^{(-)}=M_{i}=\frac{2 E I}{L_{i}}\left(2 \delta_{3}+\delta_{6}\right)+\frac{6 \mathbf{E I}}{L_{i}^{2}}\left(-\delta_{1}+\delta_{4}\right)-\frac{p \mathbf{L}_{i}^{2}}{12}
$$

sendo adotada a convenção ilustrada na figura (12) para os deslocamentos lineares e angulares $\delta$. Adicionalmente, T representa o esforço de torção em cada extremidade do elemento, $\mathbf{G}$ o módulo de elasticidade transversal do material, e $\mathbf{I}_{\mathbf{x}}$ e $\mathbf{I}_{\mathbf{y}}$, respectivamente, os momentos de inércia relativos à torção e à flexão. Por simplicidade de notação, representa-se a partir da equação (73) o momento de inércia à flexão sem o respectivo sub-índice $\left(\mathbf{I}=\mathbf{I}_{\mathbf{y}}\right)$.

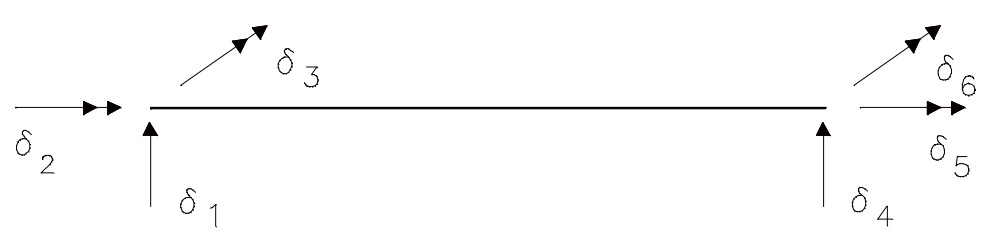

FIGURA (12) - Modelo de grelha: convenção empregada 
Em relação aos métodos e técnicas empregados no processo de otimização, a princípio foram efetuadas apenas as alterações das necessárias à adaptação ao novo modelo estrutural, dadas as semelhanças entre as características gerais dos dois problemas. Apresenta-se a seguir alguns dos resultados obtidos a partir de testes iniciais da formulação.

\subsection{Testes iniciais}

Um primeiro tipo de estrutura analisado consistiu em uma grelha formada por duas sequências biapoiadas, perpendiculares entre si, conforme ilustrado na figura (13), na qual os números dos elementos estão circundados. Foi aplicado à estrutura um carregamento uniformemente distribuído p de intensidade igual a $20,0 \mathrm{kN} / \mathrm{m}$. A área da seção transversal de cada elemento é de 20 x $60 \mathrm{~cm}$, sendo a inércia à torção, neste e nos exemplos seguintes, considerada como 1 por cento da determinada pela resistência dos materiais para material homogêneo. Considerou-se ainda Módulo de Elasticidade longitudinal $\mathrm{E}=.210 \times 10^{8} \mathrm{kN} / \mathrm{m}^{2}$, e Módulo de Elasticidade Transversal $\mathrm{G}=.875 \times 10^{7} \mathrm{kN} / \mathrm{m}^{2}$. Explicitando-se o problema de acordo com a formulação descrita pelas expressões (67) a (71), tem-se então:

$\min \left[\left(\mathbf{M}_{2}^{(-)}\right)^{2}+\left(\mathbf{M}_{4}^{(-)}\right)^{2}+\left(\mathbf{M}_{6}^{(-)}\right)^{2}+\left(\mathbf{M}_{8}^{(-)}\right)^{2}\right]$

s. a. $\mathrm{h}_{1}: \quad \mathbf{M}_{\mathbf{4}}^{(-)}-\mathbf{M}_{\mathbf{2}}^{(-)}=\mathbf{0}$

$$
\begin{aligned}
& M_{6}^{(-)}-M_{4}^{(-)}=0 \\
& M_{8}^{(-)}-M_{6}^{(-)}=0 \\
& M_{2}^{(-)}-M_{8}^{(-)}=0
\end{aligned}
$$




$$
\begin{array}{ll}
\mathrm{g}_{1}: & \mathbf{M}_{2}^{(+)}+\mathbf{M}_{\mathbf{4}}^{(-)} \leq \mathbf{0} \\
& \mathbf{M}_{\mathbf{6}}^{(+)}+\mathbf{M}_{2}^{(-)} \leq \mathbf{0} \\
\mathrm{g}_{2}: \quad & \mathbf{M}_{3}^{(+)}+\mathbf{M}_{\mathbf{6}}^{(-)} \leq \mathbf{0} \\
& \mathbf{M}_{7}^{(+)}+\mathbf{M}_{\mathbf{8}}^{(-)} \leq \mathbf{0} \\
\mathrm{g}_{3}: \quad \mathbf{M}_{2}^{(-)} \leq \mathbf{0} \\
\mathbf{M}_{\mathbf{4}}^{(-)} \leq \mathbf{0} \\
\mathbf{M}_{\mathbf{6}}^{(-)} \leq \mathbf{0} \\
\mathbf{M}_{\mathbf{8}}^{(-)} \leq \mathbf{0}
\end{array}
$$

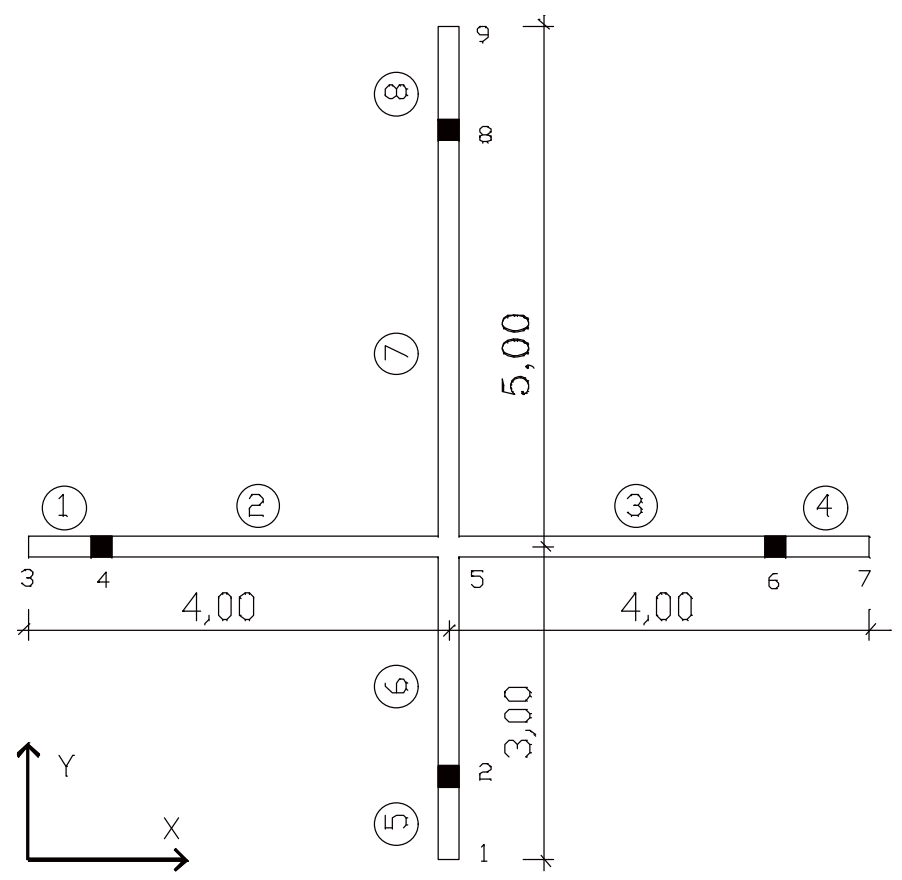

FIGURA (13) - Teste 1: croquis (em metros) 
De acordo com a tabela (10), o caso A ilustra os valores obtidos pela consideração dos apoios nos extremos de cada sequência, enquanto o caso B representa a situação ótima, de acordo com a formulação proposta. Como convenção, designa-se por Mmax o maior momento fletor e Vmax o maior esforço cortante na estrutura, independente do sentido do esforço. Adicionalmente refere-se a cada sequência em função da direção do sistema global de referencia (X ou Y).

TABELA (10) - Teste 1: situações inicial e ótima

\begin{tabular}{|c|c|c|c|c|c|c|c|c|}
\hline caso & $\begin{array}{c}\mathrm{x}_{4} \equiv \mathrm{y}_{2} \\
(\mathrm{~m})\end{array}$ & $\begin{array}{c}\mathrm{x}_{6 \equiv \mathrm{y}_{8}} \\
(\mathrm{~m})\end{array}$ & $\begin{array}{c}\mathrm{Mmax}_{\mathrm{x}} \\
(\mathrm{kN} . \mathrm{m})\end{array}$ & $\begin{array}{c}\mathrm{Vmax}_{\mathrm{x}} \\
(\mathrm{kN})\end{array}$ & $\begin{array}{c}\mathrm{Mmax}_{\mathrm{y}} \\
(\mathrm{kN} . \mathrm{m})\end{array}$ & $\begin{array}{c}\mathrm{V} \max _{\mathrm{y}} \\
(\mathrm{kN})\end{array}$ & $\begin{array}{c}\mathrm{Mmax} / \\
\mathrm{Mmax}(\mathrm{A})\end{array}$ & $\begin{array}{c}\mathrm{Vmax} / \\
\mathrm{Vmax}(\mathrm{A})\end{array}$ \\
\hline $\mathrm{A}$ & 0,000 & 8,000 & 152,20 & 78,03 & 170,03 & 82,47 & 1,000 & 1,000 \\
\hline $\mathrm{B}$ & 1,677 & 6,323 & 28,13 & 44,72 & 28,13 & 48,94 & 0,165 & 0,593 \\
\hline
\end{tabular}

Segundo a tabela, observa-se grande redução (cerca de 83,5 por cento) nos momentos fletores em ambas as sequências componentes da estrutura, bem como do máximo esforço cortante (superior a 40 por cento). Além disso, foi obtida uma uniformização nos valores dos momentos fletores extremos (negativos iguais aos positivos e entre si) e também dos esforços cortantes. Desta forma, a adoção da configuração ótima para a estrutura conduz a uma redução considerável no consumo de aço, no caso da manutenção das seções transversais, sem redução no grau de segurança. Novamente, apesar de não se constituir em objetivo do presente estudo, cabe ressaltar que o procedimento aplicado faculta o redimensionamento dos elementos, acarretando em grande redução na altura da seção transversal. Em ambas as opções, não foi considerada a economia adicional tanto em formas como em mão de obra. Adicionalmente, ainda que não se constitua de forma explícita no objetivo da formulação empregada, também foi observada a uniformização nas reações dos apoios. 
Com o objetivo de verificar empiricamente a existência de um mínimo global da função para a estrutura foram tomadas diversas posições iniciais para os apoios. Em todos os casos foram obtidos esforços finais bastante semelhantes e, mais importante, a mesma configuração final sugerindo a caracterização da função como sendo estritamente convexa. A tabela (11) apresenta os resultados de alguns desse testes efetuados. Nestes, os superíndices * representam os valores ótimos, enquanto os sub-índices 0 são relativos à configuração originalmente idealizada. São indicados na tabela os esforços iniciais extremos e os valores inicial e final da função. Indica-se ainda na última coluna da tabela o número de iterações necessário à convergência segundo os critérios definidos quando da implementação do modelo de viga. Posteriormente, com o refinamento do programa, de forma geral o número de iterações sofreu pequena redução em relação aos constantes na tabela.

TABELA (11) - Teste 1: verificação da convergência (unidades em kN e m)

\begin{tabular}{|c|c|c|c|c|c|c|c|c|c|}
\hline sit & $\mathrm{x}_{4}$ & $\mathrm{x}_{6}$ & $\mathrm{y}_{2}$ & $\mathrm{y}_{8}$ & $\mathrm{Mmax}^{(-)} 0$ & $\mathrm{Mmax}^{(+)} 0$ & $\mathrm{f}_{0}$ & $\mathrm{f}^{*}$ & iter \\
\hline 1 & 1,00 & 7,00 & 1,00 & 7,00 & $-10,00$ & 84,93 & 579,36 & 3166,31 & 55 \\
\hline 2 & 0,50 & 6,00 & 0,50 & 6,00 & $-40,00$ & 58,52 & 3297,54 & 3166,67 & 41 \\
\hline 3 & 1,00 & 7,50 & 1,50 & 6,00 & $-40,00$ & 73,08 & 2279,16 & 3166,47 & 46 \\
\hline
\end{tabular}

Na tabela (11) podem ser verificadas as diferenças pouco significativas para os valores finais da função objetivo, principalmente lembrando que os valores indicados representam o somatório do quadrado dos momentos fletores negativos, e portanto praticamente não apresentam reflexos nos valores destes últimos. Também com base na tabela, observa-se que em duas das três situações apresentadas o valor ótimo da função objetivo é maior que o valor inicial. Este comportamento, aparentemente contraditório quando se raciocina em termos de um processo de minimização, foi bastante frequente nos exemplos analisados, visto que as soluções iniciais não necessariamente atendem às restrições do problema. Vale portanto ressaltar que a forma adotada para a penalização das restrições, conhecida por 
penalização exterior, permite que se tome quaisquer valores iniciais para cada uma das variáveis de projeto, buscando-se uma solução final factível, ou seja, que atenda efetivamente às restrições impostas. A grande vantagem da aplicação deste procedimento consiste basicamente no fato de que para estruturas de maior complexidade a busca por um conjunto inicial factível poderia ser por demais trabalhosa sendo que, uma vez obtidos esses valores iniciais, provavelmente os mesmos constituíssem a própria solução do problema.

Relativamente ao número de iterações necessárias à convergência em cada situação, pelos dados contidos na tabela (11) se poderia supor a existência de uma relação direta entre este número e a diferença, em valor absoluto, entre os valores inicial e final tanto da função como do esforço extremo. No entanto, efetuando uma verificação deste comportamento para diversas outras estruturas, constatou-se a inexistência de qualquer relação nesse sentido.

Ainda em relação ao número de iterações decorrentes de cada configuração inicial observou-se que, embora este número seja bastante grande principalmente pela simplicidade da estrutura, o tempo de processamento pode ser considerado desprezível. Deve-se relevar o fato de que a tolerância adotada para cada variável separadamente foi igual a $1 \times 10^{-5}$, indicando como aceitáveis valores inferiores a centésimos de milímetros. Esta tolerância foi definida fundamentalmente com base em critérios matemáticos, objetivando o estudo do comportamento das funções e do próprio algoritmo empregado. Acredita-se que em termos práticos uma tolerância bem superior a adotada seria perfeitamente admissível. Com base nessas considerações, apresenta-se no gráfico (8) os valores obtidos para uma das variáveis de projeto (no caso $\mathrm{y}_{2}$, ou a posição do nó 2 na direção global $\mathrm{Y}$ ) de forma a demonstrar a rapidez de convergência e portanto a possibilidade de adoção de outros valores mais flexíveis como critério de parada. Ilustra-se nestas duas figuras apenas resultados obtido a partir da análise da situação 1 , considerada a mais crítica dentre as apresentadas na tabela (11). 


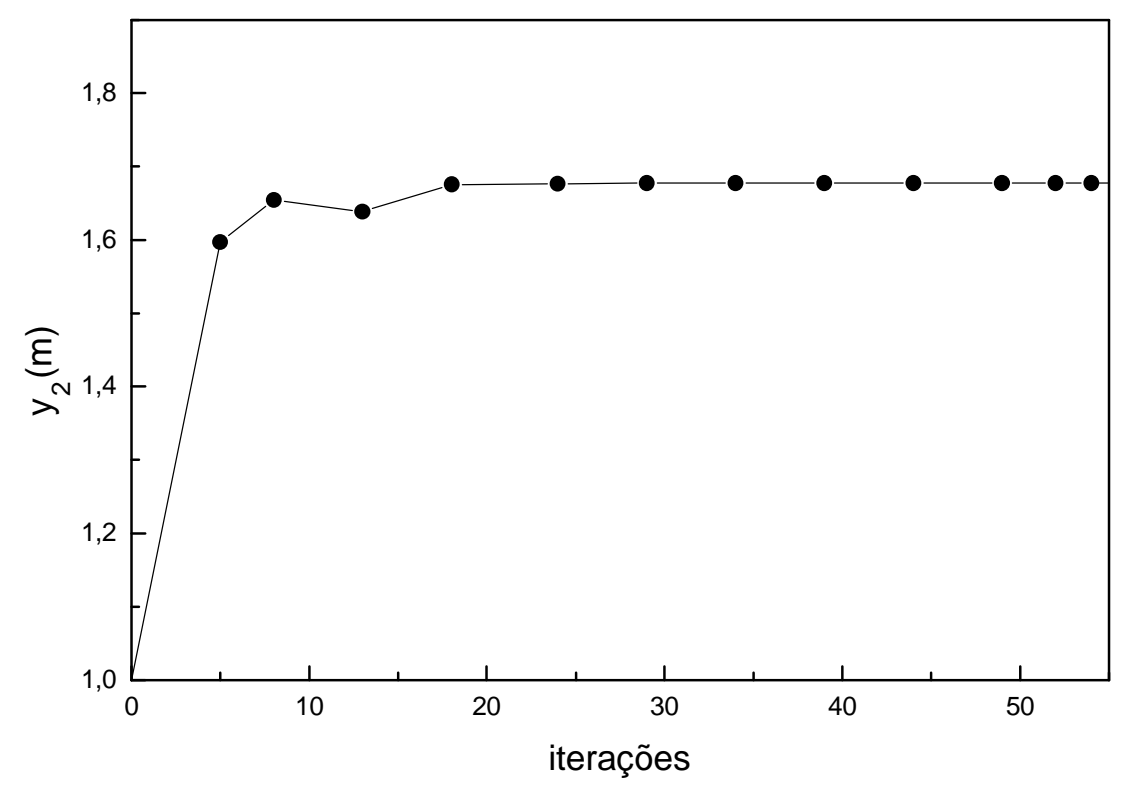

GRÁFICO (8) - Teste 1: variação na posição de um ponto de ótimo para a situação 1

Cada ponto indicado no gráfico anterior corresponde a convergência obtida para um determinado valor do coeficiente de penalização $r$, sendo tomados, como já descrito, um coeficiente inicial $\mathbf{r}_{\text {ini }}$ igual a unidade e um fator de multiplicação $\boldsymbol{\gamma}$ igual a 3. Em razão do critério adotado, o qual consiste em considerar como ponto de partida para cada ciclo iterativo (cada novo r) o ótimo do ciclo anterior, a convergência de fato é obtida em um número de iterações bastante inferior ao apontado na tabela (11). Exemplificando, já com 18 iterações a diferença percentual entre a posição indicada e a posição definida como ótima apresentam valores inferiores a 0,1 por cento.

Adicionalmente, são indicadas no gráfico (9) as diferenças entre os valores tanto da função objetivo como da função penalizada. Observa-se a rápida convergência de ambas as funções a um mesmo valor, o que representa o atendimento às restrições do problema. A título de ilustração, verificou-se para $18 \mathrm{ou}$ mais iterações uma diferença inferior a 3 por cento. Após 24 iterações esta diferença percentual cai a valores percentuais inferiores a 0,34 . 


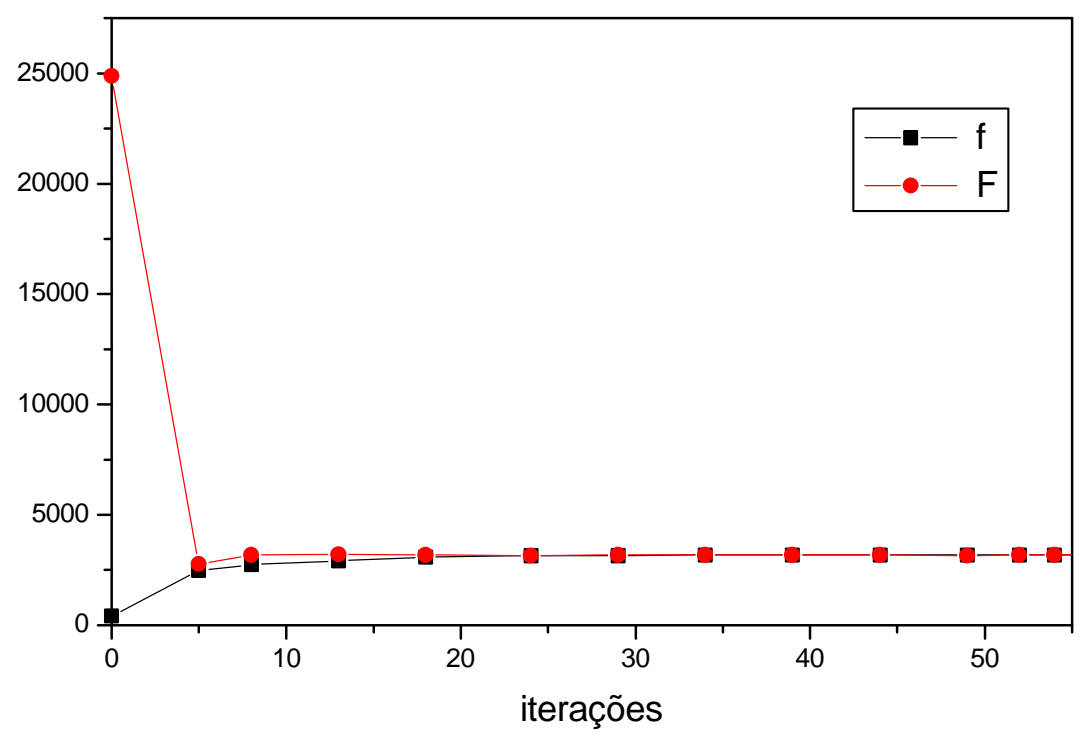

GRÁFICO (9) - Teste 1: variação do valor ótimo para a situação 1

De modo a facilitar a observação da rápida convergência dos valores da função objetivo, apresenta-se no gráfico (10) apenas a variação nos valores da mesma. 


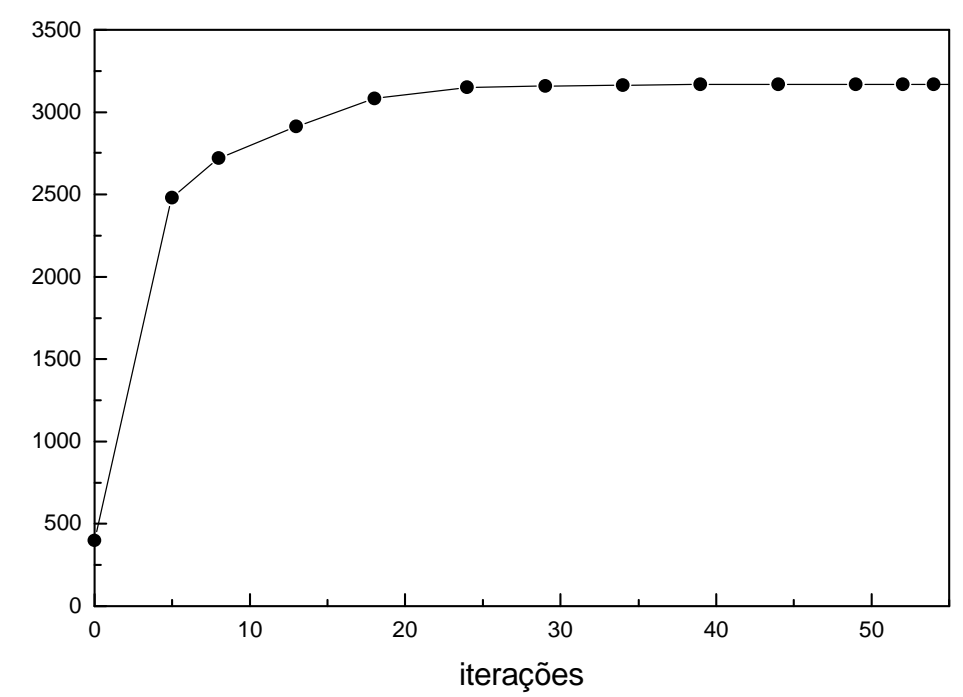

GRÁFICO (10) - Teste 1: variação do valor ótimo da função para a situação 1

O croquis da segunda grelha analisada, aqui denominado teste 2, é apresentado na figura (14). Todos os elementos, com seção transversal 20 x 60 centímetros, possuem módulos de elasticidade longitudinal E e transversal G, respectivamente, iguais a $.21 \times 10^{8} \mathrm{kN} / \mathrm{m}^{2}$ e $.875 \times 10^{7} \mathrm{kN} / \mathrm{m}^{2}$. Aos elementos periféricos foi aplicado um carregamento uniformemente distribuído de $15 \mathrm{kN} / \mathrm{m}$, e ao elemento interno um carregamento também uniformemente distribuído de 30 kN/m. Para a determinação da disposição ótima dos apoios foi, neste exemplo, permitido o deslocamento destes apenas ao longo da direção global X (coincidente com a direção de $x$ na figura), partindo-se do posicionamento aleatório dos apoios sobre as sequências paralelas a $\mathrm{X}$. 

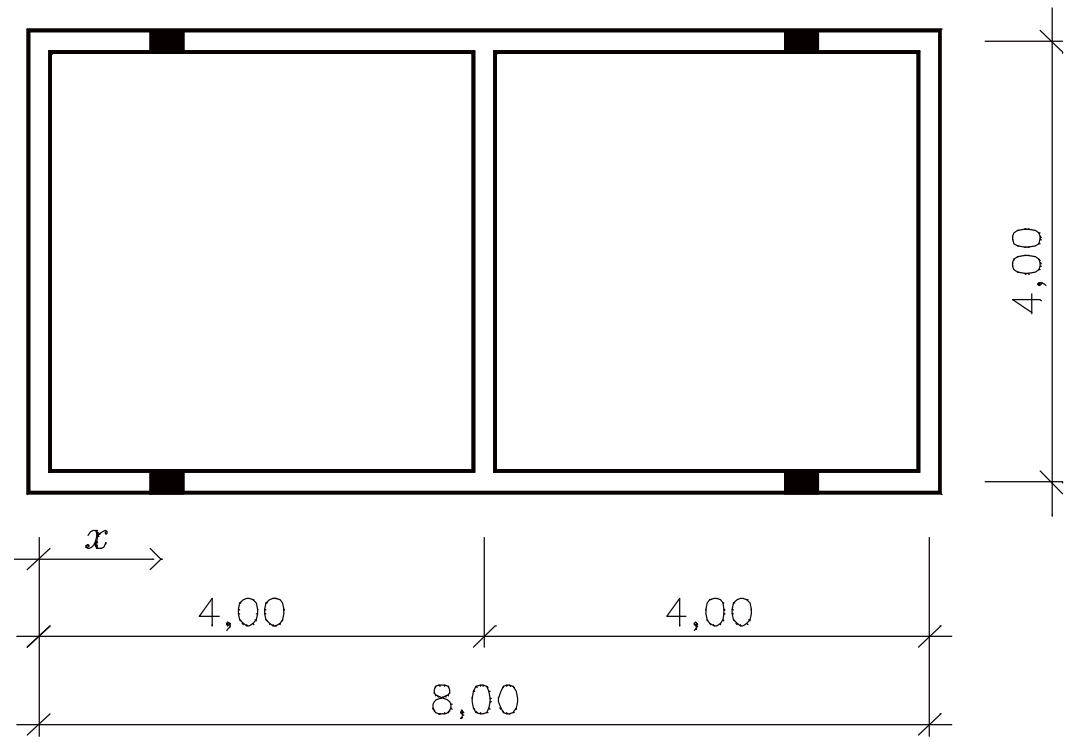

FIGURA (14) - Teste 2: croquis (em metros)

A tabela (12) apresenta resultados relativos aos apoios situados nos cantos (caso A), bem como os resultados obtidos para o posicionamento dos apoios nos pontos considerados ótimos (caso B). Em razão da dupla simetria apresentada pela estrutura, apenas a posição final de um dos apoios é indicada na tabela. Na figura (14), $\boldsymbol{x}$ representa a distância de cada apoio ao canto mais próximo. Para o presente exemplo comparou-se também a flecha $\delta$, a qual ocorre no ponto de dupla simetria.

TABELA (12)- Teste 2: situações inicial e ótima

\begin{tabular}{|c|c|c|c|c|c|c|}
\hline Caso & $\mathrm{x}(\mathrm{m})$ & $\begin{array}{c}\mathrm{Mmax}^{(+)} \\
(\mathrm{kN} . \mathrm{m})\end{array}$ & $\begin{array}{c}\mathrm{Mmax}^{(-)} \\
(\mathrm{kN} . \mathrm{m})\end{array}$ & $\begin{array}{c}\operatorname{Mmax}(\mathrm{B}) \\
/ \operatorname{Mmax}(\mathrm{A})\end{array}$ & $\begin{array}{c}\operatorname{Mmax}(\mathrm{A}) \\
/ \operatorname{Mmax}(\mathrm{B})\end{array}$ & $\delta / \delta(\mathrm{A})$ \\
\hline $\mathrm{A}$ & 0,000 & 240,00 & 0,00 & 1,000 & 3,915 & 1,000 \\
\hline $\mathrm{B}$ & 1,489 & 61,31 & 61,31 & 0,255 & 1,000 & 0,123 \\
\hline
\end{tabular}


Os momentos fletores listados na tabela são relativos apenas as sequências paralelas a $x$, visto que ao longo dos elementos contidos nas demais sequências estes esforços não sofrem alteração. Ainda assim, representam os momentos fletores máximos em ambas as situações. Cabe então salientar que a grande economia apontada pela comparação entre os esforços indicados na tabela não reflete o ganho real de material, uma vez que apenas as sequências de elementos que contêm apoios são otimizadas, não constituindo portanto a estrutura como um todo.

A exemplo do teste anterior, diversos conjuntos de valores iniciais para as variáveis de projeto foram arbitrados, obtendo-se para todos estes os mesmos resultados finais.

A estrutura a seguir analisada é constituída por uma laje quadrada com elementos no contorno, apoiada sobre oito pilares, conforme figura (15). A carga distribuída sobre a laje é de $10,0 \mathrm{kN} / \mathrm{m}^{2}$. Considera-se ainda o peso-próprio dos elementos, os quais possuem seção transversal 20 x $50 \mathrm{~cm}$. Os módulos de elasticidade adotados foram $\mathrm{E}=.322 \times 10^{8} \mathrm{kN} / \mathrm{m}^{2} \mathrm{e} \mathrm{G}=.134 \times 10^{8} \mathrm{kN} / \mathrm{m}^{2}$.

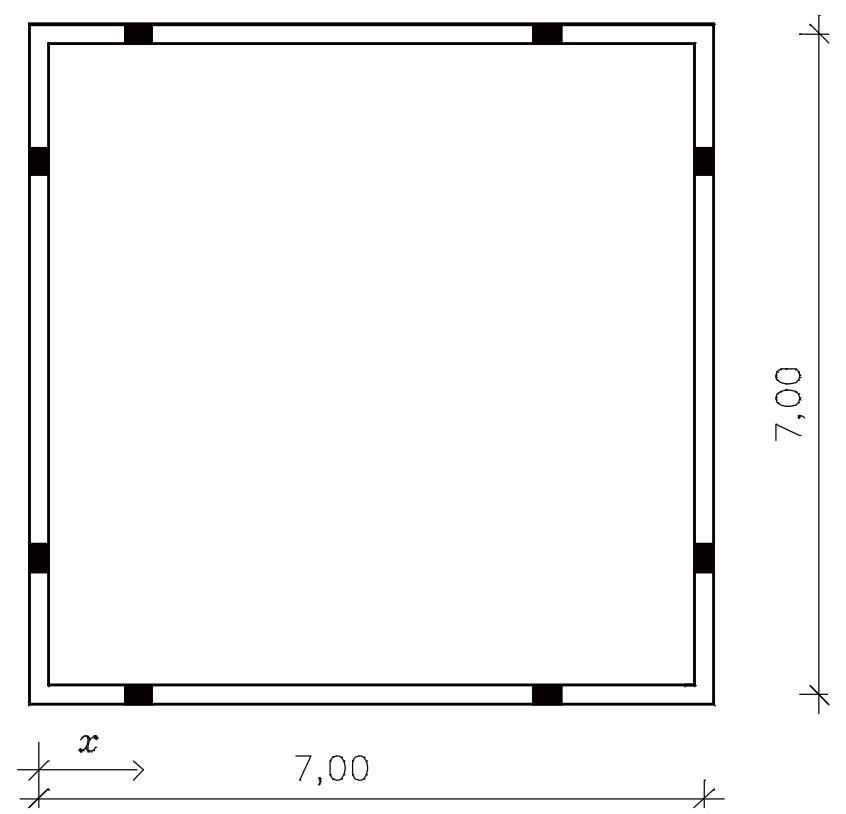

FIGURA (15) - Teste 3: croquis (em metros) 
Na tabela (13) designa-se por caso A a situação ótima. Em função da dupla simetria, a exemplo do teste 2 , indica-se na tabela resultados relativos a apenas um dos apoios. Pelo fato da disposição dos apoios nos extremos como efetuado nos exemplos anteriores alterar o número de apoios, não foi considerada esta situação para efeito de comparação de esforços na grelha, uma vez que poderia conduzir a resultados irreais quando da análise da estrutura como um todo. Pretende-se com esta tabela, a partir da consideração de que os apoios nem sempre podem ser dispostos nas posições consideradas ótimas, devido a aberturas e outras limitações ao livre movimento, representar nos caso B e C, respectivamente, deslocamentos dos apoios em 1 por cento no sentido do centro e das extremidades de cada sequência de elementos. Verifica-se que estas alterações a partir das posições ótimas, ainda que praticamente desprezíveis em relação ao comprimento total de cada sequência (deslocamentos de 7 centímetros), apresentam acréscimos significativos nos esforços.

TABELA (13)- Teste 3: situações ótima e próximas da ótima

\begin{tabular}{|c|c|c|c|c|}
\hline Caso & $\mathrm{x}(\mathrm{m})$ & $\begin{array}{c}\mathrm{Mmax}^{(+)} \\
(\mathrm{kN} . \mathrm{m})\end{array}$ & $\begin{array}{c}\mathrm{Mmax}^{(-)} \\
(\mathrm{kN} . \mathrm{m})\end{array}$ & $\begin{array}{c}\mathrm{Mmax} \\
/ \operatorname{Mmax}(\mathrm{A})\end{array}$ \\
\hline $\mathrm{A}$ & 1,45 & 19,70 & 19,70 & 1,000 \\
\hline $\mathrm{B}$ & 1,52 & 15,15 & 21,66 & 1,099 \\
\hline $\mathrm{C}$ & 1,38 & 24,28 & 17,85 & 1,232 \\
\hline
\end{tabular}

Para a grelha do teste 3, a exemplo das demais estruturas apresentadas, buscou-se a confirmação da existência de um mínimo global partindo-se de várias configurações iniciais. Ao contrário do esperado, porém, nem sempre havia a convergência da função penalizada para um mesmo valor. A partir do comportamento desta e de outras estruturas efetuou-se alguns estudos com o intuito de identificar as causas e, se possível, contornar os problemas decorrentes desta falta de unicidade de solução. 
4.4 Estudo do comportamento das funções para o modelo de viga

A análise da estrutura do teste 3 a partir de diversas soluções iniciais conduziu a resultados os quais acarretaram em distintas configurações finais. A imensa maioria destas configurações, além de não apresentar as esperadas características de dupla simetria, sequer atendia às restrições do problema. Como a caracterização de um ponto como sendo um mínimo local da função está condicionada ao atendimento das restrições, e uma vez que esta não se verificava para diversos conjuntos iniciais de variáveis de projeto, descartou-se a possibilidade de existência de mínimos locais.

Ainda com base na grelha do teste 3, observou-se que uma solução factível só poderia ser obtida caso o conjunto inicial das variáveis de projeto também atendesse às condições de dupla simetria. Pelas características de cada função isoladamente, a condição implica no atendimento a priori das restrições de igualdade entre momentos fletores negativos. Mais precisamente, o somatório do quadrado da diferença entre o momento fletor sobre um apoio e o momento sobre o apoio subsequente deve ser nulo. Desta forma, partindo-se da restrição de igualdade ativa, a mesma se manteria com valor igual a zero ou próximo de zero durante todo o processo de minimização. Consequentemente, foi suposto que a restrição de igualdade seria não-convexa, supondo-se o contrário tanto em relação a função objetivo como as funções de restrição.

De modo a verificar, ainda que de forma simplificada, a veracidade das hipóteses consideradas, procedeu-se inicialmente ao estudo de uma viga biapoiada, em função principalmente da maior facilidade tanto de desenvolvimento analítico das expressões como da visualização do comportamento das funções.

A viga estudada, representada na figura (16), possui vão total $\mathbf{L}$ igual a 10 metros, sendo submetida a um carregamento $\mathbf{p}$ uniformemente distribuído de 10,0 $\mathrm{kN} / \mathrm{m}$. A exemplo das demais vigas anteriormente consideradas, tem-se seção transversal constante ao longo da estrutura.

Com o objetivo de facultar o estudo das funções no plano, o apoio da direita foi fixado em seu ponto de ótimo, equivalente a 20,71 por cento do comprimento total da estrutura, conforme determinado no capítulo anterior (no caso, $\mathbf{x}_{\mathbf{2}}$ igual a 
2,071 metros). Assim, tem-se o problema original como função do posicionamento do apoio situado à esquerda, originalmente denominado por $\mathbf{x}_{\mathbf{1}}$ e no presente caso simplesmente por $\mathbf{x}$.

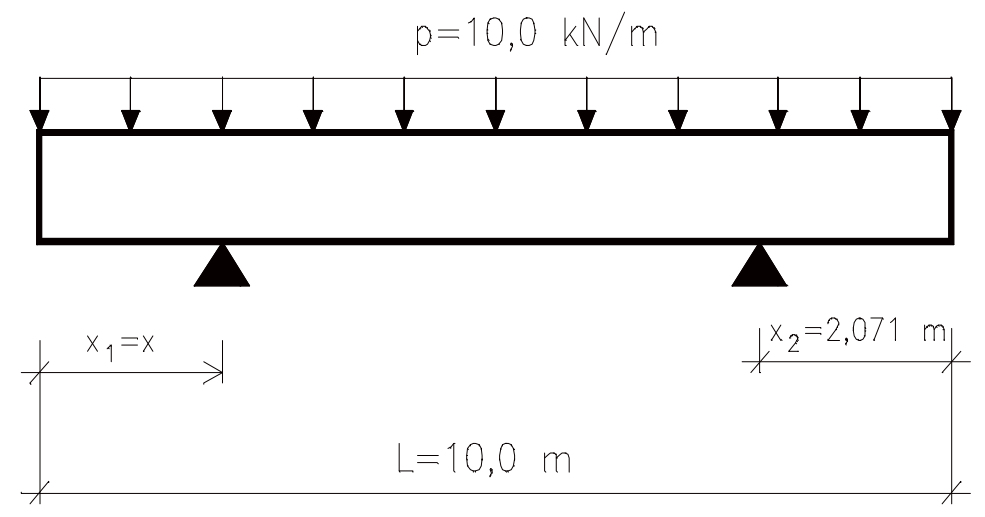

FIGURA (16) - viga biapoiada: convenções adotadas

Retomando a formulação adotada para o problema de otimização geométrica de vigas, descrita no sub-ítem (3.5.1) e a seguir reproduzida, tem-se como objetivo

$\min \sum_{\mathbf{i}=\mathbf{2}}^{\mathbf{N N O}-\mathbf{1}}\left[\mathbf{M}_{\mathbf{i}}^{(-)}\right]^{\mathbf{2}}$
s.a. $\quad \mathbf{h}_{\mathbf{1}}: \mathbf{M}_{\mathbf{j}+\mathbf{1}}^{(-)}-\mathbf{M}_{\mathbf{j}}^{(-)}=\mathbf{0}$
$\mathrm{j}=2, \mathrm{NNO}-2$
$g_{1}: M_{2}^{(+)}+M_{2}^{(-)} \leq 0$
$\mathrm{g}_{2}: \mathrm{M}_{\mathrm{NNO}-2}^{(+)}+\mathrm{M}_{\mathrm{NNO}-1}^{(-)} \leq 0$
$\mathbf{g}_{3}: M_{k}^{(-)} \leq \mathbf{0}$
$\mathrm{k}=2, \mathrm{NNO}-1$ 
A figura (17) representa de forma aproximada as curvas de isovalores traçadas apenas para a função objetivo. Efetuando-se um corte paralelo ao eixo $\mathbf{x}_{\mathbf{1}}$ correspondente ao posicionamento ótimo de $\mathbf{x}_{\mathbf{2}}$, chega-se ao gráfico (11), traçado tanto para a função penalizada como para a função objetivo e restrições, sendo que estas últimas aparecem também devidamente penalizadas. Devido as diferentes magnitudes dos valores das funções, representa-se no gráfico (12) as variações na função objetivo e na restrição de igualdade de momentos. Salvo indicação em contrário, tanto estes como os gráficos subsequentes consideram o coeficiente de penalização $\mathbf{r}$ igual a unidade (valor adotado para $\mathbf{r}$ inicial).

Salienta-se que a restrição $\mathbf{g}_{3}$, a qual determina que os momentos fletores sobre os apoios devem ser não-negativas, não consta dos gráficos, uma vez que esta condição é sempre atendida para vigas biapoiadas.

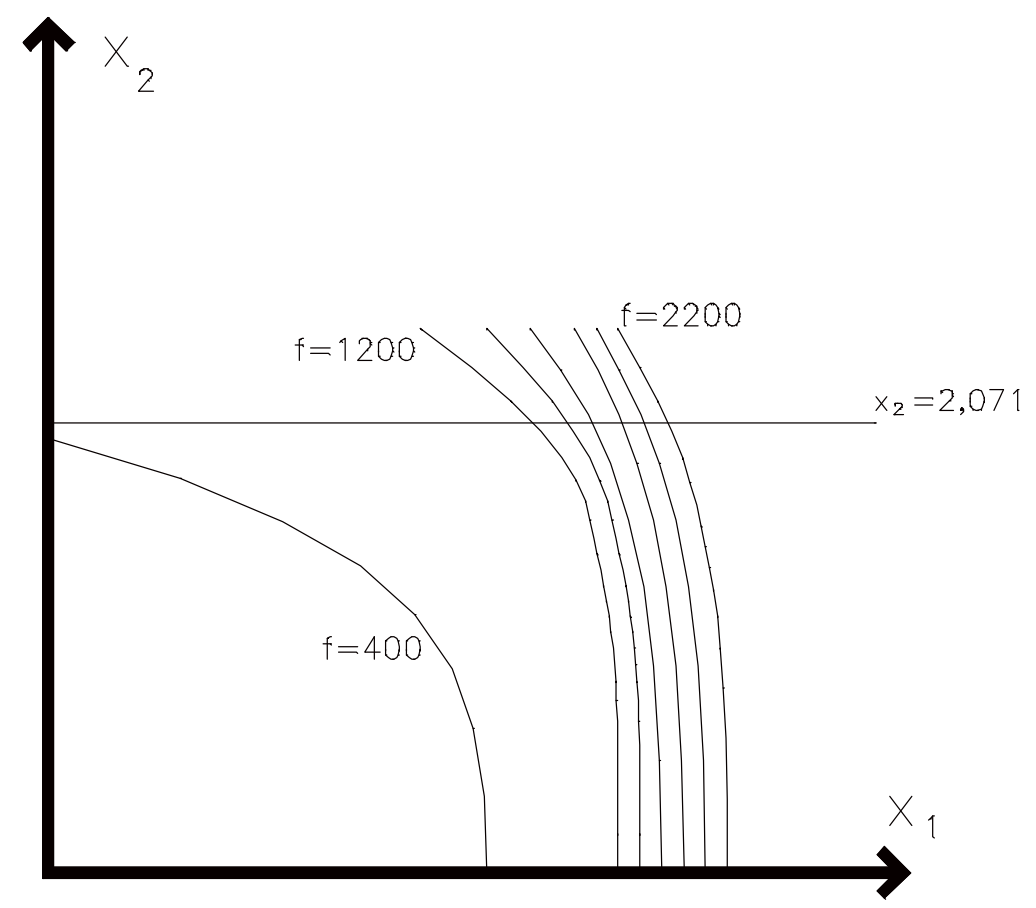

FIGURA (17)- viga biapoiada: isovalores para a função objetivo 


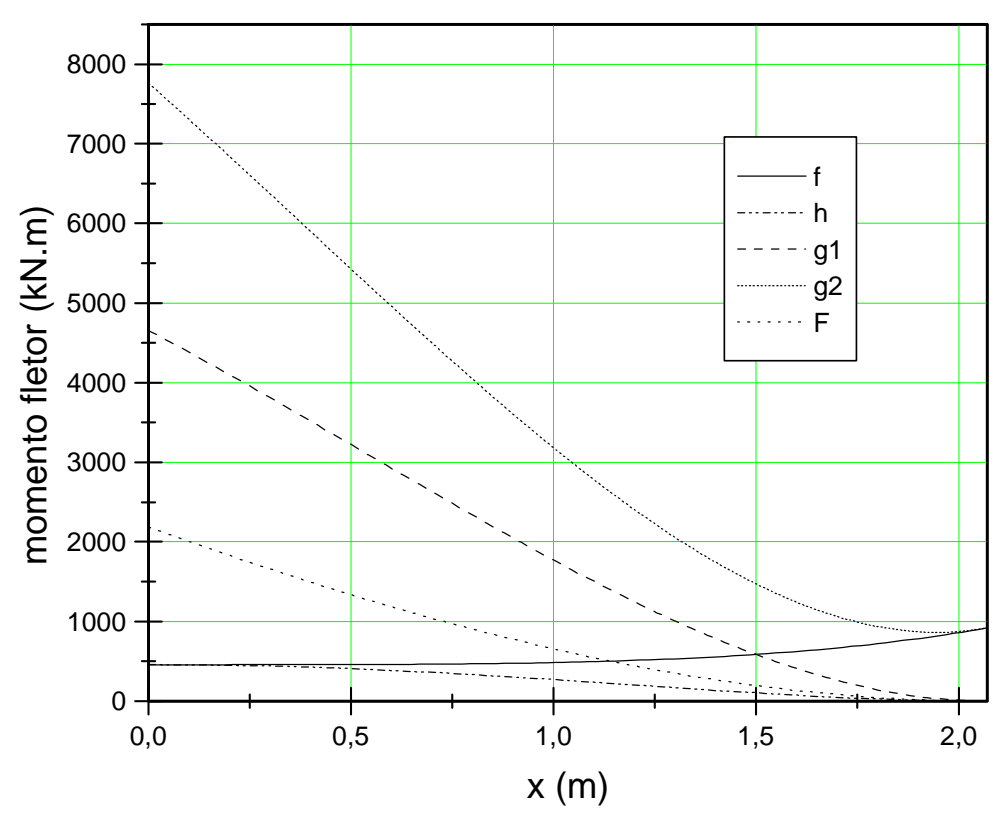

GRÁFICO (11) - valores das funções para $\mathbf{x}_{2}$ constante e igual a 2,071 m

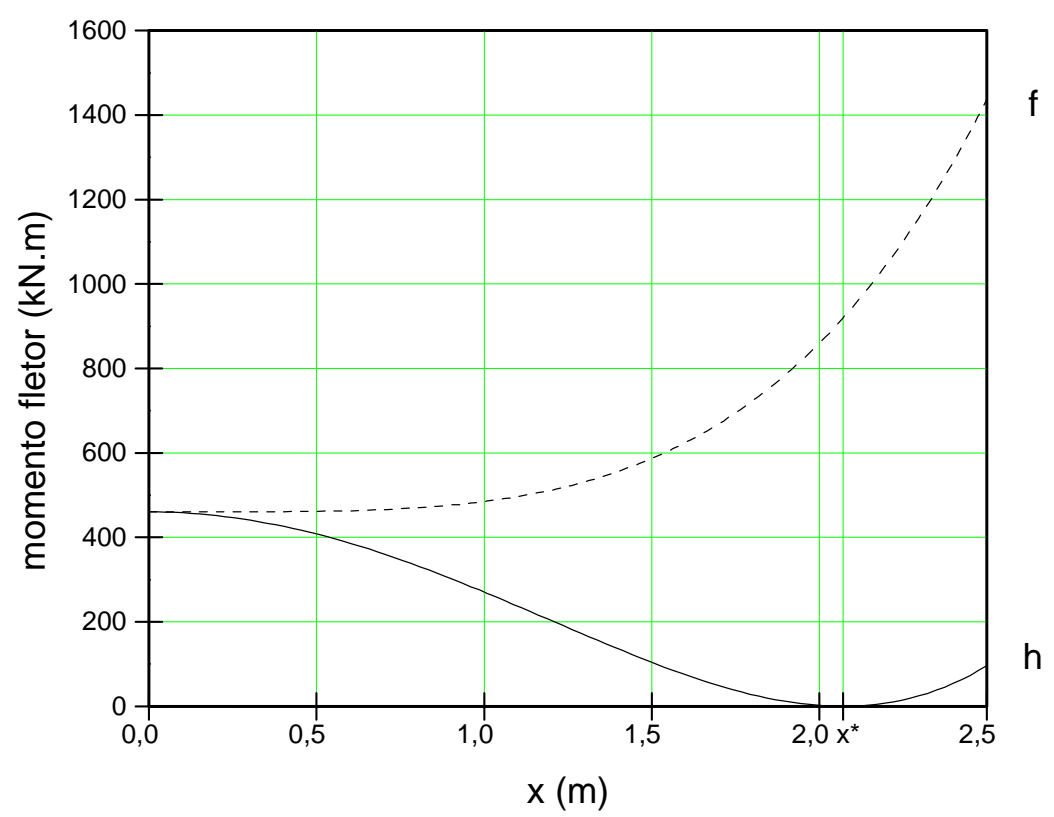

GRÁFICO (12) - detalhe: valores das funções objetivo e restrição de igualdade 
Como verificado no gráfico (11), e mais claramente no gráfico (12), de fato a restrição de igualdade não apresenta a característica de convexidade. Ao contrário do esperado, porém, a restrição de desigualdade $\mathbf{g}_{1}$ também não é convexa. Este comportamento acaba por se refletir nos valores assumidos pela função penalizada, uma vez que a convexidade desta última estaria garantida se (e somente se) resultasse da convexidade de cada uma das funções isoladamente.

Os gráficos (13) a (17), apresentados na sequência, representam os valores das primeiras e segundas derivadas de cada função. Como o exemplo analisado contém apenas uma variável, estas derivadas equivalem respectivamente ao gradiente e a hessiana da função. O conjunto de posições possíveis para a variável de projeto foram limitados nos gráficos pelos valores 0,00 e 2,071. Respectivamente, apoio situado na extremidade esquerda da estrutura e apoio posicionado no ponto de ótimo.

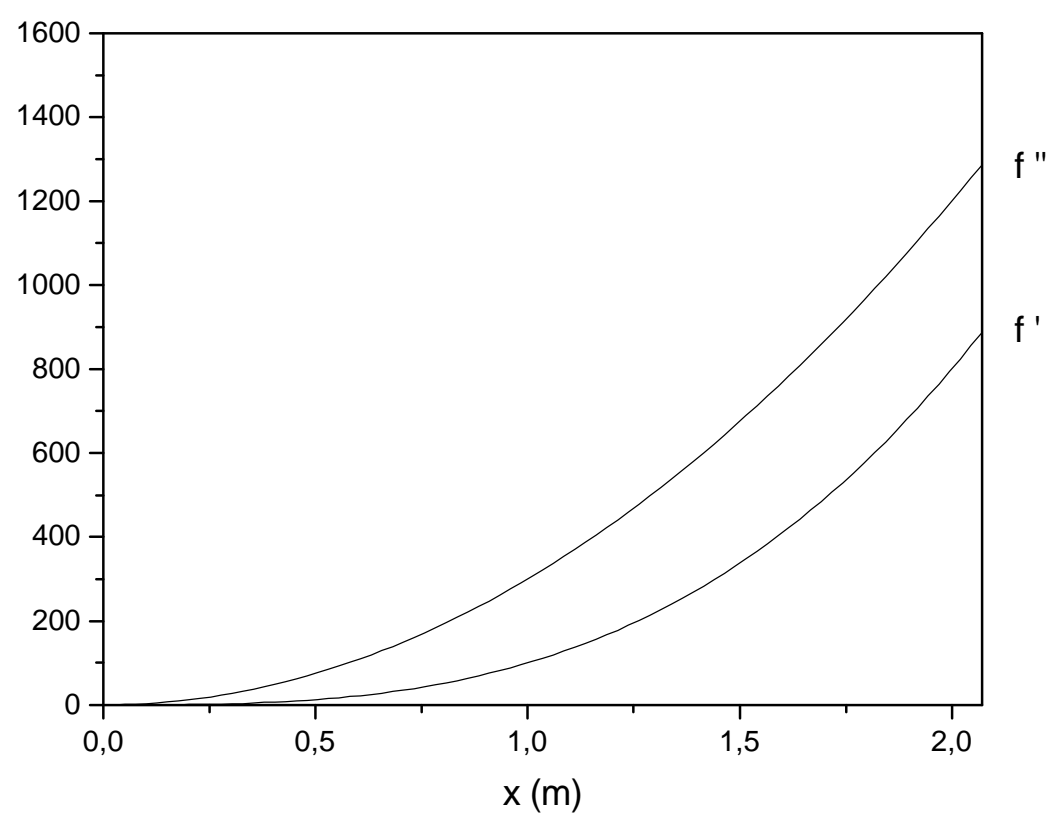

GRÁFICO (13) - função objetivo: derivadas 


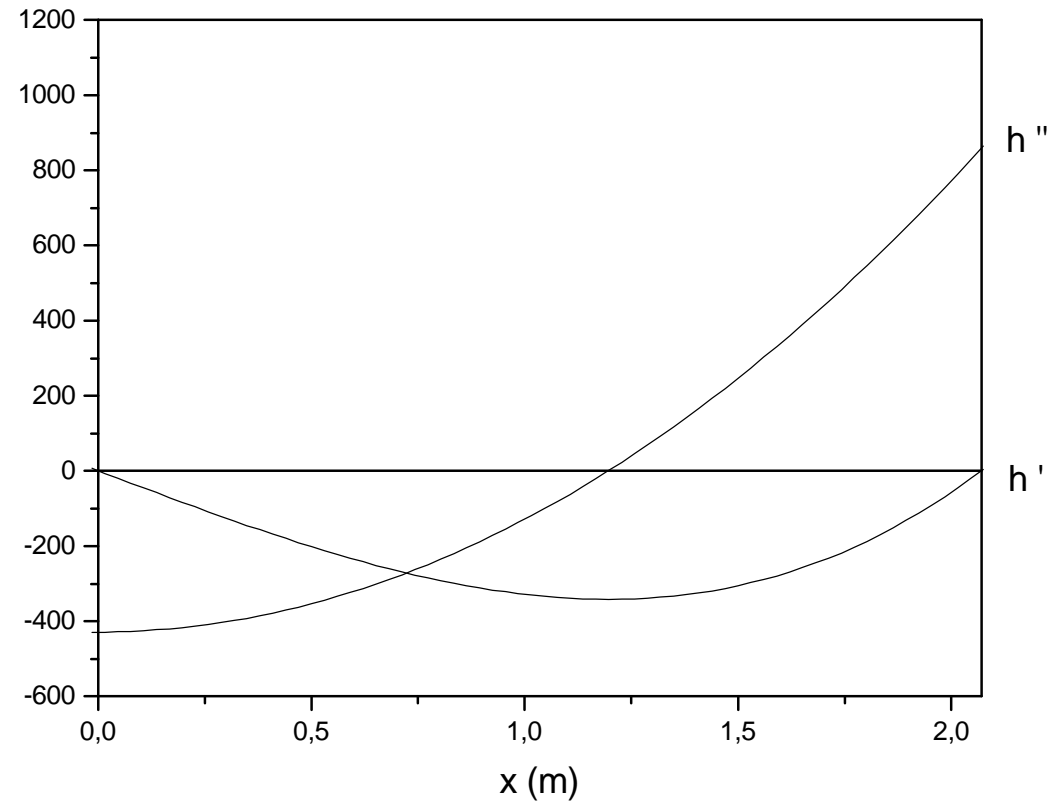

GRÁFICO (14) - restrição de igualdade: derivadas

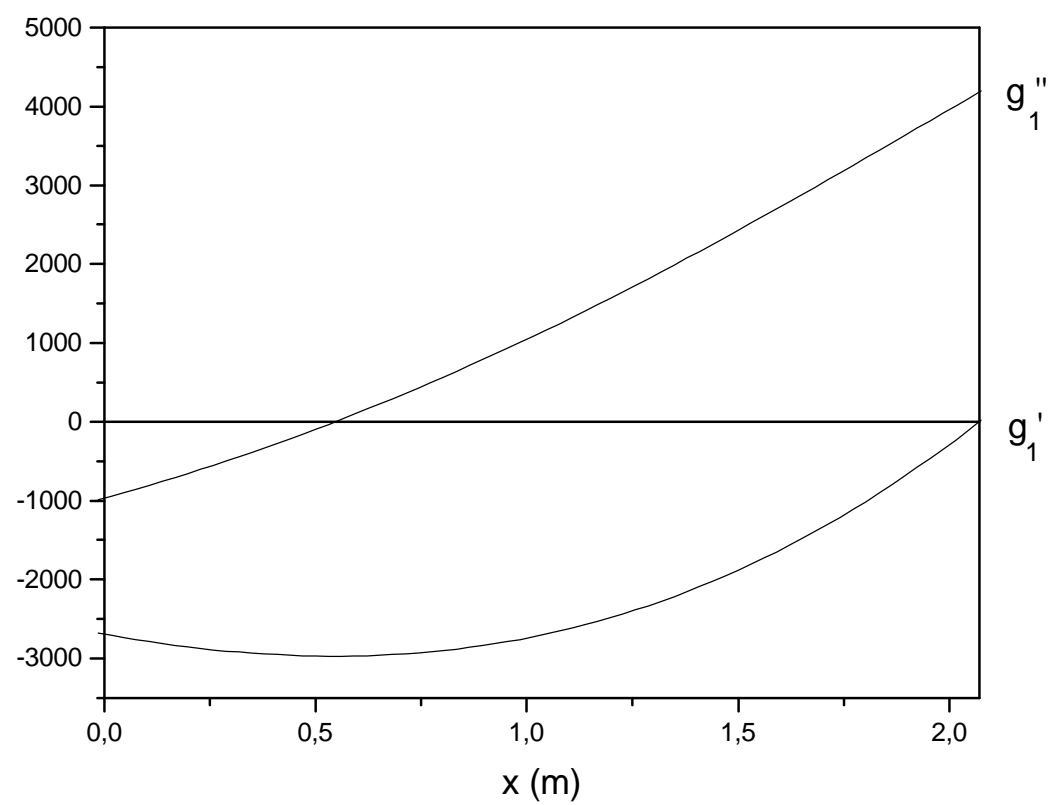

GRÁFICO (15) - restrição de desigualdade $\mathbf{g}_{\mathbf{1}}$ : derivadas 


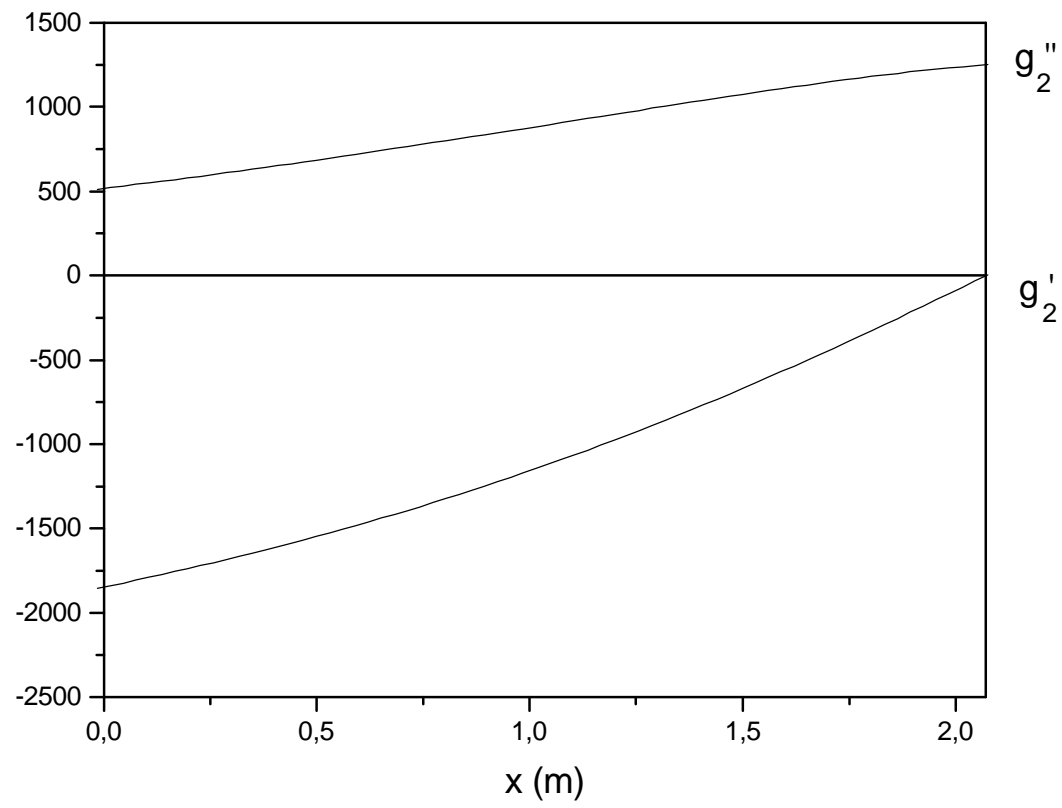

GRÁFICO (16) - restrição de desigualdade g 2: derivadas

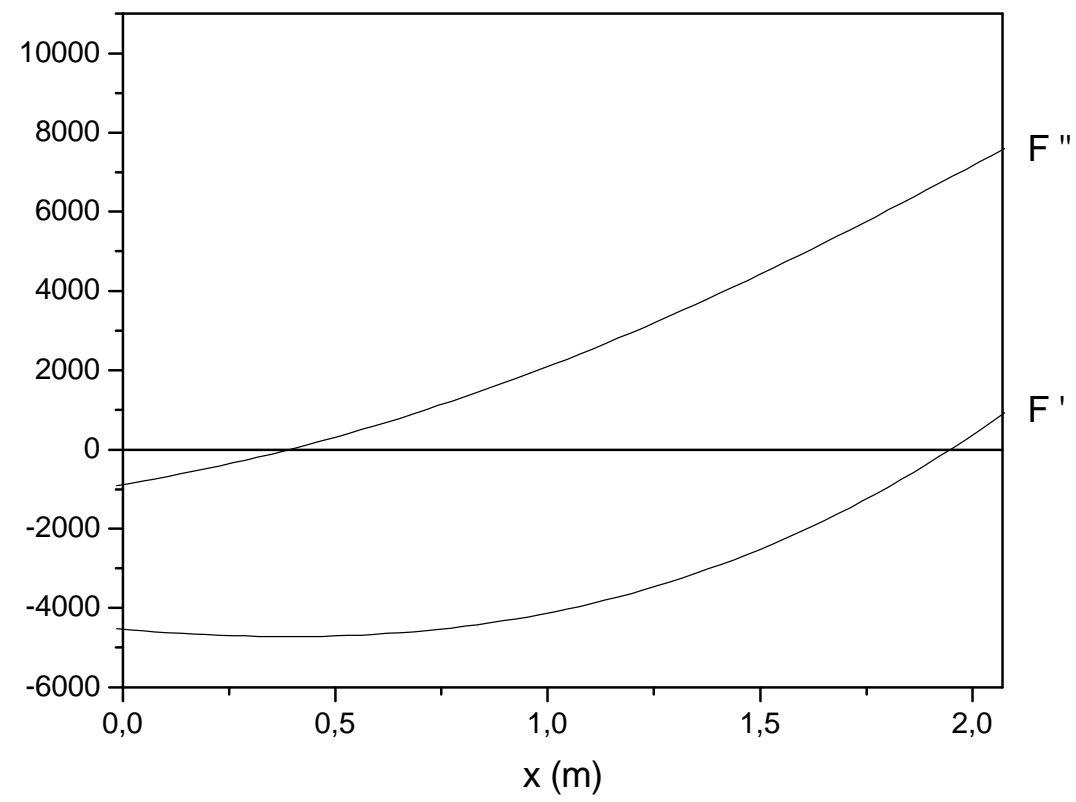

GRÁFICO (17) - função penalizada: derivadas 
Pela análise dos gráficos anteriores, algumas observações podem ser efetuadas, quais sejam:

-O fato da matriz Hessiana ser definida positiva implica na convexidade da função. Desta forma, o ponto de segunda derivada nula, ou hessiana não-definida, indica a mudança na forma da função, a qual passa a ser côncava à esquerda deste ponto. Tem-se então verificada a convexidade da função objetivo e da restrição $\mathbf{g} \mathbf{2}$. Já a restrição de igualdade é a que possui menor trecho convexo, comparativamente às demais, com ponto de inversão da curvatura situado a aproximadamente 1,196 metros da extremidade esquerda da estrutura;

-Os pontos nos quais a primeira derivada é nula indicam valores extremos assumidos pela função correspondente. Pela análise dos gráficos relativos tanto a cada função isoladamente como a função penalizada, observa-se a existência de um único ponto de mínimo (mínimo global). Apenas para a função objetivo este ponto não coincide com o ponto de ótimo;

-Mesmo para as funções que não apresentam característica de convexidade, observa-se que a esquerda do ponto de ótimo as primeiras derivadas, ou gradientes, são negativos. Como o gradiente indica o sentido de crescimento da função estes valores negativos permitem supor que, ainda que o apoio esteja situado em uma posição na qual a função seja não-convexa, ao se optar por uma direção de busca oposta à do gradiente (critério adotado pelo Método do Gradiente) esta direção seja efetivamente de descida;

-As direções fornecidas pela consideração das informações oriundas da observação do gradiente da função são de fato direções de descida, porém nada se poderia afirmar no trecho à esquerda do ponto de inflexão. À direita deste ponto, no entanto, a hessiana definida positiva assegura a direção de descida como uma direção de mínimo;

Em resumo, o fato da função não ser estritamente convexa não impede a existência de uma única solução factível (mínimo global). Esta solução, como destacado para o estudo de vigas, vinha efetivamente sendo obtida, fato comprovado 
pelo grande número de análises efetuado para uma mesma estrutura, considerando-se diversas combinações de valores iniciais para as variáveis de projeto.

Desta forma, em razão das observações efetuadas, concluiu-se que, dentre as funções do exemplo, as funções não-convexas podem ser caracterizadas como Quasiconvexas, ou mais exatamente como estritamente Quasi-convexas, conforme ilustrado na figura (18).

Segundo BAZARAA \& SHETTY (1979), define-se uma função Quasiconvexa como sendo aquela para qual, dados dois pontos quaisquer sobre a curva que define a função e unindo-os por um segmento de reta, qualquer valor obtido para um ponto contido sobre este segmento é menor ou igual ao maior valor da função em um destes dois pontos. Por definição,

seja $\boldsymbol{f}: \mathbf{S} \rightarrow \mathbf{R}$, onde $\mathbf{S}$ representa um conjunto convexo não-vazio em $\mathbf{R}_{\mathbf{n}}$. A função $\boldsymbol{f}$ é dita Quasi-convexa se, para qualquer $\mathbf{x}_{\mathbf{1}}$ e $\mathbf{x}_{\mathbf{2}} \in \mathbf{S}$, a seguinte desigualdade é válida:

$$
f\left[\lambda \mathbf{x}_{1}+(1-\lambda) \mathbf{x}_{2}\right] \leq \max \left\{f\left(\mathbf{x}_{1}\right), f\left(\mathbf{x}_{2}\right)\right\} \forall \lambda \in(0,1)
$$

Já uma função estritamente Quasi-convexa elimina a restrição de igualdade da equação anterior, ou seja, passa a existir a garantia de que um mínimo local é simultaneamente um mínimo global, confirmando desta forma as conclusões obtidas empiricamente. Em razão dos resultados obtidos a partir da análise de uma série de vigas, parte-se da suposição de que o comportamento verificado, bem como as observações decorrentes, podem ser estendidas para um número qualquer de apoios. 


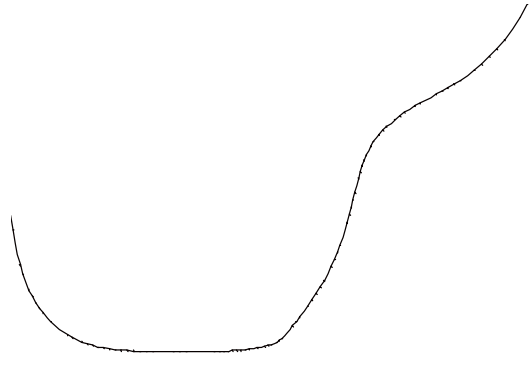

Quasi-convexa

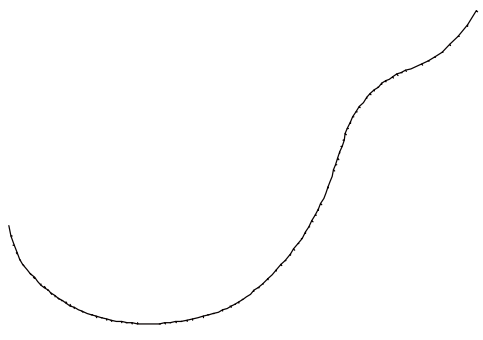

estritamente Quasi-convexa

FIGURA (18) - funções Quasi-convexas: representação geométrica

Em complemento às observações relativas à análise da viga em questão, verificou-se o comportamento dessa estrutura relativamente a forma de penalização empregada. De acordo com o gráfico (18) e, mais detalhadamente com o gráfico (19), nota-se que apesar da suavidade inicial da função penalizada, o fator de penalização $\gamma=3$, faz com que rapidamente se caminhe no sentido do ponto de ótimo, para o qual $\mathrm{x}=2,071$ metros. A título de observação, fica claro que a técnica de minimização sequencial de problemas sem restrição (SUMT), além possuir a grande vantagem de não necessitar de uma solução inicial factível, normalmente pode partir desta solução e sair dela, retornando às proximidades deste ponto ou dele pouco se afastando na medida em que o coeficiente de penalização é aumentado. $\mathrm{O}$ gráfico (20), relativo ao gradiente de cada uma das funções penalizadas, ajuda a visualizar este comportamento. Observa-se o ponto de ótimo obtido para cada coeficiente de penalização como sendo o ponto equivalente ao gradiente (primeira derivada) nulo, com um aumento na tangente da curva no ponto de ótimo, sendo que $\mathbf{r}$ tende ao infinito (tangente vertical). O ponto no qual as três curvas se interceptam corresponde ao atendimento a todas as restrições, ou seja, função objetivo idêntica à função penalizada. 


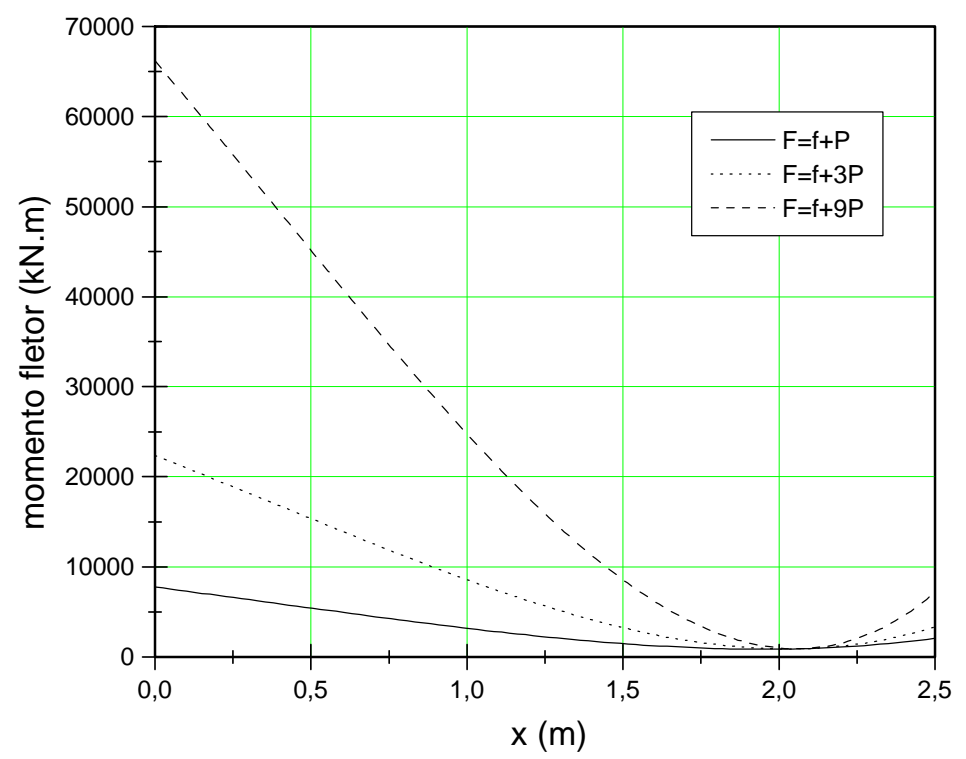

GRÁFICO (18) - Aumento da convexidade em função da penalização

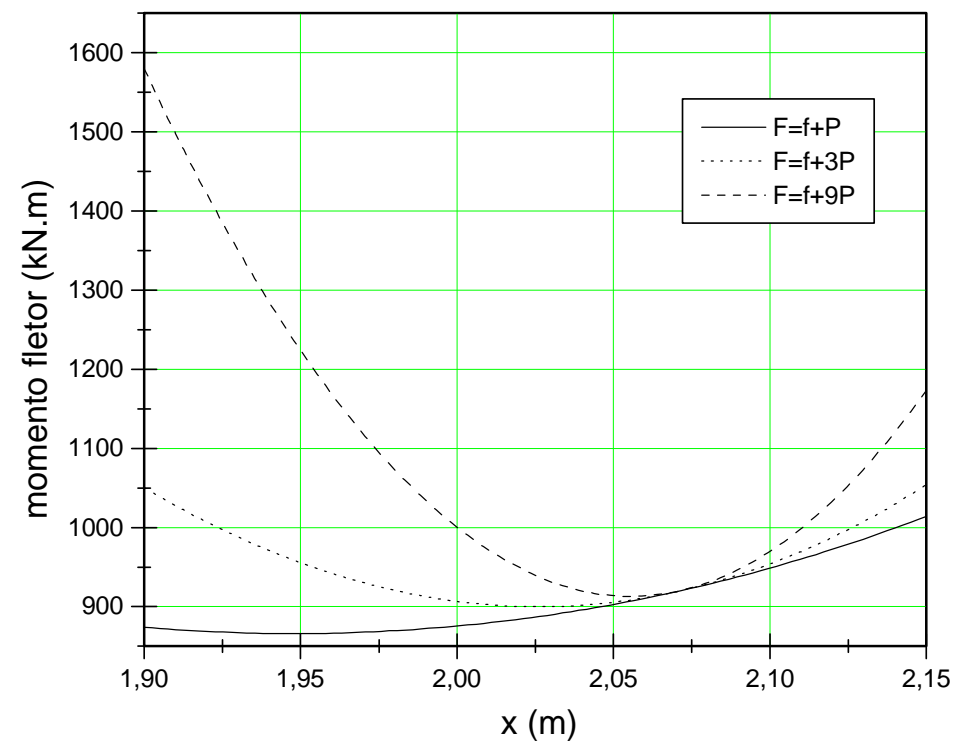

GRÁFICO (19) - Aumento da convexidade em função da penalização: detalhe 


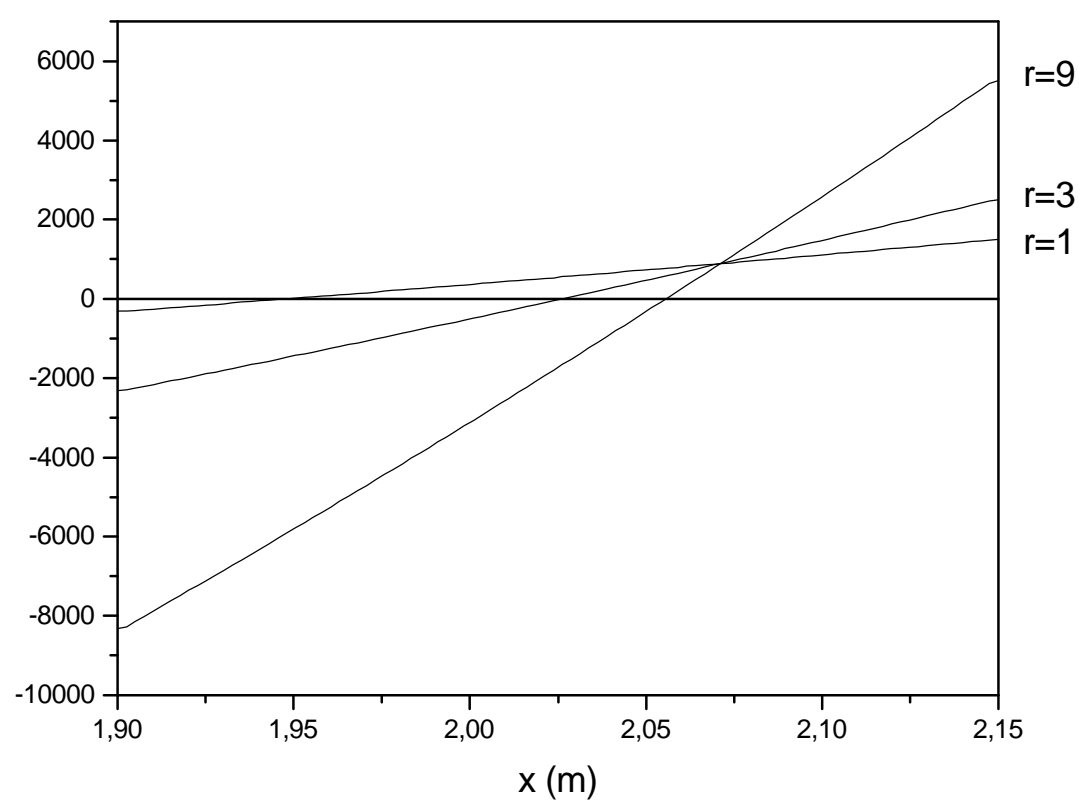

GRÁFICO (20) - Pontos de ótimo em função da penalização

Retomando o estudo de estruturas analisadas segundo o modelo de grelha, verifica-se que a maior complexidade da estrutura e da consequente visualização da interação entre os diferentes elementos tornam quase impraticável a descrição do comportamento das funções envolvidas. Portanto, embora se tenha obtido na prática resultados satisfatórios para os testes 1 e 2 apresentados no sub-ítem (4.3), apenas para as respectivas grelhas, ou para grelhas semelhantes a estas, obteve-se convergência para alguma solução factível. Como características gerais, estas estruturas apresentam tanto balanços nas extremidades das vigas componentes como apoios móveis dispostos apenas sobre vigas paralelas entre si.

Com o objetivo de tentar identificar alguma tendência de comportamento dos esforços na grelha do teste 3, apresenta-se a seguir valores obtidos a partir de um procedimento análogo ao efetuado na análise da viga anterior. A figura (19) representa parte da estrutura em questão, indicando a numeração adotada para os apoios considerados. 


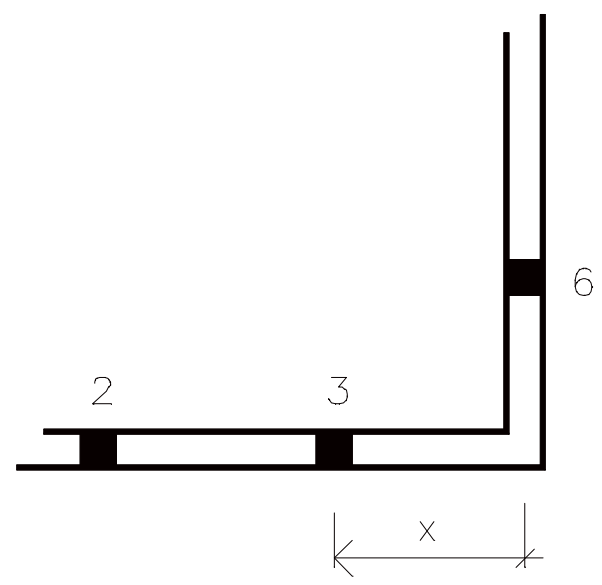

FIGURA (19) - Teste 3: detalhe - numeração dos nós

Os valores indicados na sequência referem-se à análise da estrutura tendo como variável apenas a posição do nó 3 , sendo todos os demais mantidos fixos na posição ótima determinada anteriormente, para a restrição de igualdade ativa. Como apenas quando a solução inicial atende à igualdade de momentos sobre os apoios é obtida a convergência, optou-se pela verificação dos valores assumidos pelos momentos fletores sobre os apoios mais próximos, sem desconsiderar porém o comportamento global da estrutura. A variação em módulo destes momentos em função da alteração na posição do apoio 3 é apresentada no gráfico (21), enquanto o gráfico (22) representa a variação na deflexão do nó de canto.

Pela situação representada no gráfico (21) fica evidente o ponto para o qual os momentos fletores sobre os apoios se equivalem, correspondendo portanto ao posicionamento ótimo dos apoios visto que a restrição de igualdade é ativa neste ponto.

A variação dos momentos fletores sobre os apoios 2 e 3 apresenta um comportamento esperado, já que a um aumento de $\mathbf{M}_{3}^{(-)}$corresponde uma redução, ainda que não diretamente proporcional, no valor de $\mathbf{M}_{2}^{(-)}$. Já $\mathbf{M}_{6}^{(-)}$sofre, respectivamente, redução e aumento em seu valor, variação diretamente relacionada à deflexão no ponto comum aos elementos que conectam os apoios 3 e 6 e que por consequência caracteriza a interação entre as sequências de elementos 
perpendiculares. Adicionalmente, observa-se que o valor mínimo assumido pelo momento no apoio 6 equivale no ponto ao momento $\mathbf{M}_{\mathbf{3}}^{(-)}$.

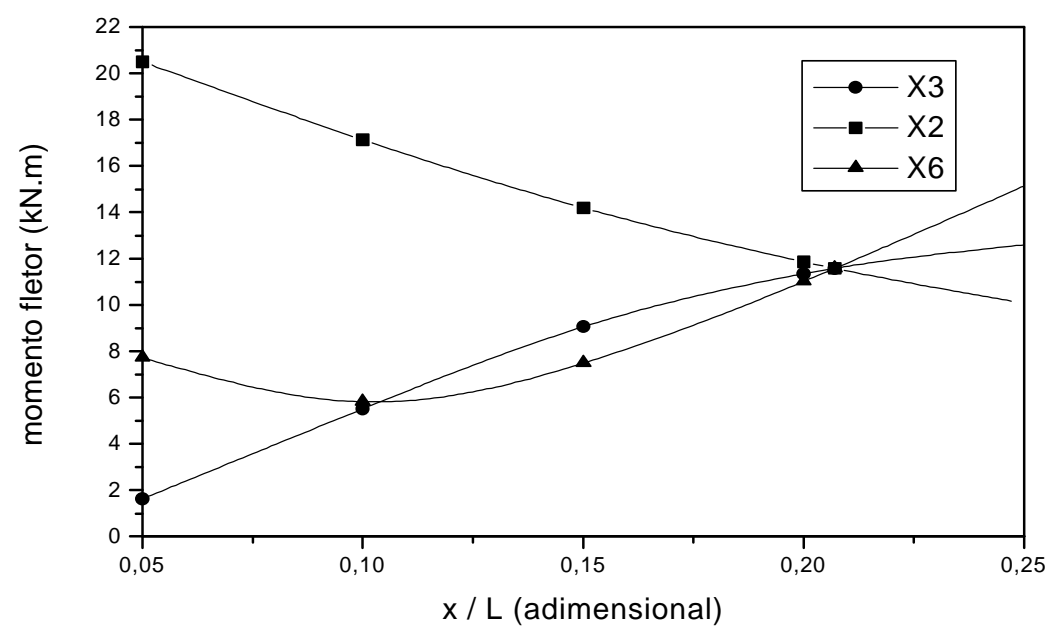

GRÁFICO (21) - Teste 3: variação dos momentos fletores próximos ao apoio 3

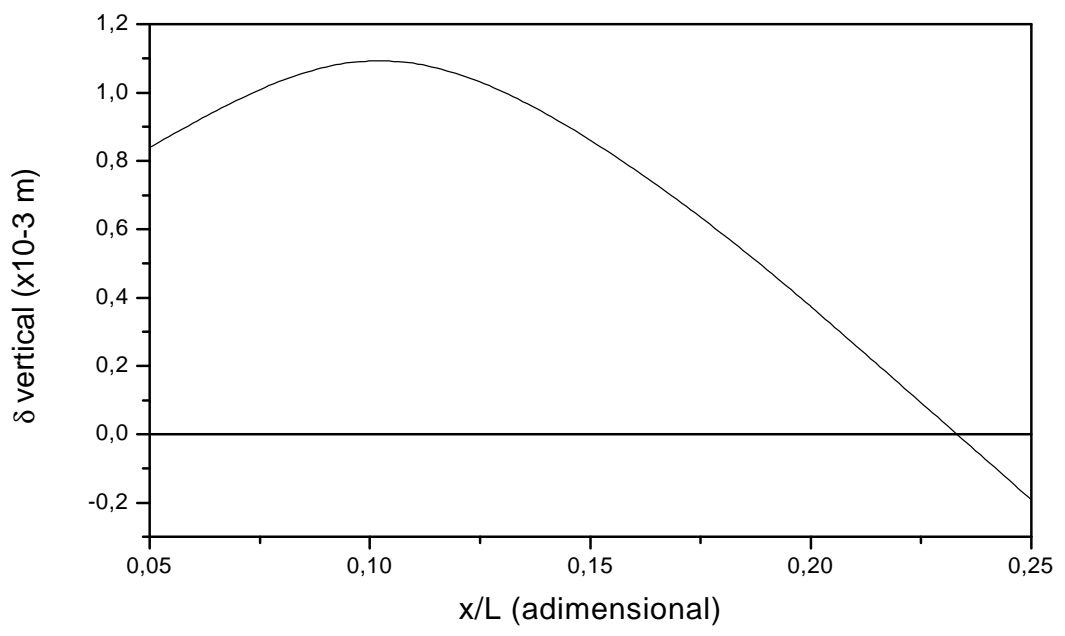

GRÁFICO (22) - Teste 3: variação da deflexão do nó de canto 
A grande diferença entre os modelos de viga e de grelha devido à interação, neste último, entre elementos com distintas orientações em relação a um referencial único, fornece fortes indícios da perda da quasi-convexidade da restrição de igualdade para grelhas com determinada geometria. Desta forma, as técnicas de otimização empregadas usualmente na resolução de problemas de programação nãolinear podem ainda ser aplicadas, porém sem qualquer garantia quanto ao resultado obtido ser efetivamente um minimizador .

Como fator complicador na análise, a numeração dos apoios em estruturas de viga segue uma sequência natural, usualmente iniciando pelo nó situado à esquerda dos demais e acarretando com isso na coincidência entre os sentido positivos dos eixos de referência local e global. Já para a formulação de grelhas optou-se por comparar os esforços nodais em função da sequência de numeração dos apoios na entrada de dados do programa. O gráfico (23) apresenta os valores da função objetivo e da função penalizada para uma dada sequência de numeração.

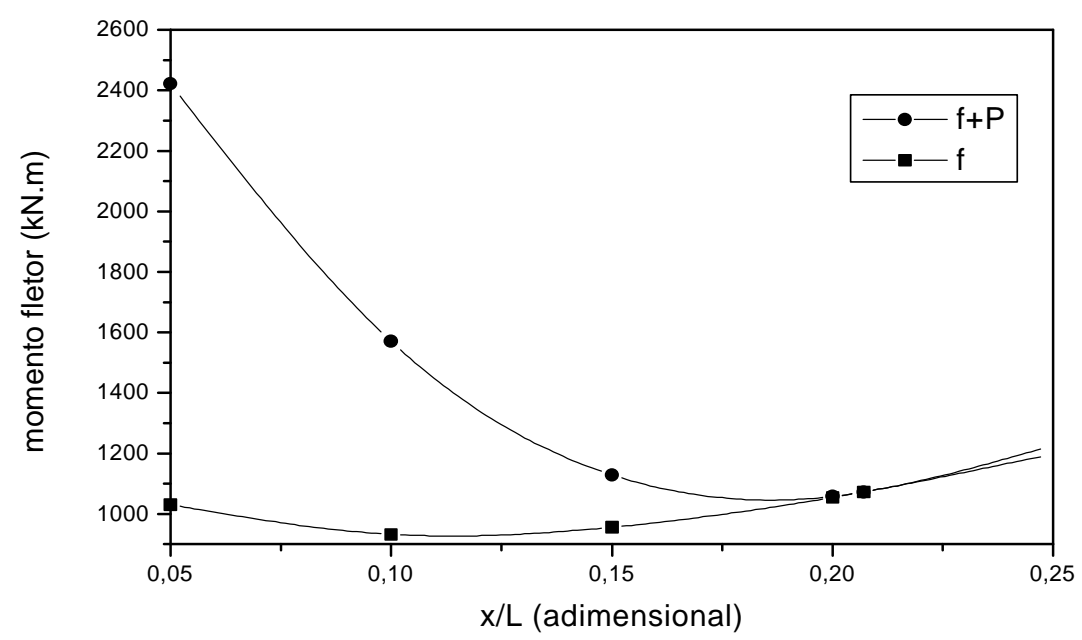

GRÁFICO (23) - Teste 3: valores da função objetivo e da função penalizada

Pela formulação do problema de grelhas verifica-se que tanto a função objetivo como as restrições de desigualdade independem dessa sequência. Já para a 
restrição de igualdade, porém, a cada sequência da numeração corresponderá provavelmente um novo valor inicial para a função penalizada.

4.5 Alternativas para o aperfeiçoamento da formulação aplicada a grelhas

\subsubsection{Introdução}

Em função dos valores obtidos a partir da análise tanto da estrutura do teste 3 como de outras com características similares, buscou-se alguns procedimentos que tanto permitissem a verificação das causas dos maus resultados alcançados como também uma forma de permitir a abrangência de uma maior diversidade de estruturas passíveis de análise.

Preliminarmente ao estudo de novas alternativas, intenso esforço foi feito com o intuito de se detectar falhas na implementação do problema ou mesmo má escolha de valores para os parâmetros envolvidos no problema. Quanto às estruturas analisadas, estas foram selecionadas de forma a impedir a ocorrência de um comportamento possível e não tão incomum, destacado por KIRSCH (1991). Segundo este, as condições impostas na formulação do problema podem acarretar na impossibilidade de atendimento às restrições, de modo que passe a não mais existir uma solução factível. Seria o caso, por exemplo, da grelha ilustrada na figura (20), para a qual se exige a igualdade de todos os momentos fletores negativos. Observa-se que, dependendo das dimensões relativas que venham a ser adotadas para as sequências de elementos, os momentos nos apoios situados sobre as sequências que contém apenas um apoio são impedidos de assumir valores iguais aos dos apoios das sequências nas quais estão contidos três apoios. Analogamente, pode-se gerar uma estrutura sem solução do ponto de vista da otimização geométrica nos casos em que a magnitude dos carregamentos varia de forma significativa para os diferentes elementos. 


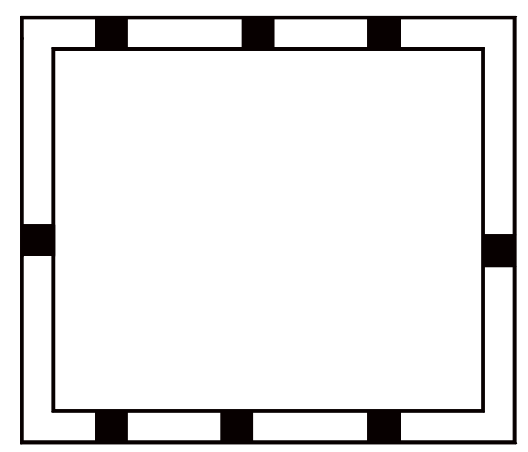

FIGURA (20) - Exemplo: estrutura sem solução factível

Dentre os estudos preliminares, destaca-se:

-verificação dos valores determinados analiticamente para os gradientes, bem como de sua correta implementação;

-alteração da tolerância definida como um dos critérios de parada. Também retomado o valor anteriormente adotado;

-verificação e posterior comprovação da unimodalidade da função, necessária para a correta utilização do Método da Seção Áurea para busca unidimensional (por unimodalidade entende-se a existência de um único ponto de mínimo no domínio, independendo da continuidade da função).

Devido à pouca ou nenhuma alteração nos resultados devido aos procedimentos descritos outros estudos foram necessários. Relaciona-se na sequência estes novos estudos, bem como as consequentes medidas tomadas.

4.5.2 Alterações dos parâmetros de penalização

Tendo em vista a importância fundamental tanto dos fatores como dos coeficientes de penalização quando da aplicação da Técnica de Minimização Sequencial de Problemas sem Restrições (SUMT), novo estudo de valores e 
combinação de valores foram feitos. As já esperadas alterações nos resultados foram verificadas, porém foi mantida a divergência da função.

Retomados os valores anteriores, procedeu-se a implementação, com pequenas modificações, no "scaling" das restrições, sugerido por VANDERPLAATS (1984a). Como alguma fase do processo iterativo normalmente é dominada por uma determinada restrição, devido à grande diferença entre os valores dos gradientes, procura-se compensar esta diferença pela adoção de fatores de penalização independentes para cada restrição, sendo estes relacionados ao gradiente da função objetivo.

Desta forma, ao invés de penalizar as funções de restrição com anteriormente descrito nas expressões (29) e (30), ou seja

$$
\Phi(\mathbf{X}, \mathbf{r})=\mathbf{F}(\mathbf{X})+\mathbf{r} \mathbf{P}(\mathbf{X})
$$

$\mathrm{e}$

$$
P(X)=\sum_{j=1}^{m}\left\{\max \left[0, g_{j}(X)\right]\right\}^{2}+\sum_{k=1}^{l}\left[h_{k}(X)\right]^{2}
$$

tem-se

$$
\mathbf{P}(X)=\sum_{j=1}^{m}\left\{\max \left[0, \mathbf{c}_{\mathbf{j}} \mathbf{g}_{\mathbf{j}}(\mathbf{X})\right]\right\}^{2}+\sum_{\mathbf{k}=1}^{l}\left[\mathbf{c}_{\mathbf{k}} \mathbf{h}_{\mathbf{k}}(\mathrm{X})\right]^{2}
$$

onde

$$
\mathbf{c}_{\mathbf{j}}=\frac{\left|\nabla \mathbf{F}\left(\mathbf{X}_{\mathbf{i}}\right)\right|}{\left|\nabla \mathbf{g}_{\mathbf{j}}\left(\mathbf{X}_{\mathbf{i}}\right)\right|}
$$




$$
\mathbf{c}_{\mathbf{k}}=\frac{\left|\nabla \mathbf{F}\left(\mathbf{X}_{\mathbf{i}}\right)\right|}{\left|\nabla \mathbf{h}_{\mathbf{k}}\left(\mathbf{X}_{\mathbf{i}}\right)\right|}
$$

sendo $\mathbf{c}_{\mathbf{j}}$ e $\mathbf{c}_{\mathbf{k}}$ os fatores de escala para cada restrição de desigualdade e igualdade, respectivamente, reavaliados a cada iteração $\mathbf{i}$.

Implementado este procedimento verificou-se que, somada à maior complexidade do código computacional, as alterações nos valores finais devido ao processo de "scaling" não apontaram nenhuma tendência de melhora destes valores. Concluiu-se desta forma pelo retorno ao processo originalmente empregado.

\subsubsection{Valores obtidos no cálculo da direção de descida}

Com a definição de uma formulação eficiente para a otimização de vigas, procedeu-se a um estudo visando a redução dos erros de aproximação. Ao se efetuar o processo de determinação da direção de descida pelo método proposto por Davidon, Fletcher e Powell, optou-se pela implementação deste em detrimento do Método de Newton, inicialmente utilizado. Esta troca, como descrito anteriormente, não acarretou em alterações significativas nos resultados, sendo porém de grande utilidade entre outros pelo fato de não necessitar do cálculo das segundas derivadas.

$\mathrm{Na}$ presente etapa do trabalho, o intuito foi o de verificar numericamente o não atendimento às condições que caracterizam um problema como tendo um minimizador. Assim, as segundas derivadas das funções foram calculadas analiticamente para o modelo de viga, e implementadas em substituição à rotina na qual é determinada sua aproximação a partir de informações de primeira ordem. Uma vez efetuada esta substituição, a verdadeira matriz Hessiana pode ser obtida para alguns exemplos e conjuntos iniciais de variáveis. Observou-se que em diversos casos o determinante da matriz Hessiana (bem com de seus menores principais) para a primeira iteração de fato não indicava uma matriz sequer definida semi-positiva, 
enquanto o Método DFP, ao tomar como primeiro valor para a aproximação da Hessiana a matriz identidade, indicava uma matriz logicamente definida positiva.

Adicionalmente, para estruturas que apresentavam convergência para um ponto de mínimo, verificou-se para o Método DFP um aparente bom condicionamento ao longo do processo iterativo, bem como para a matriz obtida ao final do processo. Ainda assim, optou-se pela reinicialização do cálculo da aproximação da Hessiana a cada $\mathbf{n}_{\mathbf{c c}} / 2$ iterações, e não mais a cada $\mathbf{n}_{\mathbf{c c}}$ iterações, como sugerido na literatura, visto que em estruturas de pavimentos o número de variáveis pode ser bastante significativo. Apesar de não demonstrar eficiência para a situação em estudo, foi posteriormente adotado apresentando bons resultados, uma vez que cada ciclo do processo iterativo dificilmente atingiria um número de iterações igual ao número de apoios.

Pelas características do problema, e ainda que apontando para resultados bastante distintos, nenhum dos métodos apresentou melhora nos resultados a ponto de indicar que as funções atuais pudessem ser mantidas. Como consequência, após a tentativa de se obter uma restrição de igualdade que mantivesse o mesmo objetivo da restrição inicialmente implementada, optou-se pela definição de uma nova restrição a qual acarretou na radical alteração das características inicialmente propostas porém demonstrando maior coerência em termos práticos.

4.6 Formulação adotada para o modelo de grelha

\subsubsection{Alteração na restrição de igualdade de momentos fletores}

Mantidas as demais funções da formulação adaptada diretamente do modelo de viga optou-se pela substituição da restrição de igualdade de momentos fletores nos apoios da estrutura, uma vez que para determinadas configurações da grelha a convergência somente seria obtida caso esta restrição fosse atendida a priori. De forma equivalente, uma vez que a restrição de igualdade fosse ativa para a solução inicial, a mesma se manteria ativa ao longo do processo iterativo, demonstrando-se portanto totalmente desnecessária. 
De modo a garantir a convergência para uma disposição ótima considerou-se válida a manutenção da restrição de igualdade porém com características similares às aplicadas à otimização para o modelo de viga. Ou seja, uma vez que a grelha é definida no programa segundo as sequências de elementos que a constitui, pode-se alterar a restrição de igualdade de momentos fletores sobre os apoios da estrutura objetivando-se agora a igualdade de momentos fletores apenas sobre os apoios de cada sequência de elementos isoladamente. Assim, a restrição de igualdade descrita pela expressão (68), qual seja

$$
\mathbf{h}_{1}: M_{\operatorname{NNR}(i+1)}^{(-)}-M_{\operatorname{NNR}(i)}^{(-)}=0
$$

passa a ser substituída por

$$
\begin{array}{ll}
\mathbf{h}_{\mathbf{1}}: \mathbf{M}_{\mathbf{j}, \mathbf{N N R}(\mathbf{i}+\mathbf{1})}^{(-)}-\mathbf{M}_{\mathbf{j}, \mathbf{N N R}(\mathbf{i})}^{(-)}=\mathbf{0} & \mathrm{j}=1, \mathrm{NV} \\
& \mathrm{i}=1, \operatorname{NELVIG}(\mathrm{j}-1)
\end{array}
$$

A mudança na restrição e em consequência na própria formulação do problema, ainda que não se considere seu reflexo na economia, acabou por gerar uma série de efeitos benéficos relativamente à formulação anterior, destacando-se na sequência os principais.

A análise de algumas grelhas como a ilustrada na figura (20) passa a permitir a obtenção de uma solução factível. Independente tanto da configuração como do carregamento da estrutura a igualdade de momentos fletores sobre os apoios de cada sequência de elementos de maneira individual torna-se possível. Adicionalmente, como a formulação do problema não prevê a seleção de grupos de sequências para os quais os momentos deveriam ser igualados, a restrição $\mathbf{h}$ anterior tenderia a igualar os esforços em elementos de seção transversal bastante distintos, acarretando possivelmente em resultados inteiramente opostos aos objetivos propostos pelo presente estudo. 
Ainda que não fosse originalmente o objetivo quando da imposição desta nova restrição, o número de equações passa a ser bastante reduzido, uma vez que apenas os momentos fletores em uma mesma sequência de elementos são comparados. Exemplificando, para a estrutura do teste 3 (oito apoios e quatro sequências de elementos, resultando em dois apoios por sequência), a restrição de igualdade anterior gerava oito restrições, enquanto a nova restrição reduz este número pela metade.

A exemplo das demais formulações propostas, e em especial por tratar-se desta a proposta como definitiva para os fins a que o presente estudo se propõe, testes diversos foram efetuados. Uma vez que o objetivo destes testes consistia basicamente na verificação da consistência da formulação e de sua correta implementação, optou-se em apresentá-los em capítulo a parte, já incluídos tanto o detalhamento como implementações adicionais, descritas a seguir.

\subsubsection{Demais implementações}

Com a finalidade de permitir de forma ainda que gradual a reprodução e consequente análise de estruturas correntes, foram adicionadas as programa tanto a possibilidade de consideração de apoios fixos como o impedimento à livre movimentação dos apoios no plano da estrutura (restrições canalizadas).

Como até o presente estágio do programa todos os apoios eram considerados móveis no plano da estrutura, foi facultada a inclusão de apoios fixos, de modo a permitir, entre outros, o posicionamento de apoios na interseção de elementos perpendiculares entre si. O número total de apoios passa a ser composto pelo somatório dos $\mathbf{n}_{\mathbf{c c}}$ apoios móveis e dos agora $\mathbf{n}_{\mathbf{a f}}$ apoios fixos. É importante destacar que estes apoios fixos não são incluídos na formulação do problema de otimização, e portanto a alteração nos respectivos esforços decorre somente da alteração na disposição dos demais apoios ao longo do processo.

Foi frisado anteriormente neste trabalho a existência de limitações, fundamentalmente de ordem arquitetônica, ao livre posicionamento dos apoios. Por ter sido constatado que mesmo pequenos deslocamentos dos apoios no plano da 
estrutura podem acarretar em significativa redistribuição dos esforços na grelha, incluiu-se na formulação restrições laterais de modo a limitar o deslocamento de cada variável a um determinado domínio. Desta forma, supondo que não exista liberdade total a nenhum dos apoios, são acrescidas duas restrições de desigualdade a cada apoio móvel.

Efetuadas as necessárias considerações, o problema de otimização geométrica de grelhas passa a ser descrito de acordo com a seguinte formulação:

$$
\min \sum_{\mathbf{i}=1}^{\mathbf{N e c}}\left[\mathbf{M}_{\mathrm{NNR}(\mathbf{i})}^{(-)}\right]^{2}
$$

s. a. $\quad \mathbf{g}_{1}: \mathbf{M}_{2, \mathbf{k}}^{(+)}+\mathbf{M}_{2, \mathbf{k}}^{(-)} \leq \mathbf{0} \quad \mathrm{k}=1, \mathrm{NV}$

$$
\begin{aligned}
& g_{2}: M_{\text {NELVIG(k)-2,k }}^{(+)}+M_{\text {NELVIG(k)-1,k }}^{(-)} \leq 0 \\
& g_{3}: M_{\text {NNR(i) }}^{(-)} \leq 0 \\
& h_{1}: M_{j, ~ N N R(i+1)}^{(-)}-M_{j, N N R(i)}^{(-)}=0 \quad j=1, N V
\end{aligned}
$$$$
\mathrm{i}=1, \operatorname{NELVIG}(\mathrm{j})-1 \ldots .
$$

$$
\begin{aligned}
& h_{2}: X_{\text {NNR(i) }}^{l}-X_{N N R(i)} \leq 0 \\
& h_{3}: X_{N N R(i)}-X_{\text {NNR(i) }}^{u} \leq 0
\end{aligned}
$$




\subsubsection{Descrição geral do programa}

Uma vez caracterizado o problema e efetuados os necessários testes decorrentes tanto da implementação como os relativos às técnicas empregadas, apresenta-se de forma sucinta a estrutura do programa desenvolvido. Representa-se na figura (21) as subrotinas chamadas pelo programa principal na sequência com que são acionadas, seguindo-se a descrição do papel destas e das demais subrotinas.

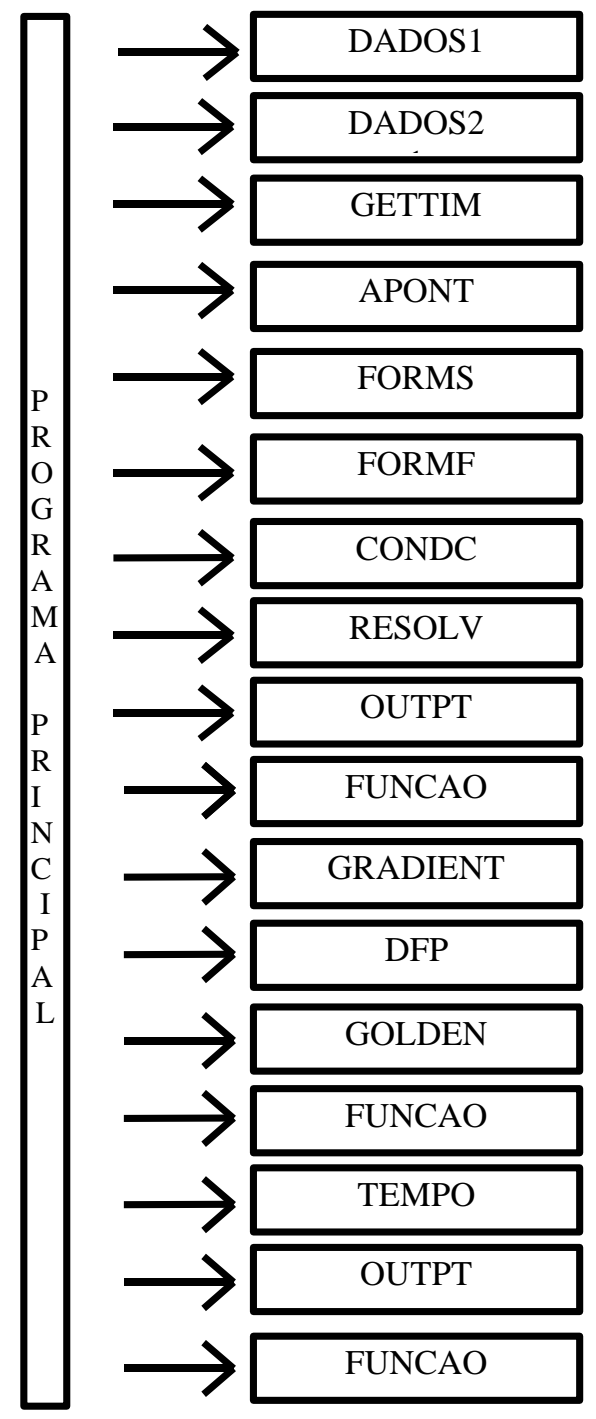

FIGURA (21) - Programa principal e subrotinas acionadas por este 
-Programa principal: além da inicialização de matrizes e definição de parâmetros, comanda o processo iterativo e efetua a verificação do atendimento aos critérios de parada. Efetua ainda a impressão dos valores iniciais das variáveis de projeto e dos resultados obtidos a cada iteração. Permite também, pela impressão a cada iteração do valor da função objetivo e da função penalizada, que estes sejam comparados de forma a validar o resultado final;

-Subrotina DADOS1: leitura e impressão das características da estrutura e dos elementos;

-Subrotina DADOS2: leitura e impressão dos dados relativos ao carregamento aplicado à cada sequência de elementos componente da estrutura;

-Subrotina GETTIM: integrante da biblioteca do compilador, é acionada pelo programa principal e pela subrotina TEMPO, indicando respectivamente horário inicial e final;

-Subrotina APONT: para armazenamento da matriz de rigidez da estrutura em um único vetor (técnica do perfil), indica em um vetor próprio (vetor apontador) a posição do coeficiente relativo à diagonal principal uma vez conhecida a conectividade dos elementos;

-Subrotina FORMS: processa a montagem da matriz de rigidez de cada elemento no referencial local (subrotina FORMS1) e gera o armazenamento dos respectivos coeficientes, já rotacionados para o referencial global pela subrotina ROTALG;

-Subrotina FORMF: montagem do vetor global de ações nodais. Como não se considera a existência de ações diretamente aplicadas aos nós, trabalha apenas com as ações nodais equivalentes (ações de engastamento perfeito), calculadas pela subrotina ACOESEP;

-Subrotina CONDC: introdução das condições do contorno pela técnica de um e zeros. Utilizada tanto para o posterior cálculo dos deslocamentos nodais como das derivadas dos deslocamentos (matriz Jacobiana);

-Subrotina RESOLV: resolução do sistema de equações lineares pelo Método de Cholesky. Calcula tanto os deslocamentos nodais como as derivadas dos deslocamentos; 
-Subrotina OUTPT: impressão dos deslocamentos, esforços e reações de apoio, tanto para a configuração inicial como para a final;

-Subrotina FUNÇÃO: determinação analítica do valor da função objetivo e das restrições. Acessada para cálculo dos valores iniciais, intermediários e finais (a partir do programa principal) e para o cálculo do tamanho do passo (subrotina GOLDEN);

-Subrotina RESTR: determina se uma sequência de elementos possui apoios móveis de modo a acelerar o processo de cálculo;

-Subrotina GRADIENT: determinação analítica da matriz Jacobiana. Os coeficientes relativos à rigidez dos elementos e das ações de engastamento perfeito são derivados diretamente, enquanto os coeficientes relativos aos deslocamentos são calculados pela subrotina DERIU;

-Subrotina DFP: cálculo da aproximação da inversa da matriz Hessiana pelo Método DFP. Tanto para a primeira iteração como para uma iteração múltipla da metade do número de apoios deslocáveis, considera como aproximação a matriz identidade;

-Subrotina GOLDEN: efetua a busca unidimensional pelo Método da Seção Áurea. De modo a facilitar a determinação de um intervalo inicial para a busca, normaliza as direções de descida sendo que, uma vez calculado o tamanho do passo, restitui os valores iniciais;

-Subrotina TEMPO: em função dos dados fornecidos por GETTIM calcula o tempo total de processamento;

-Subrotina DERIU: chamada pela subrotina GRADIENT, determina os valores das derivadas dos deslocamentos. Procedimento análogo ao cálculo dos deslocamentos nodais, necessita a priori do cálculo da derivada dos coeficientes de rigidez (subrotina DKDX) e da derivada das ações nodais equivalentes (subrotina DP);

-Subrotinas ROTAGL e ROTALG: matrizes de transformação de eixos para os referenciais local e global, respectivamente. 


\section{EXEMPLOS}

\subsection{Edifício 1}

De modo a ilustrar algumas das potencialidades do procedimento de otimização geométrica de grelhas, apresenta-se neste capítulo alguns exemplos de pavimentos analisados segundo a formulação idealizada. A escolha destes exemplos foi feita basicamente com o intuito de destacar a efetiva economia obtida, sem desconsiderar porém a necessária compatibilização com o projeto arquitetônico. Com o objetivo de uniformizar os critérios para dimensionamento e detalhamento, estes foram efetuados com a utilização de um mesmo software, tendo sido adotado o sistema TQS, cedido pelo Departamento de Estruturas. Em relação aos diagramas de esforços que ilustram o presente capítulo, os mesmos foram traçados com o auxílio do sistema SALT, em desenvolvimento na UFRJ sob a responsabilidade do professor Humberto Lima Soriano.

A primeira estrutura apresentada consiste no teto-tipo de uma edificação fictícia com apoios apenas na periferia de cada pavimento, como ilustrado na figura (22). Todos os elementos lineares contidos no pavimento possuem área da seção transversal igual a 20x40 centímetros, estando submetidos a um carregamento uniformemente distribuído de intensidade igual a 45,0 kN/m. Os materiais estruturais considerados foram o concreto $\mathrm{C} 20$ e aço CA-50A. A rigidez à torção neste e no exemplo seguinte é desconsiderada, bem como a contribuição de rigidez das lajes.

Mantidas as características acima descritas, bem como as dimensões do pavimento, a estrutura foi inicialmente analisada com o número de apoios representado na figura (22), quais sejam sete apoios ao longo de cada segmento de elementos sendo dois destes posicionados nos extremos dos segmentos, constituindo um total de 24 apoios e 24 elementos. Segundo limitação da formulação, os apoios 
situados nos cantos são considerados fixos, enquanto aos demais é facultado o deslocamento no plano da estrutura. Estes últimos, denominados como apoios móveis, são dispostos inicialmente com espaçamento uniforme e igual a 3 metros.

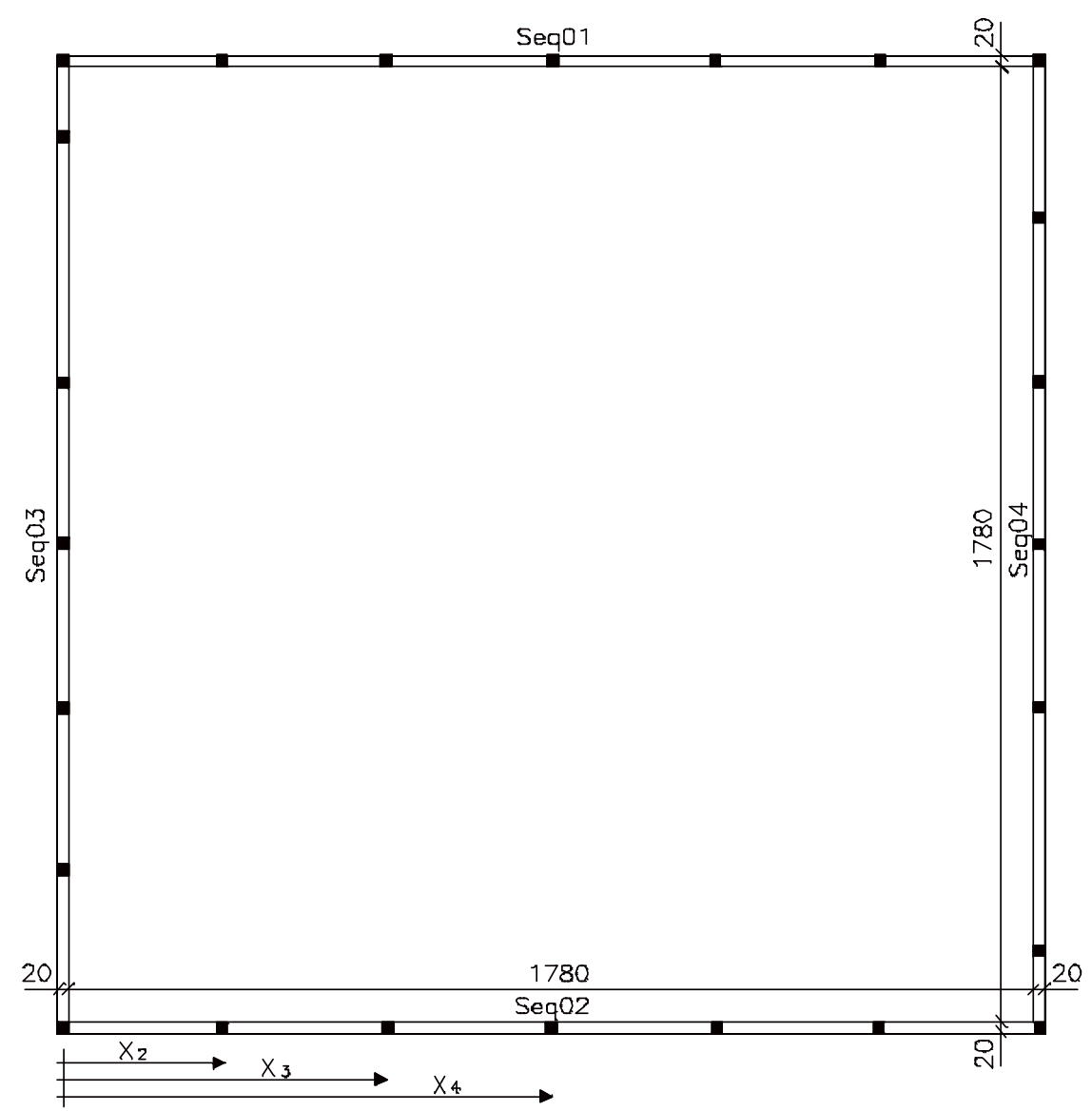

FIGURA (22) - Edifício 1: teto-tipo (em centímetros)

Em razão da dupla simetria da estrutura, apresenta-se na tabela (14), e na forma de diagramas na figura (23), os esforços cortante e de flexão relativos a uma das sequências de elementos, tanto para a situação inicial (designada por caso A) como para a configuração considerada ótima segundo a formulação utilizada no processo (caso B). Por concisão, na tabela são apresentados apenas os esforços extremos relativos a cada caso. Destaca-se ainda que, para efeito de análise, todos os 
apoios são considerados puntuais e indeslocáveis na direção perpendicular ao plano da grelha, desprezando-se ainda as rigidezes dos mesmos.

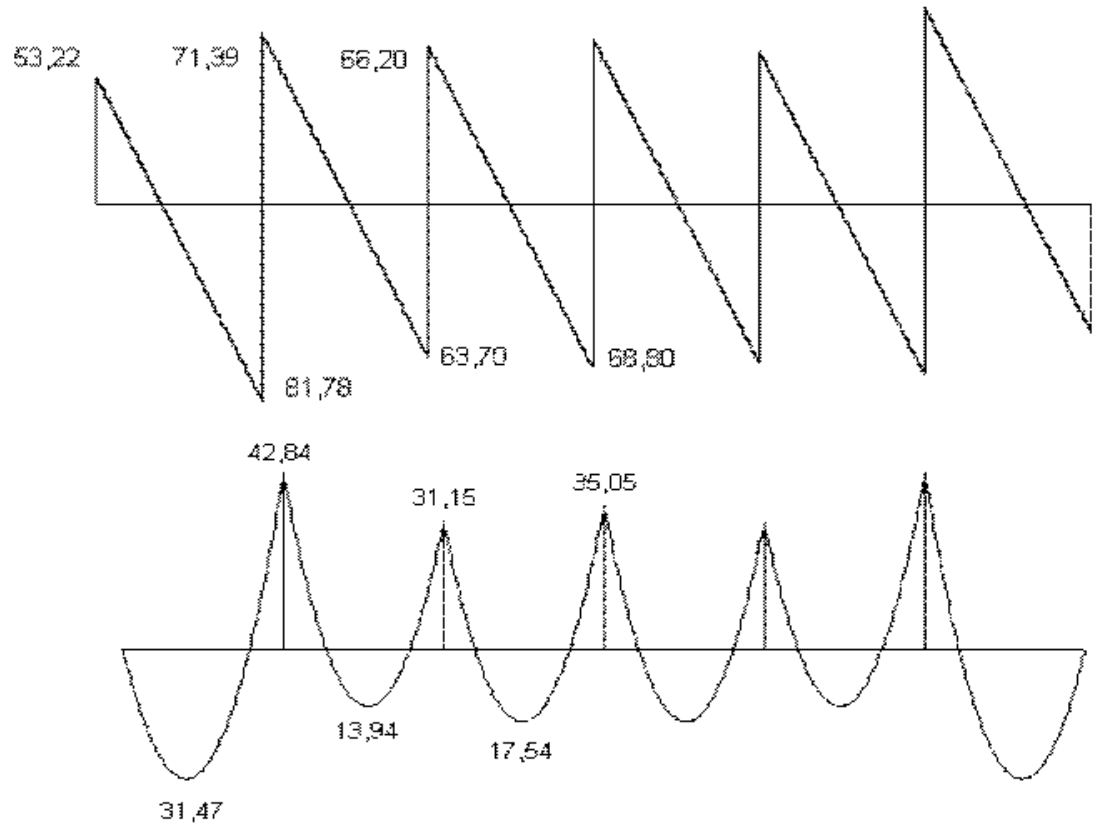

caso A: apoios equidistantes
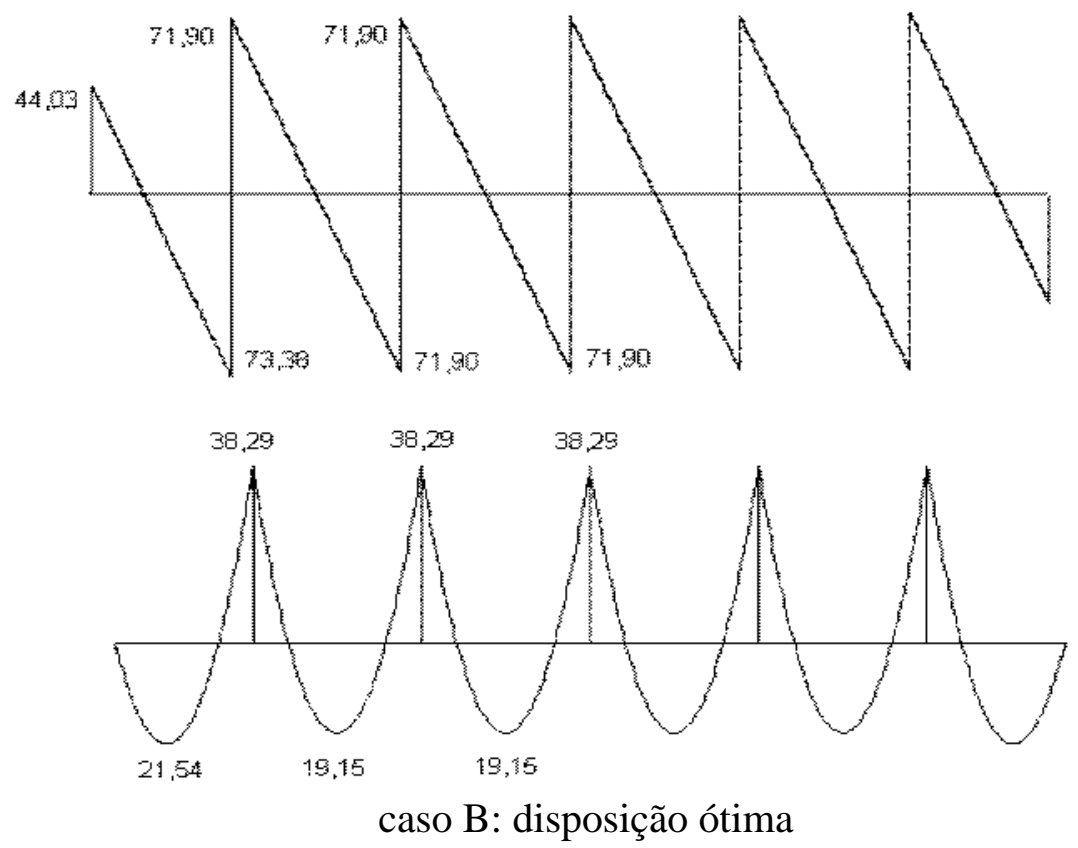

FIGURA (23) - diagramas de esforços 
TABELA (14) - posicionamento dos apoios e valores dos esforços

\begin{tabular}{|c|c|c|c|c|c|c|c|c|}
\hline caso & $\mathrm{x}_{2}(\mathrm{~m})$ & $\mathrm{x}_{3}(\mathrm{~m})$ & $\mathrm{x}_{4}(\mathrm{~m})$ & $\begin{array}{c}\mathrm{M}_{\max }^{(+)} \\
(\mathrm{kN} \cdot \mathrm{m})\end{array}$ & $\begin{array}{c}\mathrm{M}_{\max }^{(-)} \\
(\mathrm{kN} . \mathrm{m})\end{array}$ & $\begin{array}{c}\mathrm{M}_{\min }^{(+)} \\
(\mathrm{kN} . \mathrm{m})\end{array}$ & $\begin{array}{c}\mathrm{M}_{\min }{ }^{(-)} \\
(\mathrm{kN} \cdot \mathrm{m})\end{array}$ & $\begin{array}{c}\mathrm{V}_{\max } \\
(\mathrm{kN})\end{array}$ \\
\hline $\mathrm{A}$ & 3,000 & 6,000 & 9,000 & 31,47 & 42,84 & 13,94 & 31,15 & 81,78 \\
\hline $\mathrm{B}$ & 2,609 & 5,805 & 9,000 & 21,54 & 38,29 & 19,15 & 38,29 & 73,38 \\
\hline
\end{tabular}

Pela observação da figura (23), nota-se uma tendência nem tanto à redução, mas principalmente à uniformização dos momentos fletores. Como consequência têm-se também a uniformização dos esforços cortantes e das reações nos apoios. Pela manutenção dos apoios nos extremos, contudo, este comportamento não é obtido tanto para os apoios extremos como ao longo dos tramos imediatamente adjacentes.

Uma vez que efetivamente busca-se não apenas a redução dos esforços mas sim do consequente peso de aço, apresenta-se na tabela (15) o consumo total de armadura em termos absolutos e relativos no pavimento analisado.

TABELA (15) - consumo de armadura

\begin{tabular}{|c|c|c|}
\hline caso & Ps $(\mathrm{Kg})$ & Ps / Ps (A) \\
\hline A & 587 & 1,000 \\
\hline B & 571 & 0,978 \\
\hline
\end{tabular}

Observa-se que, devido ao caráter discreto das seções das barras de aço, a otimização dos esforços não é acompanhada por uma economia em peso equivalente. No entanto, a uniformização dos esforços acarreta em um ganho indireto, qual seja a maior padronização no corte das barras. Para a estrutura em questão representa-se nas tabelas (16) e (17) respectivamente antes e após a otimização, os comprimentos das barras resultantes do detalhamento de um único segmento de elementos (ou seja, devido à dupla simetria, um quarto da armadura necessária). Verifica-se que, 
mantidos os comprimentos fornecidos automaticamente pelo sistema TQS, o número de distintos comprimentos de barras para uma mesma bitola é reduzido de sete para quatro. Caso dois comprimentos semelhantes fossem uniformizados manualmente, certamente pelo maior valor, o consumo relativo de armadura representado na tabela (15) também sofreria alteração.

TABELA (16) - caso A: comprimento das barras para uma sequência de elementos

\begin{tabular}{|c|c|c|c|}
\hline bitola $(\mathrm{mm})$ & quantidade & comprimento unitário $(\mathrm{cm})$ & comprimento total $(\mathrm{cm})$ \\
\hline 12.5 & 4 & 781 & 3124 \\
12.5 & 2 & 272 & 554 \\
12.5 & 2 & 396 & 792 \\
12.5 & 1 & 278 & 278 \\
12.5 & 6 & 358 & 2148 \\
12.5 & 2 & 930 & 1860 \\
12.5 & 2 & 330 & 660 \\
8 & 102 & 127 & 12954 \\
\hline
\end{tabular}

TABELA (17) - caso B: comprimento das barras para uma sequência de elementos

\begin{tabular}{|c|c|c|c|}
\hline bitola $(\mathrm{mm})$ & quantidade & comprimento unitário $(\mathrm{cm})$ & comprimento total $(\mathrm{cm})$ \\
\hline 12.5 & 4 & 792 & 3168 \\
12.5 & 5 & 279 & 1395 \\
12.5 & 2 & 405 & 810 \\
12.5 & 4 & 957 & 3828 \\
8 & 100 & 127 & 12700 \\
\hline
\end{tabular}


O tempo utilizado pelo programa para a análise e otimização dessa estrutura pode ser considerado como pouco significativo, comparativamente aos eventuais benefícios gerados a partir de seus resultados. Para uma tolerância igual ou inferior a um décimo de milímetro (nada relevante em termos de engenharia), foram necessários 1 minuto e 21 segundos para as 58 iterações. Caso se alterasse a tolerância para 1 milímetro, o número de iterações se reduziria a 21, tomando um tempo de 32 segundos. Ou seja, além de não acarretar em redução relevante no tempo de processamento geraria uma maior perda de precisão nos resultados, uma vez que a diferença nas posições dos apoios na quarta casa decimal se reflete em uma alteração dos esforços na segunda casa decimal. Desta forma, importância secundária é dada ao tempo de processamento no presente trabalho.

Foi a seguir efetuada uma nova análise para o mesmo pavimento do edifício 1, mantendo-se as características anteriormente descritas porém com a variação no número de apoios. Com os apoios inicialmente dispostos de maneira equidistante, cada sequência de elementos foi então analisada com seis apoios (cinco tramos de 3,60 metros e total de 20 apoios). Para a nova situação designa-se por caso $\mathrm{C}$ a análise efetuada para apoios equidistantes e por caso D o posicionamento ótimo. A comparação dos esforços é apresentada na tabela (18), sendo o consumo de aço apresentado na tabela (19). Para a correta interpretação da tabela (18) ressalta-se que novamente, devido à dupla simetria, a numeração indicada tanto para nós como para elementos é efetuada da esquerda para a direita, referindo-se a uma única sequência de elementos.

TABELA (18) - pavimento com 20 apoios: posicionamento e valores dos esforços

\begin{tabular}{|c|c|c|c|c|c|c|c|}
\hline Caso & $\mathrm{x}_{2}(\mathrm{~m})$ & $\mathrm{x}_{3}(\mathrm{~m})$ & $\begin{array}{c}\mathrm{M}_{\max }^{(+)} \\
(\mathrm{kN} . \mathrm{m})\end{array}$ & $\begin{array}{c}\mathrm{M}_{\max }^{(-)} \\
(\mathrm{kN} . \mathrm{m})\end{array}$ & $\begin{array}{c}\mathrm{M}_{\min }^{(+)} \\
(\mathrm{kN} . \mathrm{m})\end{array}$ & $\begin{array}{c}\mathrm{M}_{\min }{ }^{(-)} \\
(\mathrm{kN} . \mathrm{m})\end{array}$ & $\begin{array}{c}\mathrm{V}_{\max } \\
(\mathrm{kN})\end{array}$ \\
\hline $\mathrm{C}$ & 3,600 & 7,200 & 45,44 & 61,39 & 19,39 & 46,04 & 98,05 \\
\hline $\mathrm{D}$ & 3,508 & 6,995 & 44,20 & 55,59 & 37,36 & 53,07 & 94,77 \\
\hline
\end{tabular}


TABELA (19) - pavimento com 20 apoios: consumo de armadura

\begin{tabular}{|c|c|c|}
\hline caso & Ps $(\mathrm{Kg})$ & Ps / Ps $(\mathrm{C})$ \\
\hline C & 747 & 1,000 \\
\hline D & 728 & 0,975 \\
\hline
\end{tabular}

Novamente é verificada uma economia praticamente desprezível apesar de, do ponto de vista da formulação empregada, as estruturas analisadas para o edifício 1 atenderem a todas as restrições impostas bem como, mais importante, fornecerem um mínimo estrito. A consideração de apoios fixos, porém, impossibilita tanto a igualdade de momentos fletores positivos como de reações nos apoios. Assim, efetuou-se a análise para o mesmo pavimento estudado, desta vez comparando-se a disposição inicial (caso A) aos valores ótimos fornecidos para um mesmo número de apoios, porém sem apoios nos extremos, conforme indica a figura (24).

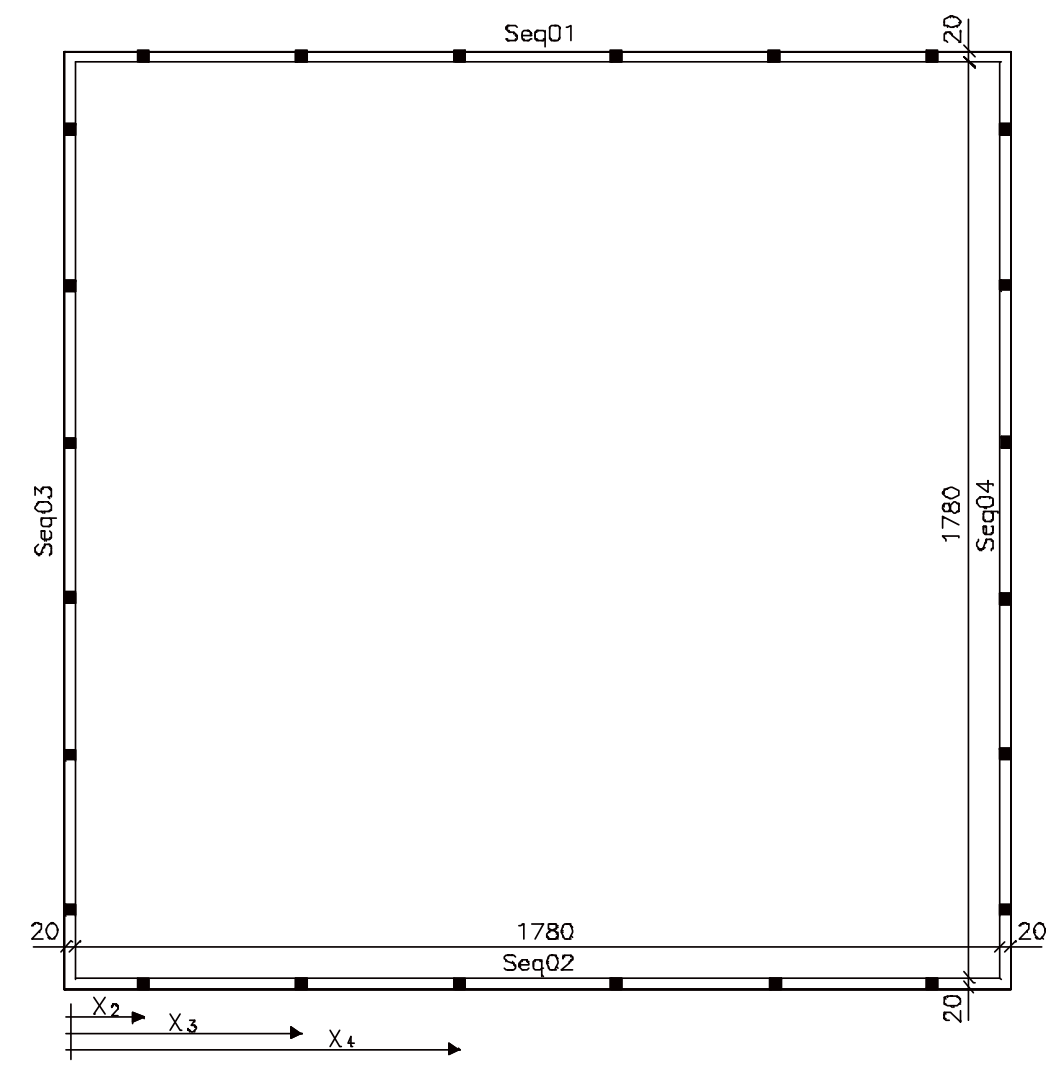

FIGURA (24) - Edifício 1: teto-tipo para estrutura sem apoios fixos (em centímetros) 
Salienta-se que, pela impossibilidade na geração automática de novos elementos, tomou-se como solução inicial para a obtenção desses valores uma disposição qualquer que já considerasse a inexistência de apoios nos cantos.

Analogamente à primeira análise, apresenta-se na tabela (20) os valores dos esforços e posicionamentos ótimos, obtidos para o pavimento constituído por 24 apoios e 24 elementos (caso E).

TABELA (20) - pavimento com 24 apoios: posicionamento e valores dos esforços (sem apoios na interseção das sequências de elementos)

\begin{tabular}{|c|c|c|c|c|c|c|c|c|}
\hline caso & $\mathrm{x}_{2}(\mathrm{~m})$ & $\mathrm{x}_{3}(\mathrm{~m})$ & $\mathrm{x}_{4}(\mathrm{~m})$ & $\begin{array}{c}\mathrm{M}_{\max }^{(+)} \\
(\mathrm{kN} . \mathrm{m})\end{array}$ & $\begin{array}{c}\mathrm{M}_{\max }^{(-)} \\
(\mathrm{kN} . \mathrm{m})\end{array}$ & $\begin{array}{c}\mathrm{M}_{\min }{ }^{(+)} \\
(\mathrm{kN} . \mathrm{m})\end{array}$ & $\begin{array}{c}\mathrm{M}_{\min }{ }^{(-)} \\
(\mathrm{kN} . \mathrm{m})\end{array}$ & $\begin{array}{c}\mathrm{V}_{\max } \\
(\mathrm{kN})\end{array}$ \\
\hline $\mathrm{A}$ & 3,000 & 6,000 & 9,000 & 31,47 & 42,84 & 13,94 & 31,15 & 81,78 \\
\hline $\mathrm{E}$ & 1,258 & 4,442 & 7,408 & 21,46 & 35,59 & 13.87 & 35,59 & 71,65 \\
\hline
\end{tabular}

A economia em peso de aço obtida a partir da situação ilustrada aumentou, ainda que de forma pouco significativa em termos globais (de 2,22 para 3,60 por cento). A exemplo da estrutura do pavimento anteriormente analisada para um número menor de apoios ( $\operatorname{casos} \mathrm{C}$ e D), procedimento similar foi seguido para a estrutura sem apoios nos extremos. Novo decréscimo no consumo de aço foi obtido, desta vez de 2,54 para 4,02 por cento em peso.

Assim procedendo para um número ainda menor de apoios, observa-se a manutenção dessa tendência de menor consumo relativo de aço para os casos em que não se considera a limitação imposta pela existência de apoios fixos nos extremos. Como foi verificado, contudo, a economia final em termos percentuais para as presentes estruturas não foi significativa. 


\subsection{Edifício 2}

O segundo exemplo analisado consiste em um edifício composto por 13 apartamentos por pavimento, delimitados de forma clara no croquis do teto-tipo, ilustrado na figura (25). Neste, novamente designa-se por Seq as sequências de elementos, as quais possuem como característica comum as dimensões da seção transversal e o carregamento aplicado.

Todas as vigas possuem área da seção transversal de 20x50 centímetros. Os pilares contidos originalmente nas sequências Seq 10, 11 e 15 possuem dimensões em planta de 20x40 centímetros, enquanto os demais pilares possuem dimensões de 20x50 centímetros. Os materiais utilizados foram o concreto C 18 e aço CA-50A.

O carregamento total aplicado a cada sequência, uma vez uniformizado a partir do projeto original, foi o seguinte:

-Seq01 e 09: $16,40 \mathrm{kN} / \mathrm{m}$

-Seq02 e 08: 29,79 kN/m

-Seq03 e 07: 29,07 kN/m

-Seq04: 23,61 kN/m

-Seq05: 14,75 kN/m

-Seq06: 22,30 kN/m

-Seq10, 11 e 15: 17,89 kN/m

-Seq12: 17,76 kN/m

-Seq13: 19,90 kN/m

-Seq14: 18,96 kN/m 


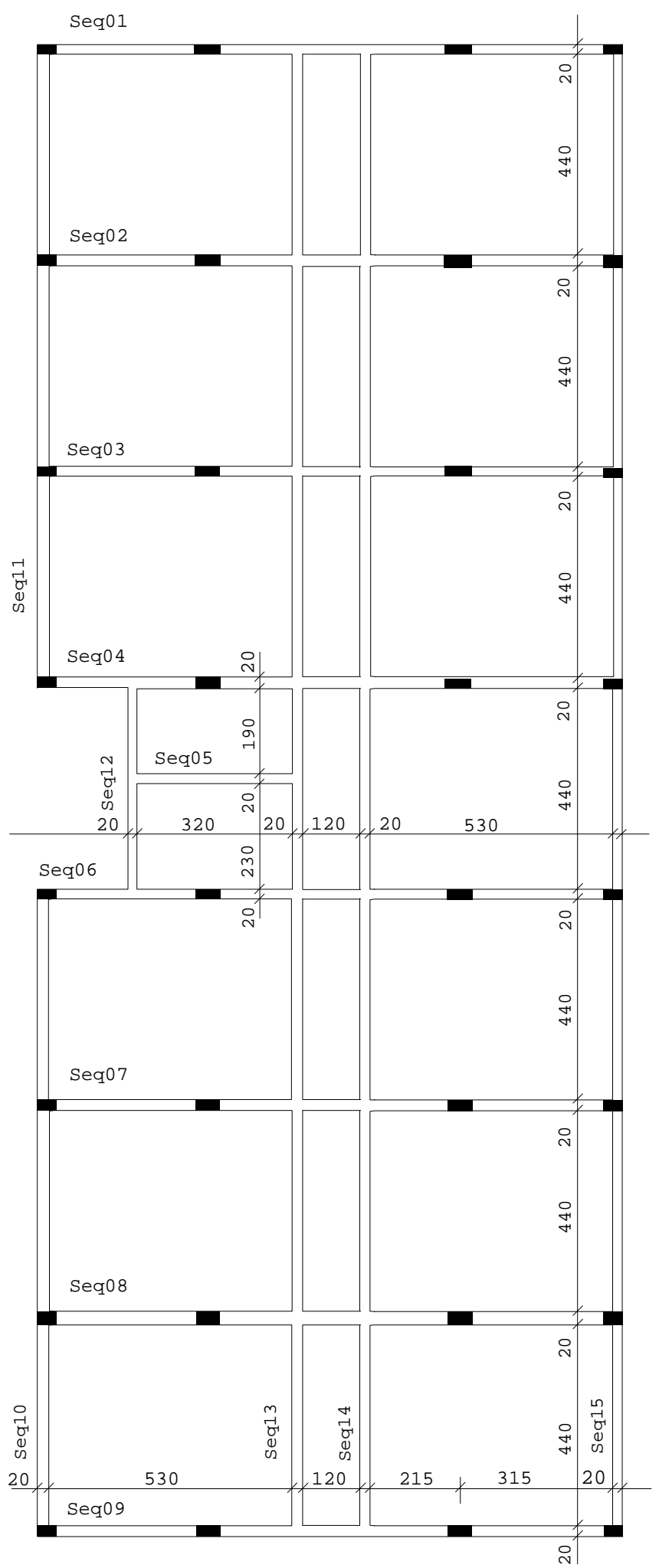

FIGURA (25) - Edifício 2: teto-tipo (em centímetros) 
A maior dimensão em planta dos pilares coincide com a direção de menor inércia da estrutura. É permitido o deslocamento dos mesmos nesta direção sem que surja qualquer interferência tanto estética como funcional, uma vez que as aberturas situam-se sobre os elementos perpendiculares e os pilares não são visíveis nos pavimentos devido à espessura das paredes.

Inicialmente, foi proposta a movimentação dos pilares de maior dimensão (internos às sequências 01 a 09), mantendo fixas as coordenadas dos demais apoios. Tomando-se como solução inicial o posicionamento real ilustrado na figura imediatamente anterior (3,25 metros do eixo dos elementos contidos nas sequências Seq10, Seq11 e Seq15), obteve-se uma redução no valor da função penalizada em cerca de 54 por cento, não sendo porém plenamente atendidas as restrições devido as limitações impostas aos deslocamentos no plano pela interseção com os demais elementos estruturais.

Para o posicionamento final dos apoios, foram observadas variações, a partir das posições iniciais, entre 0,633 metros e 1,902 metros no sentido do centro da estrutura. As consequentes variações nos esforços podem ser vistas nos diagramas apresentados nas figuras (26) e (27), respectivamente representando a Seq09 (sequência extrema) e a Seq06 (sequência interna à estrutura). 

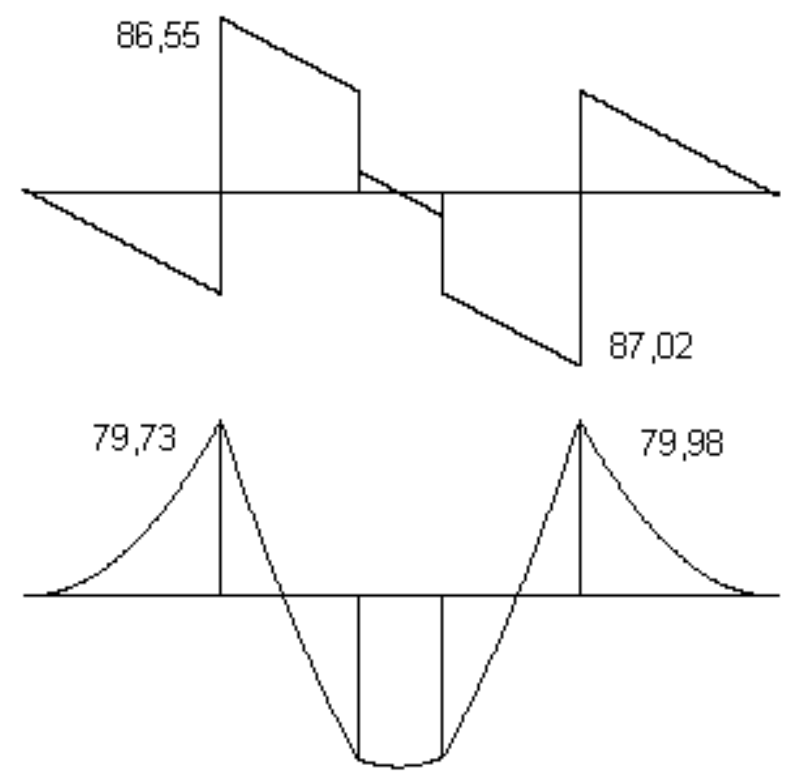

Disposição inicial
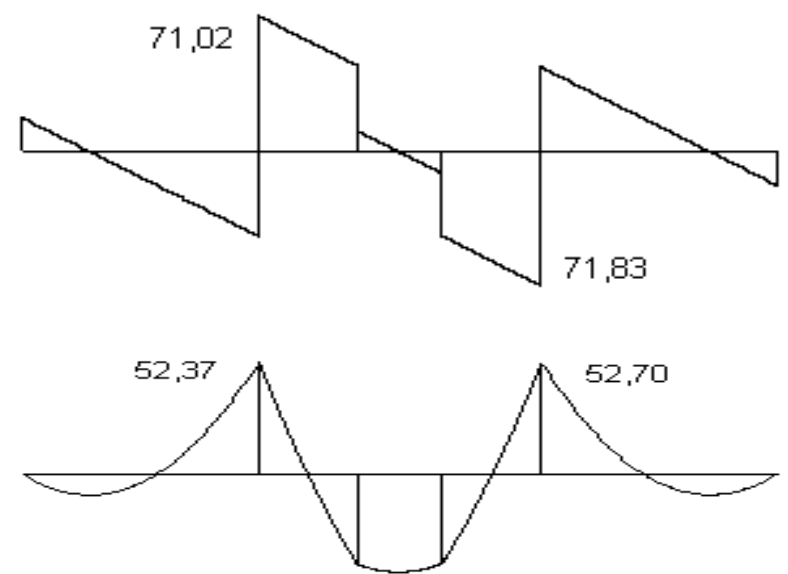

Disposição ótima

FIGURA (26) - Sequência Seq09: diagramas de esforços 

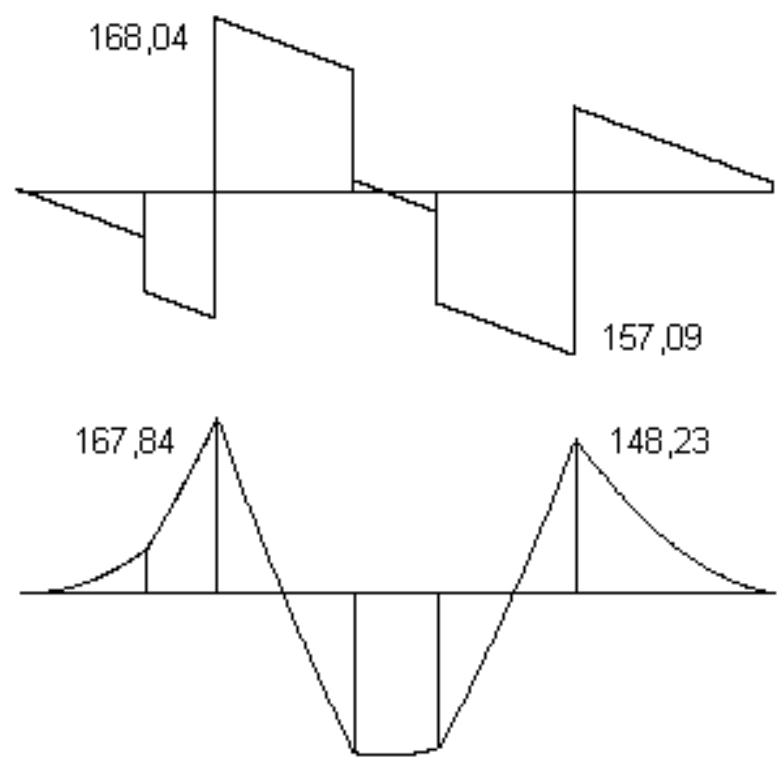

Disposição inicial
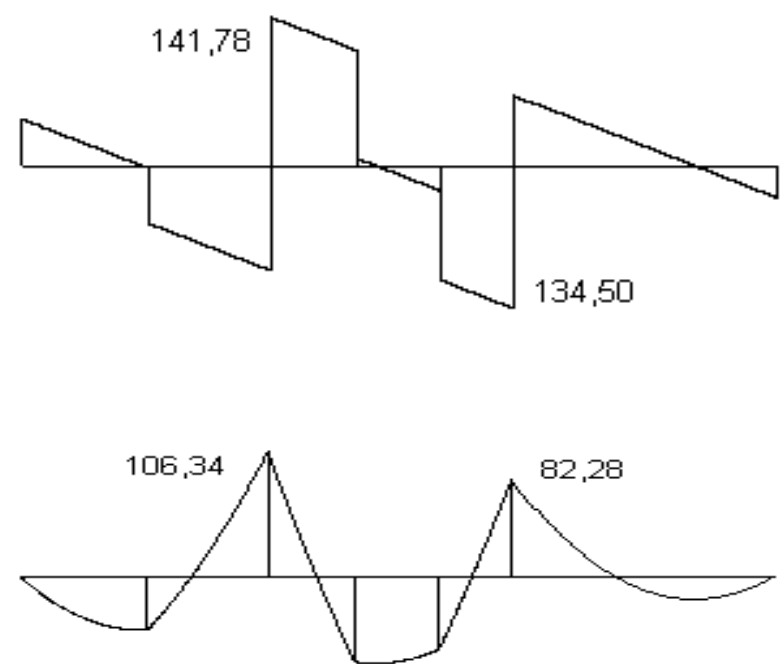

Disposição ótima

FIGURA (27) - Sequência Seq06: diagramas de esforços 
Detalhando a estrutura para a configuração obtida, chegou-se à redução no peso de aço dos elementos lineares do pavimento da ordem de 36,1 por cento, como se verifica pela comparação das tabelas (21) e (22), além de uma redução também na diversidade de bitolas, representando uma economia indireta pela redução das perdas devidas ao corte.

TABELA (21) - situação inicial: consumo de armadura

\begin{tabular}{|c|c|c|}
\hline \multicolumn{3}{|c|}{ RESUMO AÇO CA-50 A } \\
\hline bitola $(\mathrm{mm})$ & comprimento $(\mathrm{m})$ & peso $(\mathrm{kg})$ \\
\hline 6.3 & 1443 & 361 \\
8 & 667 & 267 \\
10 & 79 & 50 \\
12.5 & 627 & 627 \\
16 & 558 & 894 \\
20 & 238 & 596 \\
22.5 & 27 & 80 \\
\hline Peso total & $50 \mathrm{~A}=$ & $2874 \mathrm{Kg}$ \\
\hline
\end{tabular}

TABELA (22) - situação ótima: consumo de armadura

\begin{tabular}{|c|c|c|}
\hline \multicolumn{3}{|c|}{ RESUMO AÇO CA-50 A } \\
\hline bitola $(\mathrm{mm})$ & comprimento $(\mathrm{m})$ & peso $(\mathrm{kg})$ \\
\hline 6.3 & 1607 & 402 \\
8 & 295 & 118 \\
10 & 44 & 27 \\
12.5 & 787 & 787 \\
16 & 314 & 503 \\
\hline Peso total & $50 \mathrm{~A}=$ & $1837 \mathrm{Kg}$ \\
\hline
\end{tabular}


Supondo-se a inviabilidade da construção com os apoios situados nas posições determinadas como ótimas, procedeu-se a uma uniformização nas posições pela média aritmética das coordenadas finais, obtendo-se então uma disposição segundo a qual os apoios internos estão afastados 4,50 metros dos eixos das sequências extremas Seq10, 11 e 15. Este novo posicionamento a priori resultaria em um acréscimo no peso de aço relativamente à disposição ótima, porém apontando ainda uma economia significativa. Verificou-se, no entanto, conforme tabela (23), que o consumo de aço sofreu pequena redução após o realinhamento dos apoios, muito provavelmente devido à uniformização obtida no detalhamento. Observa-se que, apesar da pouca diferença no peso total de aço entre estas duas últimas situações, passa a haver a maior predominância de determinadas bitolas, como a de diâmetro 12.5 milímetros, a qual passou a representar de 42,8 a 49,7\% do peso total. Denominando-se respectivamente por caso A a situação inicial de projeto, por caso B o posicionamento ótimo e finalmente por $\mathrm{C}$ a última disposição descrita, pode-se comparar com o auxílio da tabela (24) tanto o valor da função como o peso de aço, em termos absolutos e relativos, obtidos para cada uma das situações. Pela comparação do valor da função objetivo, fica claro que o caso B efetivamente representa o ótimo da função, apesar de ter sido obtido um consumo de aço menor para a situação do caso C.

TABELA (23) - realinhamento dos apoios: consumo de armadura

\begin{tabular}{|c|c|c|}
\hline \multicolumn{3}{|c|}{ RESUMO AÇO CA-50 A } \\
\hline bitola $(\mathrm{mm})$ & comprimento $(\mathrm{m})$ & peso $(\mathrm{kg})$ \\
\hline 6.3 & 1557 & 389 \\
8 & 361 & 144 \\
10 & 19 & 12 \\
12.5 & 899 & 899 \\
16 & 227 & 363 \\
\hline Peso total & $50 \mathrm{~A}=$ & $1808 \mathrm{Kg}$ \\
\hline
\end{tabular}


TABELA (24) - Edifício 2: economia relativa no consumo de aço

\begin{tabular}{|c|c|c|c|}
\hline caso & $\mathrm{f}(\mathrm{kN} . \mathrm{m})$ & $\mathrm{Ps}(\mathrm{Kg})$ & $\mathrm{Ps} / \mathrm{Ps}(\mathrm{A})$ \\
\hline $\mathrm{A}$ & $3,490 \times 10^{5}$ & 2874 & 1,000 \\
\hline $\mathrm{B}$ & $0,939 \times 10^{5}$ & 1837 & 0,639 \\
\hline $\mathrm{C}$ & $1,620 \times 10^{5}$ & 1808 & 0,629 \\
\hline
\end{tabular}

Supondo-se a seguir inexistência de apoios fixos, ou seja, a liberdade de deslocamentos no plano estendida a todos os apoios, o novo problema passa a ter 32 variáveis de projeto. Esta nova situação, denominada por caso D, permite a existência de balanços nos extremos de cada sequência de elementos, incluída entre as hipóteses iniciais como uma das características que permitiria o alívio dos demais tramos. Os valores iniciais do processo foram tomados de forma aleatória, com todos os apoios originalmente situados sobre as sequências Seq10, 11 e 15 considerados como não mais integrantes destas sequências, já que a necessidade de imposição de uma solução inicial desta forma consiste unicamente na impossibilidade de geração automática de novos nós e elementos.

A situação que gera as novas posições denominadas ótimas, obtidas pela análise que possibilita a mobilidade de todos os apoios no plano da grelha, foi comparada ao caso A (projeto original).

Em razão da forte assimetria gerada pelo posicionamento ótimo, novamente tomou-se os valores médios obtidos a partir do caso D, chegando-se desta forma novamente a uma configuração ótima com características de simetria. A nova distribuição obtida com o realinhamento dos pilares é designada por caso E. Os valores resultantes deste acarretam no posicionamento em relação as sequências Seq10, 11 e 15 de, respectivamente, 0,859 metros e 4,26 metros para os pilares mais externos e para os mais internos. O caso E pode ser comparado às situações relativas aos casos A e D na tabela (25). Por esta, verifica-se pequena variação entre as situações ótima e "próxima da ótima" (alinhada), desta vez com pequeno acréscimo na armadura após o realinhamento dos pilares. 
TABELA (25) - Edifício 2: economia relativa no consumo de aço para todos os nós com posições variáveis

\begin{tabular}{|c|c|c|}
\hline caso & Ps (Kg) & Ps / Ps (A) \\
\hline A & 2874 & 1,000 \\
\hline D & 1971 & 0,686 \\
\hline E & 2000 & 0,696 \\
\hline
\end{tabular}

Ao contrário do esperado, maior redução foi obtida para a consideração dos pilares de seção 20x40 centímetros fixos. No entanto, ao se retirar estes apoios dos extremos, a razão entre a máxima e mínima reações verticais nos pilares é reduzida de 8,96 para 3,36, comparativamente aos casos A e E, certamente com grande reflexo no detalhamento dos pilares.

Ainda para o mesmo edifício do exemplo, uma nova possibilidade foi considerada. Admita-se que no pavimento térreo a área em planta limitada pelas sequências Seq10, Seq15, Seq06 e Seq09 seja destinada a vagas de garagem, e que não seja vantajosa a utilização de vigas de transição para o pilotis. Restringindo ainda mais o problema, suponha-se que as posições dos pilares componentes das sequências Seq07 a Seq09 não pudesse ser alterada, e que por facilidade construtiva os pilares com dimensões 20x40 centímetros fossem mantidos alinhados ao longo da periferia da estrutura, conforme projeto original. Com esta série de imposições, restaria apenas a possibilidade de movimentação, no plano de cada pavimento, dos apoios internos das sequências Seq01 a 06, ou seja, o problema original estaria agora limitado a 10 variáveis. Designando-se por caso F esta nova situação, verifica-se que ainda assim a formulação proposta conduziria à uma redução no consumo de armadura nos elementos da grelha. As posições dos apoios internos móveis variam de 0,60 metros a 1,56 metros no sentido do centro dos segmentos, em relação à posição original. Assumindo um valor médio de 4,41 metros, o dimensionamento resultou nos valores indicados na tabela (26), designando-se a consequente configuração por caso $\mathrm{G}$. 
TABELA (26) - Edifício 2: economia relativa no consumo de aço para 10 nós com posições variáveis

\begin{tabular}{|c|c|c|}
\hline caso & Ps (Kg) & Ps / Ps (A) \\
\hline A & 2874 & 1,000 \\
\hline F & 2238 & 0,779 \\
\hline G & 2212 & 0,770 \\
\hline
\end{tabular}

Nesta última situação, a exemplo das demais, verifica-se uma redução também significativa no consumo de aço. Também a exemplo da primeira situação proposta, o alinhamento dos pilares apresentou resultado um pouco menor que o ótimo. Para estes dois últimos casos, porém, não foi obtida redução na diversificação de bitolas, certamente pela possibilidade de movimentação de poucos apoios relativamente ao número total.

De uma forma geral, verificou-se para o presente exemplo que, ainda que o dimensionamento gere alterações no peso de aço entre o ótimo e o aqui denominado próximo do ótimo, estas variações situaram-se em patamares inferiores a 1 por cento. Para as distintas situações idealizadas foi obtida uma redução no peso de aço entre 22,1 e 37,1 por cento nos elementos de grelha em cada pavimento.

Destaca-se que, apesar das comparações terem sido efetuadas levando em consideração todos os elementos componentes da grelha, a economia verificada nas situações ilustradas no presente exemplo é obtida fundamentalmente nos elementos paralelos à menor dimensão do pavimento em planta, sendo praticamente desprezível a variação dos esforços nos demais elementos. 


\section{CONCLUSÕES E CONSIDERAÇÕES FINAIS}

O presente estudo teve como objetivo básico demonstrar a aplicabilidade da otimização dos esforços em estruturas analisadas pelo modelo de grelha quando se permite a variação relativa nas posições dos apoios. Neste sentido, apesar das inevitáveis limitações de ordem arquitetônica, bem como as simplificações inerentes à própria formulação do problema, acredita-se que a proposta inicial foi cumprida de forma satisfatória.

A utilização de técnicas de otimização associada à análise de estruturas, apesar de relativamente recente, tem sido alvo de um número muito grande de estudos. Contudo, a carência de exemplos práticos apresentados na literatura técnica, aliada à restrita divulgação das potencialidades da otimização estrutural (problemas fundamentalmente voltados à redução do peso da estrutura), pouco tem encorajado maiores investimentos na aplicação da otimização à problemas usualmente encontrados.

Com o intuito de preencher uma lacuna em relação ao cálculo de estruturas correntes de edifícios, no caso a idealização da estrutura portante, foi estudada a viabilidade do desenvolvimento de uma ferramenta auxiliar ao projetista. Acredita-se que o estudo efetuado neste sentido, ainda que bastante limitado, pode ser considerado promissor ao possibilitar a associação de outros objetivos que não apenas os abrangidos no presente trabalho. Adicionalmente, o estudo da redistribuição dos esforços em função do posicionamento dos apoios, por seu caráter incipiente, pode facultar a elaboração de uma formulação mais eficiente a partir de bases matemáticas mais sólidas.

Como citado no início do presente trabalho, a maior complexidade apresentada pelo modelo de grelha suscitou o estudo de uma formulação inicial para a otimização segundo o modelo de viga sendo que, uma vez fornecidos indícios de 
economia, esta formulação seria adaptada aos objetivos do trabalho. No entanto, em razão dos resultados obtidos, verificou-se que a otimização do posicionamento dos apoios em vigas constitui-se em um campo de estudo também bastante promissor, merecendo portanto relativo destaque no texto e incentivando o prosseguimento e aprofundamento futuros.

A otimização geométrica de grelhas, a qual em princípio aparentava ser apenas uma extensão da otimização geométrica de vigas, acarretou na necessidade de alterações na formulação original. Credita-se esta necessidade fundamentalmente à não-convexidade de restrições, associada ao alto grau de indeterminação estática do modelo. Talvez um estudo mais aprofundado relacionado ao comportamento das funções, bem como uma nova forma de descrevê-las, possibilite a imediata adaptação de um para outro modelo. Ressalva-se porém que a restrição original de igualdade entre os momentos fletores sobre todos os apoios aparentou ser de maior utilidade apenas para estruturas com elementos de geometria e carregamento semelhantes.

Ainda especificamente em relação à análise de grelhas, julgou-se preferível a apresentação de dois exemplos, procurando esgotá-los de forma a ilustrar o potencial uso do programa, a incluir mais estruturas no capítulo pertinente. Tal escolha foi fundamentada na constatação de que a eventual contribuição de outros exemplos se daria mais a nível de diversificação de aplicações, como baldrames ou pilotis, do que propriamente de resultados concretos, visto que a limitação automática a um número pré-definido de nós e elementos impede a aplicação do modelo a uma maior variedade de formas estruturais, tornando o programa desenvolvido um tanto limitado em termos de aplicabilidade prática imediata.

Apesar do material concreto armado não integrar a formulação final do problema, este material foi o adotado em função de sua maior utilização em estruturas correntes no Brasil. Para a análise e estudo de distribuição de esforços foram consideradas diversas simplificações, tais como material homogêneo, de comportamento linear e apoios puntuais. Ainda assim, para os exemplos e testes mais representativos foram efetuadas não apenas comparações entre magnitude de esforços, mas também de consumo de material, uma vez que a não observância de exigências impostas por normas técnicas poderia mascarar os resultados destas comparações (por exemplo, momentos fletores com valores bastante diferentes, 
porém ambos inferiores ao momento de fissuração, conduziriam a uma mesma armadura).

Para os diversos testes e exemplos analisados, verificou-se de uma forma geral a tendência tanto à redução como à uniformização dos momentos fletores, objetivadas pelo programa desenvolvido. Como consequência, verificou-se também a uniformização dos esforços de cisalhamento e das reações verticais e momentos fletores nos apoios. Desta maneira, ainda que não se constituísse no objetivo original, os pilares vinculados ao pavimento tendem a assumir uma mesma área da seção transversal, facultando uma economia adicional resultante desta padronização. Adicionalmente, considerando-se ainda o concreto armado como material estrutural, observou-se para as estruturas analisadas também uma forte tendência à padronização no corte e no número de distintas bitolas, podendo gerar uma economia indireta.

Como já destacado, ao tempo de processamento foi dada importância secundária, visto que é pouco significativo mesmo para estruturas de maior complexidade. Acredita-se que, caso se desejasse otimizar o processo em si, maior ênfase deveria ser dada à etapa de pré-processamento, esta sim demandando um tempo bem mais elevado.

Como prosseguimento ao presente trabalho objetiva-se, além da eliminação gradual das limitações descritas anteriormente, a associação das rotinas desenvolvidas em um ambiente de sistema especialista, de modo a facilitar a definição de uma configuração inicial para a estrutura. Critérios para a adição ou retirada de forma automática de elementos e nós do processo também deverão ser definidos (otimização topológica). É proposta ainda a viabilização do estudo do posicionamento ótimo dos apoios aplicado a modelos tridimensionais.

Quanto aos apoios aos quais foi impedido o deslocamento no plano da estrutura, designados por apoios fixos, os esforços e reações obtidos são apenas um reflexo do posicionamento dos demais apoios. Assim, seria interessante que fossem desenvolvidos estudos no sentido de reformular o problema com a consideração e consequente contribuição também destes apoios. 
Pretende-se que os estudos aqui apresentados se constituam não unicamente em uma demonstração de um campo alternativo para a aplicação de técnicas de otimização à análise estrutural, mas sim em um passo efetivo, ainda que modesto, no sentido do desenvolvimento de ferramentas computacionais para a busca tanto de uma melhor solução em problemas usuais como também para a resolução de problemas de maior complexidade. 


\section{REFERÊNCIAS BIBLIOGRÁFICAS}

ASSOCIAÇÃO BRASILEIRA DE NORMAS TÉCNICAS (1978). NBR 6118 Projeto e execução de obras de concreto armado. Rio de Janeiro, ABNT.

BAZARAA, M. S.; SHETTY, C. M. (1979). Nonlinear programming - theory and algorithms. New York, John Wiley.

COHN, M. Z.; FELLOW; DINOVITZER, A. S. (1994). Application of structural optimization. Journal of Structural Engineering, ASCE, v.120, n.2, p.617-50, Feb.

FOX, R. L. (1971). Optimization methods for engineering design. Massachusetts, Addison Wesley.

GILL, P. E.; MURRAY, W.; WRIGHT, M. H. (1981). Practical Optimization. London, Academic Press.

IMAI, K; SCHMIT, L. A. (1981). Configuration optimization of trusses. Journal of Structural Division, Proceedings of the American Society of Civil Engineers, ASCE, v.107, n.ST5, p.745-55, May.

IMAM, M. H.; AL-SHIRI, M. (1996). Optimum topology of structural supports. Computers \& Structures, v.61, n.1, p 147-54.

KIRSCH, U. (1981). Optimum structural design. New York, McGraw-Hill.

KIRSCH, U. (1989). On the relationship between optimum structural topologies and geometries. Computer Aided Optimum Design of Structures: Recent Advances. Southampton, Springer-Verlag.

KIRSCH, U. (1991). Feasibility and optimality in structural design. Computers \& Structures, v.41, n.6, p.1349-56.

KIRSCH, U.; TAYE, S. (1985). On optimal topology of grillage structures. Engineering with Computers, n.1, p.229-43. 
KO, F. T.; WANG, B. P. (1991). An improved method of optimality criteria for structural optimization. Computers \& Structures, v.41, n.4, p.629-36.

LUENBERGER, G. (1984). Linear and nonlinear programming. 2.ed. Adisson Wesley.

MINOUX, M. (1983). Programation mathématique - théorie et algorithmes. Tome 1, Paris, Dunod.

PINHEIRO, L. M. (1986). Concreto armado: tabelas e ábacos. São Carlos, EESC.

PORCELLO, E. C. (1993). Como o projeto estrutural pode melhorar o custo, o prazo e a qualidade da execução da estrutura. In: JORNADAS SUDAMERICANAS DE INGENIERIA ESTRUCTURAL, 26., Montevidéu, Uruguai. Anais. Montevidéu, ASAIE, v.4, p-327-38.

SCHMIT, L. A.; MALLETT, R. H. (1963). Structural synthesis and design parameter hierarchy. Journal of Structural Division, Proceedings of the American Society of Civil Engineers, ASCE, v.89, n.ST4, p.269-99, June.

SORIANO (1983). Análise matricial de estruturas reticuladas em computadores de pequeno porte. Rio de Janeiro, UFRJ.

SOUZA, J. C. A. O.; ANTUNES, H. M. C. C. (1995). Introdução à análise matricial de estruturas. São Carlos, EESC.

SPILLERS, W. R. (1975). Iterative design for optimal geometry. Journal of Structural Division, Proceedings of the American Society of Civil Engineers, ASCE, v.101, n.ST7, p.1435-42, July.

VANDERPLAATS, G. N. (1984a). Numerical optimization techniques for engineering design: with applications. New York, McGraw-Hill.

VANDERPLAATS, G. N. (1984b). Numerical methods for shape optimization: an assessment of the state of the art. New directions in Optimum Structural Design, p.89-103. New York, John Wiley. 


\section{BIBLIOGRAFIA COMPLEMENTAR}

CARDOSO, J. B.; ARORA, J. S. (1988). Variational method for design sensitivity analysis in nonlinear structural mechanics. AIAA Journal, v.26, n.5, p.595-603, May.

FRIEDLANDER, A. (1992). Elementos de programação não linear. Campinas, UNICAMP.

GIONGO, J. S. (1994). Concreto armado: projeto estrutural de edifícios. São Carlos, EESC.

IBAÑEZ, S. H. (1990). Metodos de diseño optimo de estructuras. Madrid, Seinor.

KIRSCH, U. (1993). Effective approximations for topological optimization. In: STRUCTURAL OPTIMIZATION 93: THE WORLD CONGRESS ON OPTIMAL DESIGN STRUCTURAL SYSTEMS. Rio de Janeiro, 1993. ABCM, v.1, p.3-10.

KUESTER, J. L. (1973) Optimization techniques with fortran. New York, McGraw-Hill.

LASDON, L. S. (1970). Optimization theory for large systems. London, CollierMacMillan.

LAUG, P. (1993). Towards a knowledge-based system for structural optimization. In: STRUCTURAL OPTIMIZATION 93: THE WORLD CONGRESS ON OPTIMAL DESIGN STRUCTURAL SYSTEMS. Rio de Janeiro, 1993. ABCM, v.2, p.475-82.

MAHEY, P. (1987). Programação não-linear: introdução à teoria e aos métodos. Rio de Janeiro, Campus.

MAHMOUD, K. G. (1997). An efficient approach to structural optimization. Computers \& Structures, v.64, n.1-4, p.97-112. 
MARTINEZ, J. M.; SANTOS, S. A. (1995). Métodos computacionais de otimização. Rio de Janeiro, IMPA.

MORRIS, A. J. (1982). Foundations of structural optimization: a unified approach. New York, John Wiley.

PIKE, R. W.; GUERRA, L. G. (1989) Optimizacion en Ingenieria. Cidade do México, Alfaomega.

ROCKAFELLAR, R. T. (1993). Lagrange multipliers and optimality. SIAM Review, v.35, n.2, p.183-238, June.

ROZVANY, G. I. N. (1994). Optimum layout of grillages: allowance for the cost of supports and optimization of support locations. Mechanics of Structures and Machines, n.22, vol.1, p.49-72.

ROZVANY, G. I. N. (1994). Topological optimization of grillages: past controversies and new directions. International Journal of Mechanical Science, v.36, n.6, p.495-512.

SORIANO, H. L.; LIMA, S. S. (1993). Análise de estruturas em computadores: estruturas reticuladas - vol.1. Rio de Janeiro, UFRJ.

TAVARES, L. V.; CORREIA, F. N. (1986). Optimização linear e não linear. Lisboa, Caloste Gulbenkian.

YAMAGUCHI, E.; OHTA, T. (1993). Accurate and efficient method for analysis of reinforced concrete structures. Journal of Structural Engineering, ASCE, v.119, n.7, p.2017-58, July. 